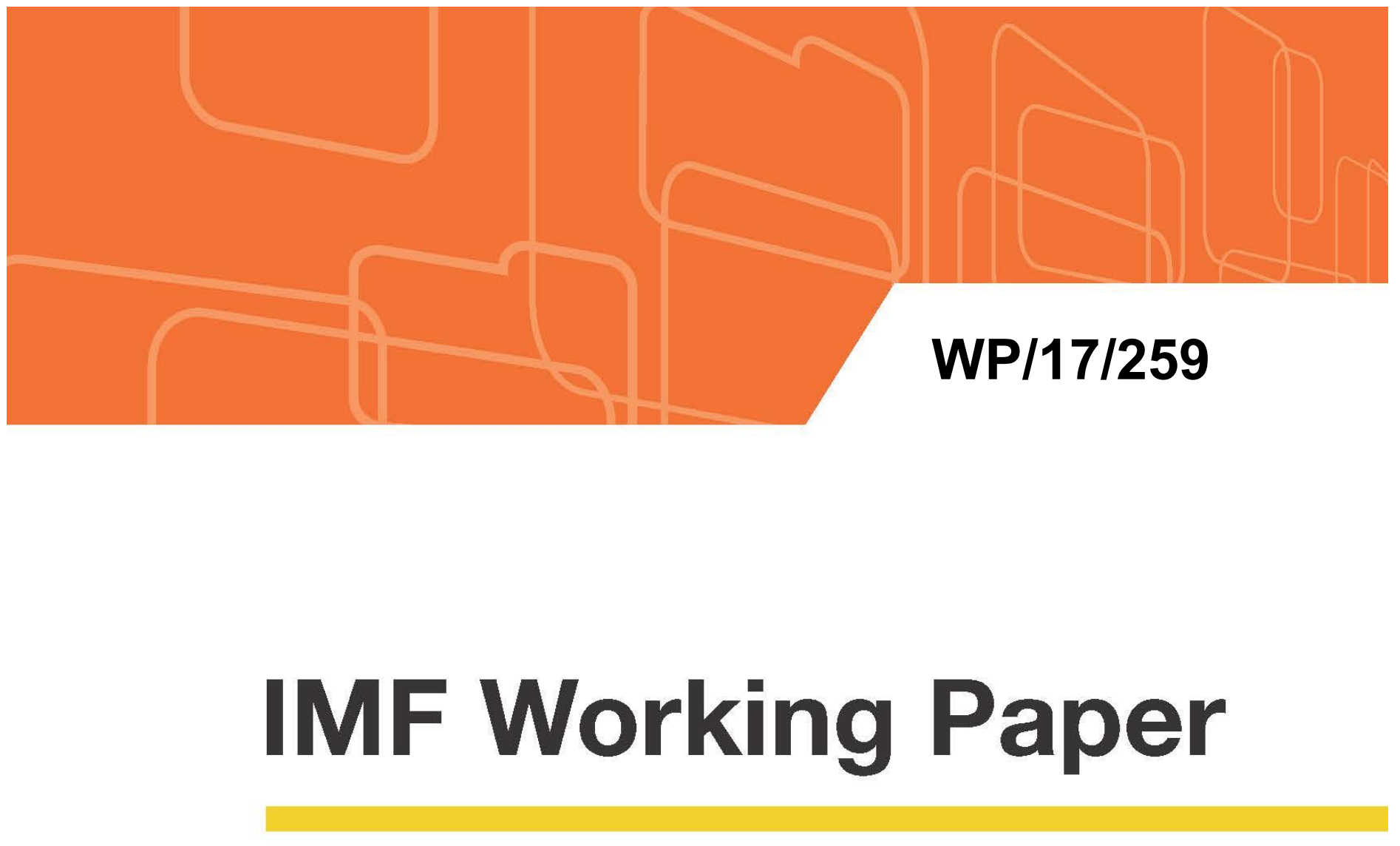

\title{
No Business Taxation Without Model Representation: Adding Corporate Income and Cash Flow Taxes to GIMF
}

by Benjamin Carton, Emilio Fernandez-Corugedo, and Benjamin Hunt

IMF Working Papers describe research in progress by the author(s) and are published to elicit comments and to encourage debate. The views expressed in IMF Working Papers are those of the author(s) and do not necessarily represent the views of the IMF, its Executive Board, or IMF management. 


\title{
IMF Working Paper
}

Research Department

\section{No Business Taxation Without Model Representation: Adding Corporate Income and Cash Flow Taxes to GIMF

\author{
Prepared by Benjamin Carton, Emilio Fernandez-Corugedo, and Benjamin Hunt ${ }^{1}$
}

Authorized for distribution by Benjamin Hunt

October 2017

\section{IMF Working Papers describe research in progress by the author(s) and are published to} elicit comments and to encourage debate. The views expressed in IMF Working Papers are those of the author(s) and do not necessarily represent the views of the IMF, its Executive Board, or IMF management.

\begin{abstract}
The Global Integrated Monetary and Fiscal model (GIMF) is a multi-region, forward-looking, DSGE model developed at the International Monetary Fund for policy analysis and international economic research. This paper documents the incorporation of corporate income, cash-flow and destination based cash-flow taxes into the model. The analysis presented considers the transmission mechanism of these taxes and details how financial frictions interact with each of the taxes.
\end{abstract}

JEL Classification Numbers: E12; E17; E52; E62; F41; F47

Keywords: tax policy; business taxation, financial accelerator, corporate leverage, dynamic stochastic general equilibrium models; macroeconomic interdependence

Author's E-Mail Address: BCarton@imf.org;EFernandezCorugedo@imf.org; BHunt@imf.org.

\footnotetext{
${ }^{1}$ We would like to thank Alan Auerbach for useful comments and discussions and seminar participants at the International Monetary Fund, Federal Reserve and Bank of Canada. Jumi Kim provided excellent research assistance. All remaining errors are our own.
} 


\section{Table of Contents}

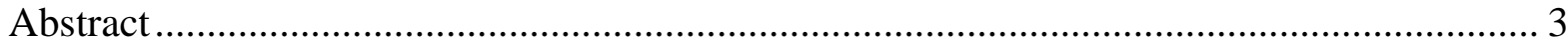

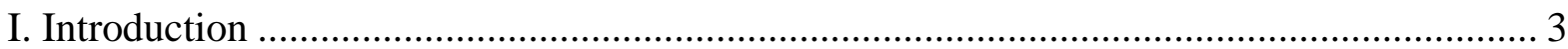

II. Summary of the Global Integrated Monetary and Fiscal Model.................................... 5

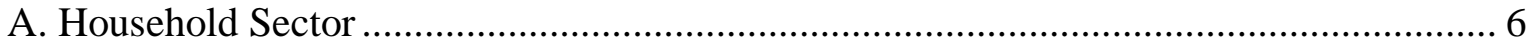

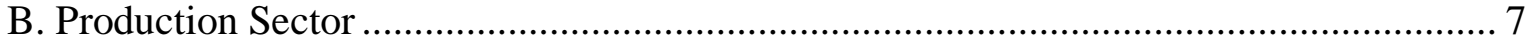

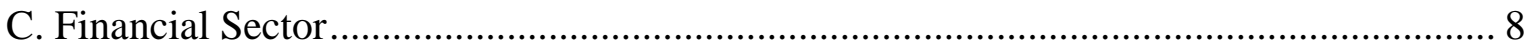

D. International Dimensions and Spillovers ........................................................... 8

E. Fiscal and Monetary Policy ................................................................................. 9

III. permanent changes to all taxes in GIMF: properties ............................................... 9

A. Long run impact from (permanent) introduction of each tax .................................. 11

1. Tax on the return to capital (KRT) ................................................................. 11

2. The corporate income tax (CIT) ................................................................... 13

On the Interaction of the Financial Accelerator and the CIT ....................................... 15

3. The Cash Flow Tax (CFT) ............................................................................... 19

4. The Cash Flow Tax vs a Destination-Based Cash Flow Tax (DBCFT) .................... 21

B. Transitional dynamics from the (permanent) introduction of each tax ........................ 23

1. On the interaction between the financial accelerator, rigidities and taxes................ 26

IV. transient changes to all taxes in GIMF: properties ............................................... 27

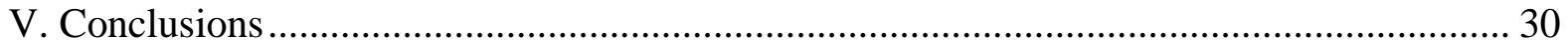

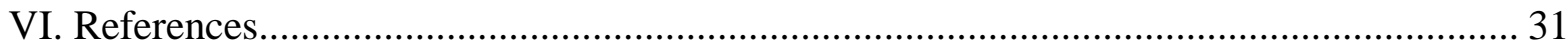

Appendix I: Calibration of the financial accelerator block ............................................ 34

Appendix II: An update on GIMF fiscal multipliers ................................................. 34

Appendix III: Detailed algebraic derivation of model changes ...................................... 38

Appendix IV: Corporate taxes and the financial accelerator .......................................... 49

Figures

1. Long-Run Impact of a Permanent Increase in the KRT ............................. 12

2. Long-Run Impact of a Permanent Increase in the CIT . ............................. 14

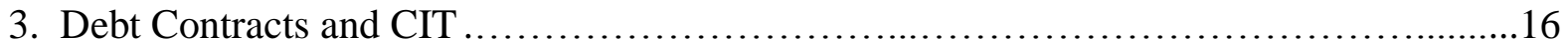

4. Long-Run Impact of a Permanent Increase in the CIT w/o Fin.Accel ......................18

5. Long-Run Impact of a Permanent Increase in the CFT ...................................20

6. Long-Run Impact of a Permanent Increase in the DBCFT.............................22

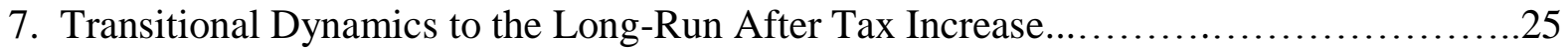

8. Transitional Dynamics to the Long-Run w/o Fin. Accel or Rigidities...................26

9. Two-Year 1\% of GDP Reduction in all Corporate-Related Taxes ........................28

10. Credit Supply and Demand Shocks in the Financial Accelerator ......................56

11. How the Business Income Tax Modifies the Financial Accelerator in the Short Run....57

12. Corporate Tax Rates, Financial Accelerator and Rental Rate of Capital in the Long Run........59

Appendix Tables

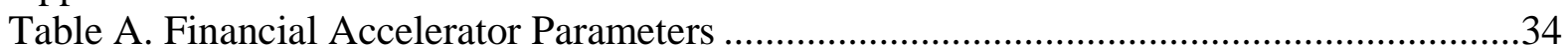

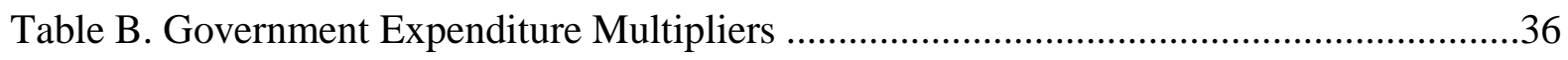

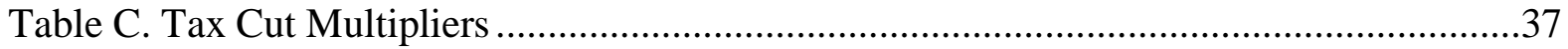




\section{INTRODUCTION}

This paper documents the changes made to the International Monetary Fund's Global Integrated Monetary and Fiscal model (GIMF) to incorporate two types of business taxes: a corporate income (CIT) and a corporate cash flow tax (CFT) that also permits a destinationbased system (DBCFT). The original GIMF model, as documented by Kumhof and others (2010) and Anderson and others (2013), incorporated only one type of business tax, a tax on capital returns (KRT), often referred to in the literature as a corporate (income) tax. ${ }^{2}$ However, corporate income taxes in many countries are not levied as a tax on capital returns, but as taxes that raise revenue by taxing firms' profits from sales. Hence, the introduction of the CIT and CFT/DBCFT allows for a more accurate and richer analysis of tax policy in GIMF.

In a pure (source-based) CIT, revenues from both domestic and foreign sales are subject to tax. In principle, all costs can be deducted from revenues to calculate the profits that form the tax base. These costs include labor, rent, capital depreciation, interest expenses, and intermediate inputs, including those that are imported. The introduction of the CIT into GIMF, allows the model to more closely resemble the corporate income tax base in many countries, so that the tax is levied on the economic profits (income) made by corporates.

In the context of Dynamic Stochastic General Equilibrium (DSGE) models, most papers have tended to introduce KRTs as proxies for CITs. ${ }^{3}$ Only a few papers have introduced a proper CIT in DSGE models. These papers are typically concerned with corporate tax reform, paying attention to the distortions that these taxes have on investment behavior. ${ }^{4}$ While some of this literature considers the impact of changes to corporate income tax policies in an open economy setting, only a few consider the impact that a CIT has on financial variables. ${ }^{5}$ None of these papers, however, examine the impact of a CIT on financial frictions of the type introduced by Carlstrom and Fuerst (1997), Kiyotaki and Moore (1997), Bernanke, Gertler and Gilchrist (1999), BGG henceforth, or Gertler and Karadi (2011). Incorporating the CIT into GIMF allows for the analysis of its interaction with financial frictions and its impact on corporate leverage and business investment.

\footnotetext{
${ }^{2}$ Harberger (1962), who first examined the impact of corporate taxes on the allocation of factors of production in a general equilibrium model, dubbed a tax on capital returns a corporate tax.

${ }^{3}$ Most general equilibrium models incorporate corporate taxes as a tax on capital returns (see for example the structural models used in Coenen and others (2012)). Early literature on corporate taxation includes Baron (1970), Sandmo (1971), in a partial equilibrium setting, and Batra (1975) in a general equilibrium setting. These papers examined the how corporate behavior is affected by corporate profit taxes and uncertainty.

${ }^{4}$ US studies include Carroll and others (2006), Diamond and Zodrow (2006), Zodrow and Diamond (2011), Fehr and others (2013), Diamond and others (2014), and Bhattarai and others (2017). For European countries Keuschnigg and Dietz (2007), Radulescu and Stimmelmayr (2010) and de Mooij and Devereux (2011).

${ }^{5}$ Exceptions are Keuscnhigg and Dietz (2007), Radulescu and Stimmelmayr (2010) and de Mooij and Devereux (2011) who look at the implications for tax changes for corporate debt and equity mix.
} 
This paper also introduces a CFT into GIMF that permits a destination-based component (DBCFT). A CFT taxes the cash flows of corporates from sales after deducting the cost of labor, investment, and intermediate inputs. Under a DBCFT, revenues from exports are not subject to tax, while the cost of imports cannot be deducted, both of which relate to the destination based component of the tax. A few papers describe the potential impact of the introduction of a CFT/ DBCFT on the economy and the potential ways to implement such a tax (see for example, Auerbach and others (2017) and references therein). However, few papers discuss the implications of such a tax (or similar taxes) in a general equilibrium setting. ${ }^{6}$ These include Keuschnigg (1991), Carroll and others (2006), and Zodrow and Diamond (2011). ${ }^{7}$ As is the case with the CIT, there has been little focus in the literature on the interaction of the CFT/DBCFT with financial frictions, its impact on corporate leverage and business investment.

Thus, a main innovation of this paper is the introduction of CIT and CFT/DBCFT in a model with a financial accelerator a la BGG. Financial frictions interact with the tax system in a rich way. Optimal leverage decisions depend on the CIT rate as interest expenses represent an implicit debt subsidy which is internalized in the debt contract leading to a reduction of the financial premium. ${ }^{8}$ CFT changes affect dividend payment policies and lead to changes in business investment in the short term and hence to the price of capital. These in turn affect the value of the firm and create balance sheet mismatches that affect the financial risk premium.

In addition to detailing how CIT and CFT/DBCFT are introduced in GIMF and how they affect financial frictions, this paper considers the macroeconomic impact of these taxes. ${ }^{9}$ The paper documents the equilibrium properties, transmission mechanism and (fiscal) multipliers associated with the new taxes and compares these with the multipliers reported in Anderson and others (2013). The analysis first shows that permanent increases in the KRT and the CIT are distortionary in the long-run, leading to notable reductions in business investment and GDP, whereas the CFT and the DBCFT are not. Although they propagate in a similar way, the reductions are largest under a KRT relative to the CIT, as the KRT falls exclusively on

\footnotetext{
${ }^{6}$ See the many papers written by the recent advocates of the DBCFT tax, Alan Auerbach and Michael Devereux. Several papers also consider corporate taxes that provide an allowance for corporate equity (ACE) and which can resemble a cash flow tax in the sense that they do not distort investment decisions (see eg Keuschnigg and Dietz (2007), Manzo and Monteduro (2011) or de Mooij and Devereux (2011)). Barbiero and others (2017) consider the impact of border adjustment in a two-country DSGE model.

${ }^{7}$ Carroll and others (2006) make use of the model by Zodrow and Diamond (2011) which permits both CIT and cash-flow taxes. Robinson and Thierfelder (2017) examine the impact of introducing a DBCFT in a general equilibrium model, but only examine how the trade balance responds to the introduction of tax depending on price and exchange rate rigidities.

${ }^{8}$ Given that the CIT affects the financial contract directly, the financial accelerator parameters need to be recalibrated. This is discussed in detail further below.

${ }^{9}$ A companion paper examines the equivalence between changes in an ad valorem tax (VAT) and labor income with those of a DBCFT tax (see Carton and others (2017)).
} 
the return to capital (which severely distorts the capital accumulation process) rather than on the return to capital as well as the rents made by corporates (which is less distortionary). Additionally, the CIT interacts in a rich way with financial frictions, as interest expense deductibility partly offsets the distortionary impact of the tax. Removing such deductibility therefore results in a more distortionary impact from the CIT tax. While permanent changes to the CFT and the DBCFT are not distortionary in the long-run, their introduction results in a temporary contraction in business investment and GDP in the short-run due to the presence of both nominal and real rigidities. In the absence of these rigidities, the contractionary effect from the introduction of these taxes is eliminated, such that their introduction is nondistortionary at all horizons. The analysis also shows that the border adjustment component, the key difference between the CFT and the DBCFT, manifests itself through real exchange rate movements: any competitive gains (losses) afforded by the destination based component are eradicated by an appreciation (depreciation) of the exchange rate to maintain equilibrium in the external sector.

The impact of temporary (two-year) cuts to all taxes is also presented to illustrate the implications of using each tax as an instrument to stimulate the economy and detail the associated fiscal multiplier. While reductions to the KRT or the CIT boost capital returns and hence stimulate business investment and GDP in the short-run, cuts to the CFT and the DBCFT create short-run incentives that lower private investment and thus output. Since both taxes fall on corporate cash flows after deducting investment expenditures, a temporary reduction in their rate acts as an incentive to delay investment until the resulting tax deduction returns to its previously higher level. ${ }^{10}$

The rest of the paper is organized as follows. Section II presents a summary overview of GIMF. The effects of permanent increases in each of the corporate taxes are shown in Section III. Section IV presents the key transmission mechanism of all corporate taxes associated with a two-year (temporary) tax reduction. Section V concludes. Four Appendices provide more details. Appendix I discusses the recalibration of the financial accelerator parameters in the presence of a CIT. Appendix II updates the multiplier estimates of Anderson and others (2013). Appendix III provides full details of the algebraic derivation associated with the new taxes when there are no financial frictions and Appendix IV details how financial frictions are affected by all taxes.

\section{SUMMARY OF THE GLOBAL INTEGRATED MONETARY AND FiSCAL MODEL ${ }^{11}$}

GIMF is a multicountry DSGE model with optimizing behavior by households and firms, and full intertemporal stock-flow accounting. Frictions in the form of sticky prices and wages,

\footnotetext{
${ }^{10}$ This result is not new. Sandmo (1979) shows that CFTs are non-distortionary only if they are not changed in the future.

${ }^{11}$ For detailed documentation on the structure of the model see Kumhof and others (2010). For details on the model's properties see Anderson and others (2013).
} 
real adjustment costs, liquidity-constrained households, along with finite-planning horizons of households, provide a role for monetary and fiscal policy in economic stabilization.

The assumption of finite horizons separates GIMF from standard monetary DSGE models and allows it to have well-defined steady states where countries can be long-run debtors or creditors. This allows users to study the transition from one steady state to another where fiscal policy and private saving behavior play a critical role in both the dynamics and longrun comparative statics. ${ }^{12}$

The non-Ricardian features of the model provide non-neutrality in both spending-based and revenue-based fiscal measures, which makes the model particularly suitable to analyze fiscal policy questions. Fiscal policy can stimulate the level of economic activity in the short run, but sustained government deficits crowd out private investment and net foreign assets in the long run. ${ }^{13}$ Sustained fiscal deficits in large economies can also lead to a higher world real interest rate, which is endogenous.

Asset markets are incomplete in the model. Government debt is only held domestically, as nominal, non-contingent, one-period bonds denominated in domestic currency. The only assets traded internationally are nominal, non-contingent, one-period bonds denominated in U.S. dollars that can be issued by the U.S. government and by private agents in any region. Firms are owned domestically. Equity is not traded in domestic financial markets; instead, households receive lump-sum dividend payments.

Firms employ capital and labor to produce tradable and nontradable intermediate goods. There is a financial sector a la BGG that incorporates a procyclical financial accelerator, with the cost of external finance facing firms rising with their indebtedness.

GIMF is multi-region, encompassing the entire world economy, explicitly modeling all the bilateral trade flows and their relative prices for each region, including exchange rates. The version used in this paper comprises of 3 regions with different calibrations for ease of exposition. The international linkages in the model allow the analysis of policy spillovers at the regional and global level.

\section{A. Household Sector}

There are two types of households, both of which consume goods and supply labor. First, there are overlapping-generation households (OLG) that optimize their borrowing and saving decisions over a 20-year planning horizon. Second, there are liquidity-constrained

\footnotetext{
${ }^{12}$ See Blanchard (1985) for the basic theoretical building blocks and Kumhof and Laxton (2007, 2009a, 2009b) to understand their fiscal policy implications.

${ }^{13}$ Coenen and others (2010) show that GIMF fiscal multipliers for temporary shocks are similar to standard monetary business cycle models, but more importantly, GIMF can handle a much broader array of permanent shocks that can be used to study transitions from one steady state to another caused by permanent changes in the level of government debt.
} 
households (LIQ), who do not save and have no access to credit. All households pay direct taxes on labor income, indirect taxes on consumption spending, and a lump-sum tax.

OLG households save by acquiring domestic government bonds, international U.S. dollar bonds, and through fixed-term deposits. They maximize their utility subject to their budget constraint. Aggregate consumption for these households is a function of financial wealth and the present discounted value of after-tax wage and investment income. The consumption of LIQ households is equal to their current net income, so their marginal propensity to consume out of current income is unity. A high proportion of LIQ households in the population would imply large fiscal multipliers from temporary changes to taxes and transfer payments.

For OLG households with finite-planning horizons, a tax cut has a short-run positive effect on output. When the cuts are matched with a tax increase in the future, to leave government debt unchanged in the long run, the short-run impact remains positive, as the change will tilt the time profile of consumption toward the present. In effect, OLG households discount future tax liabilities at a higher rate than the market rate of interest. Thus, an increase in government debt today represents an increase in their wealth, because a share of the resulting higher taxes in the future is payable beyond their planning horizon. If the increase in government debt is permanent (tax rates are assumed to rise sufficiently in the long run to stabilize the debt-to-GDP ratio by financing the higher interest burden) this will crowd out real private capital by raising real interest rates.

Increases in the interest rate have a negative effect on consumption, mainly through the impact on the value of wealth. The intertemporal substitution effect from interest rate changes is moderate and has been calibrated to be consistent with the empirical evidence. The intertemporal elasticity of substitution determines the magnitude of the long-run crowding-out effects of government debt since it pins down how much real interest rates have to rise to encourage households to provide the required savings.

\section{B. Production Sector}

Firms produce tradable and nontradable intermediate goods. They are managed in accordance with the preferences of their owners, finitely-lived households. Thus, firms also have finiteplanning horizons. The main substantive implication of this assumption is the presence of a substantial equity premium driven by impatience. ${ }^{14}$ Firms are subject to nominal rigidities in price setting as well as real adjustment costs in labor hiring and investment. They pay capital income taxes to governments, wages to all households, and dividends to OLG households.

Retained earnings are insufficient to fully finance investment, so firms must borrow from financial intermediaries. If earnings fall below the minimum required to make the contracted

\footnotetext{
14 This feature would disappear if equity was assumed to be traded in financial markets. The assumption of myopic firm behavior, and the resulting equity premium, are more plausible.
} 
interest payments, the financial intermediaries take over the firm's capital stock, less any auditing and bankruptcy costs, and redistribute it back to their depositors (households).

Firms operate in monopolistically competitive markets, and thus goods' prices contain a markup over marginal cost. Exports are priced to the local destination market and imports are subject to quantity adjustment costs. There are also price adjustment costs which lead to sticky prices.

Firms use public infrastructure (which is the government capital stock) as an input, in combination with tradable and nontradable intermediate goods. Thus, government capital adds to the productivity of the economy.

\section{Financial Sector}

GIMF contains a limited menu of financial assets. Government debt consists of one-period bonds denominated in domestic currency. Banks offer households one-period fixed-term deposits, their source of funds for loans to firms. These financial assets, as well as ownership of firms, are not tradable across borders. OLG households may, however, issue or purchase tradable U.S.-dollar-denominated obligations.

Banks pay a market rate of return on deposits, and charge a risk premium on loans. Because of the costs of bankruptcy (capital can only be liquidated at a discount), the lending rate includes an external financing premium, which varies directly with the debt-to-equity (leverage) ratio - the financial accelerator effect. Non-linearities imply steep increases in the risk premium for large negative shocks to net worth.

Uncovered interest parity may not hold, due to the presence of country risk premiums. The premiums can create deviations, both in the short run and the long run, between interest rates in different regions, even after adjustment for expected changes in exchange rates.

\section{International Dimensions and Spillovers}

All bilateral trade flows are explicitly modeled, as are the relative prices for each region, including exchange rates. These flows include the export and import of intermediate and final goods. They are calibrated in the steady state to match the flows observed in the recent data. International linkages are driven by the global saving and investment decisions, a by-product of consumers' finite horizons. This leads to uniquely defined current account balances and net foreign asset positions for each region. Since asset markets are incomplete, net foreign asset positions are represented by nominal non-contingent one-period bonds denominated in U.S. dollars.

Along with uncovered interest parity, and long-term movements in the world real interest rate, the magnitude of the international trade linkages is the main determinant of spillover effects from shocks in one region to other regions in the world. 


\section{E. Fiscal and Monetary Policy}

Fiscal policy is conducted using a variety of expenditure and tax instruments. Government spending may take the form of either consumption or investment expenditure, or lumpsum transfers to either all households or targeted towards LIQ households. In previous versions of GIMF, revenue accrued from the taxes on labor income and capital returns, consumption taxes, and lumpsum taxes. In this paper, we also allow revenue to accrue from corporate income and cash flow taxes. The model also allows for tariffs on imported goods to be a potential source of public revenue. Government investment spending augments public infrastructure, which depreciates at a constant rate over time.

There is a fiscal policy rule which ensures long-run sustainability, while allowing for shortrun counter-cyclical policies. Changes in both labor and capital income taxes provide the instrument to put the rule into effect, but this can be replaced with other tax, transfer or spending instruments if that is considered more realistic for a specific region. First, the fiscal rule ensures that in the long run, the government debt-to-GDP ratio-and hence the deficitto-GDP ratio- eventually converges to its target level. This excludes the possibility of sovereign default, as well as the risk that out-of-control financing requirements of the government will override monetary policy. Second, the rule allows for countercyclical fiscal policy as it embodies automatic stabilizers.

When conducting monetary policy, the central bank uses an inflation-forecast-based interest rate rule. The central bank varies the gap between the actual policy rate and the long-run equilibrium rate to achieve a stable target rate of inflation over time.

\section{PERMANENT CHANGES TO ALL TAXES IN GIMF: PROPERTIES}

To understand how each business tax affects the model properties, we consider two sets of simulations. ${ }^{15}$ The first set discusses the impact of a permanent increase in each of the business taxes in the model. The results are presented in this section. A second set of simulations, shown in Section IV, discusses the impact of a temporary decrease in each of the corporate taxes in line with the simulations presented in Anderson and others (2013). ${ }^{16}$ All simulations use a three-region version of GIMF, calibrated to comprise two countries that represent around $1 / 4$ of the total world economy each, plus the rest of the world.

Before presenting each set of simulations, it is important to understand the limitations of the assumptions made when introducing the taxes, which were driven partly by the existing structure of GIMF and partly to simplify the algebra and the computational burden of solving the model. Thus, several (possibly important) channels that could affect the macroeconomic

\footnotetext{
${ }^{15}$ Appendices III and IV show the detailed derivation for how the taxes were introduced into GIMF.

${ }^{16}$ Appendix II shows the fiscal multipliers associated with all nine fiscal instruments in the model. Multipliers from the original version of GIMF are compared with the new version that contains all new taxes.
} 
outcomes following changes in these taxes are omitted. For instance, one may expect to find that firms that operate in various countries may modify transfer prices, relocate patents, change their financial structure, or relocate production towards the country with the less distortionary tax system. The actions would likely imply significant profit shifting. In addition to the broad macroeconomic implications, the resulting tax-base shifts could potentially have large implication for corporate tax revenue in different countries. However, because the model's framework does not incorporate multinational firms, these potential transmission channels are absent. Additionally, owing to simplifying assumptions related to the currency denomination of foreign liabilities, the model-based analysis cannot capture the balance sheet effects of exchange rate movements.

The introduction of the CIT and CFT/DBCFT affects all firms, financial intermediaries, and the government directly and households indirectly. In the case of firms, after-tax profits (and dividends ${ }^{17}$ ) are lower with the introduction of the taxes, creating distortions. Financial intermediaries are directly affected because the introduction of the taxes affects the risk premium they charge on loans, creating further distortions. Entrepreneurs are also affected through the effect that all taxes have on their balance sheets which affects the risk premium of their debt contract.

In the case of the government sector, the new taxes serve to generate additional sources of revenue. As we shall see below, the different taxes have different tax bases and thus different tax rates are required to raise similar amounts of revenue. For households that save (OLG households), both taxes reduce the after-tax dividends that they receive from firms and therefore reduce their lifetime wealth and consumption.

To illustrate the impact of the different corporate taxes on the model, permanent increases in the four taxes are presented. It is assumed that all four business tax rates were zero to begin with. In each case the tax rate is changed such that on impact it raises additional fiscal revenue of 1 percent of GDP. No other taxes are changed. The tax proceeds are redistributed to OLG households in the form of lumpsum transfers. Once the tax is imposed, everyone understands that the change in fiscal policy is permanent. Initially the focus will be on the long-run impacts (steady-state), but a discussion of the short-run adjustment towards the steady-state follows.

\footnotetext{
${ }^{17}$ In GIMF, as in most DSGE models, taxes on firms' profits are equivalent to taxes on dividends, as the latter are rebated back to households. In reality, tax rates on dividends are levied on investors (who may themselves be subject to different rates depending on their nature) and may differ from the taxes levied on firms' profits. Modelling such detail would overcomplicate the model and is beyond the scope of this paper.
} 


\section{A. Long run impact from (permanent) introduction of each tax}

\section{Tax on the return to capital (KRT)}

The impact of introducing a tax on the return to capital is considered first and shown in Figure 1. Firms cut investment sharply as their desired level of capital is revised down given the reduction in the effective return resulting from the imposition of the tax. A lower level of the capital stock lowers marginal product of labor and thus real wages. Reduced real wages cut household disposable income and human wealth leading to lower consumption. The lower level for the capital stock implies lower potential output and GDP is reduced by roughly 2 percent below the initial baseline. With a permanently lower level of output and domestic demand, households and firms do not demand as many imports and thus the economy does not need to export as much to pay for its desired import bundle. Consequently, the real effective exchange rate is appreciated in the new steady state to maintain external equilibrium.

The decline in the capital stock is large enough so that the pre-tax physical return to capital rises so that new after-tax return is equal to the return on capital prior to the imposition of the tax. Hence, fiscal revenue as a share of GDP is higher than the initial 1 percent increase the change in the tax rate on the return to capital was calibrated to achieve. The additional revenue is returned to households in the form of lumpsum transfers. The lower level of the capital stock also means that firms need to borrow less to fund their balance sheets and corporate debt declines. However, the leverage ratio remains unchanged in the long run. With lower real wages, households save less in the new steady state. However, private savings do not fall as much as the decline in the capital stock and households replace some domestic assets in their wealth portfolios with foreign assets. Net foreign assets as a share of GDP is higher in the new steady state and this new level is supported by a small increase in the current account as a share of GDP. 
Figure 1: Long-Run Impact of a Permanent Increase in the KRT

- Tax on Return to Capital (KRT)

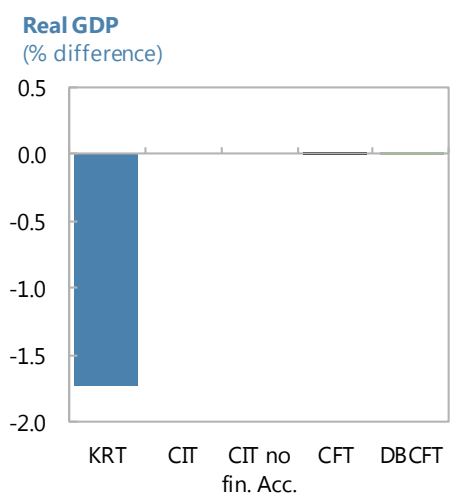

Real Investment (\% difference)

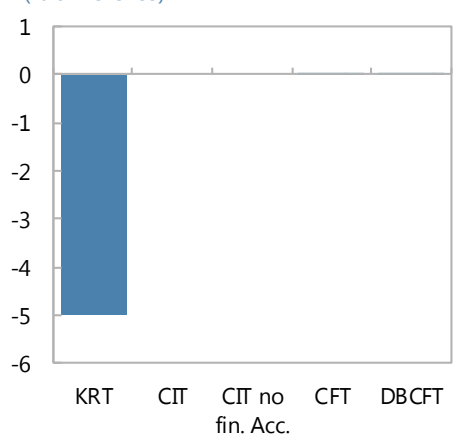

Real Imports

(\% difference)

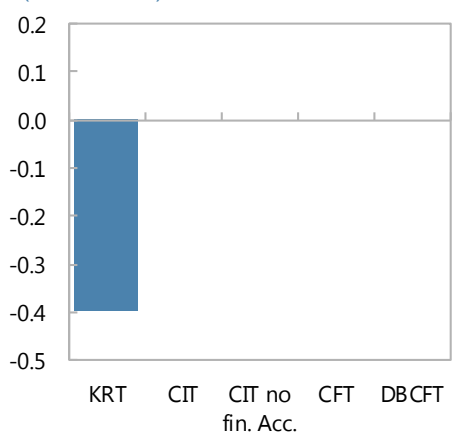

Real Exports

(\% difference)

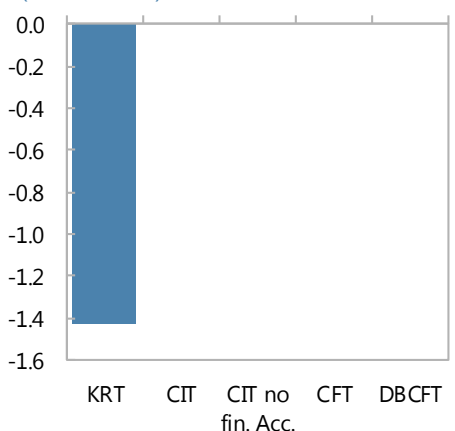

Private Saving/GDP

(\% pt difference)

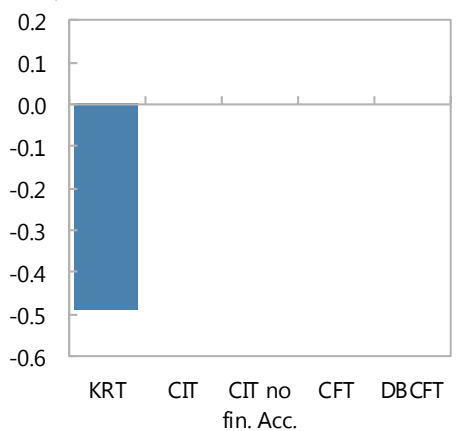

NFA/GDP

(\% pt difference)

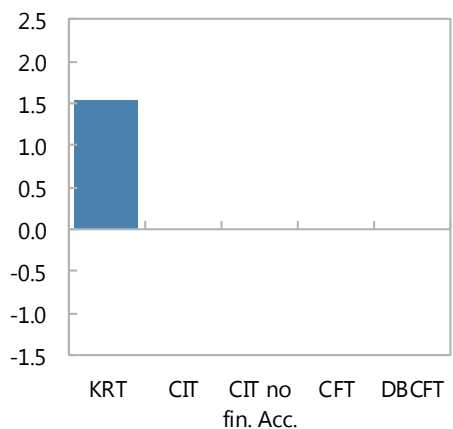

Real Consumption

(\% difference)

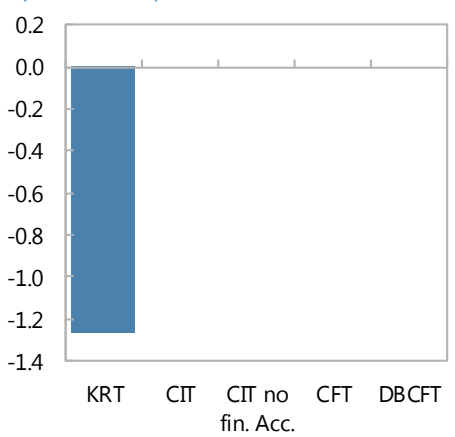

Real Effective Exchange Rate \% difference, $+=$ depreciation

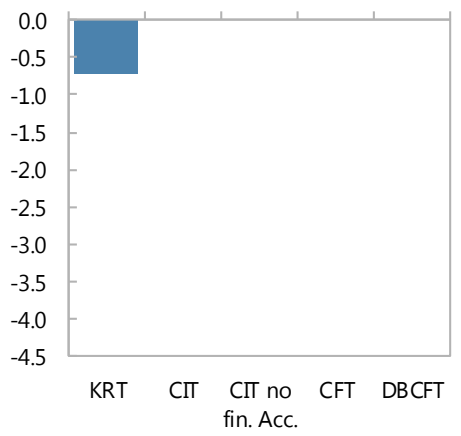

Physical Return to Capital (\% pt difference)

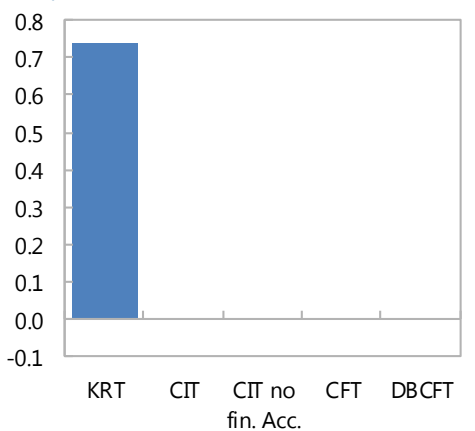

External Finance Premium

Corporate Debt

(\% pt difference)

(\% difference)

Leverage

(\% pt difference)
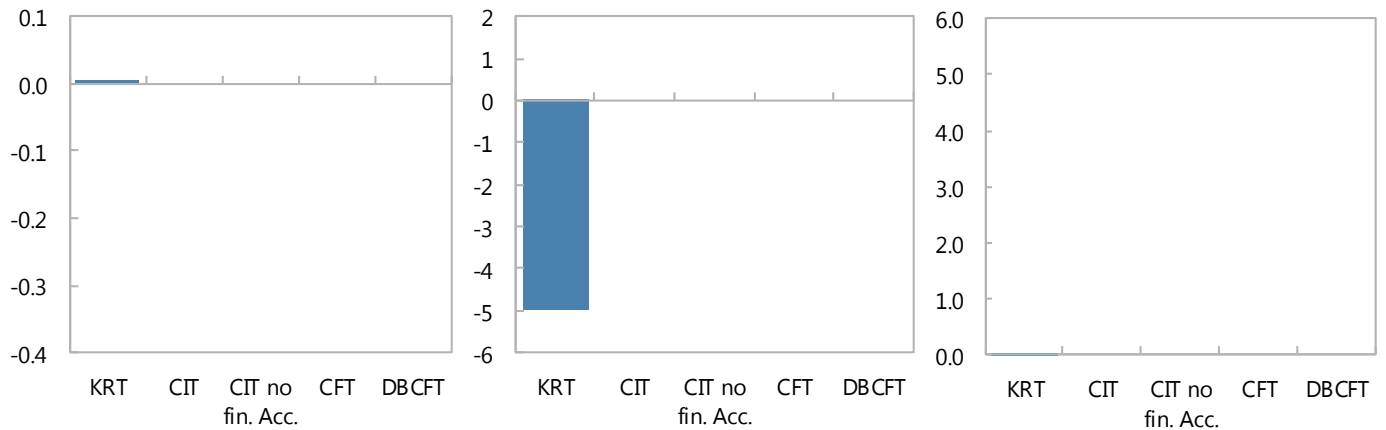

Source: GIMF simulations. 


\section{The corporate income tax (CIT)}

The impact of introducing a CIT (red bars) is compared in Figure 2 to the impact of introducing a KRT (blue bars). Although the qualitative macroeconomic impact of the two taxes for most key variables is broadly similar, the difference in the quantitative impact is striking. The imposition of the CIT is far less deleterious on the capital accumulation process and thus overall economic activity than is the KRT. This occurs for two main reasons. First, the underlying structure of the model assumes that capital is traded in a perfectly competitive market and thus the KRT does not tax rents and falls only on the economic return to capital required to make the capital investment worthwhile. Consequently, it is highly distortionary. The tax on corporate income, however, falls on the economic return that would prevail under perfect competition as well as on the rents that arise because goods producing firms operate under monopolistic competition. This means that underlying economic incentives are not distorted as much with the imposition of the CIT. Second, because under the corporate income tax, interest expenses are deductible, there is an important interaction with the model's financial accelerator that partially offsets the distortionary impact of the CIT illustrated by the increase in leverage and explained below.

One difference in the macroeconomic impact relative to the KRT is the outcome for net foreign assets. Under the CIT private saving falls by more than the decline in the capital stock and thus foreigners are required to hold some of the domestic assets. This higher level of foreign indebtedness is supported by a small deterioration in the current account. 
Figure 2: Long-Run Impact of a Permanent Increase in the CIT

- Tax on Return to Capital (KRT)

- Corporate Income Tax (CIT)

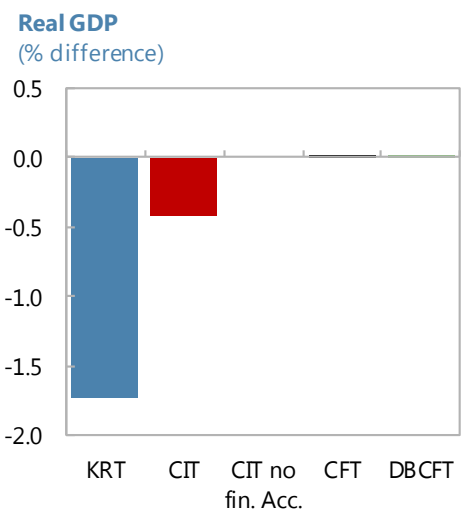

Real Investment

(\% difference)

Real Consumption

(\% difference)

(\% difference)
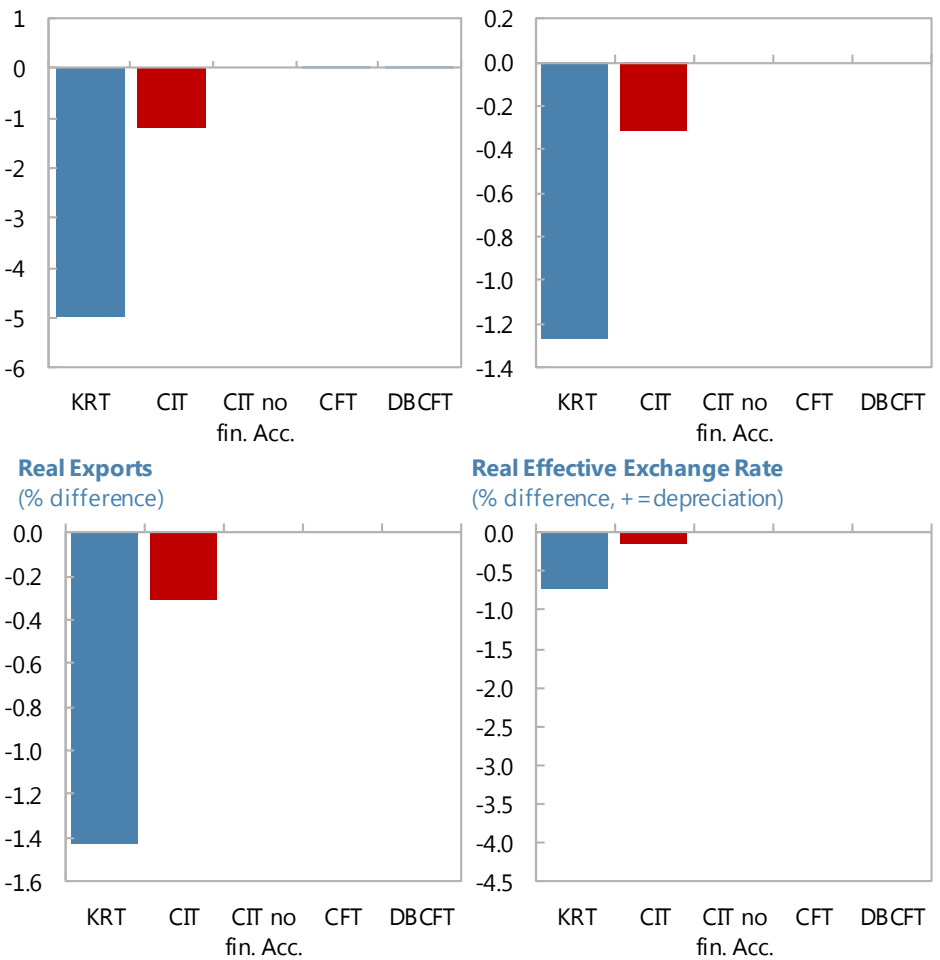

Real Effective Exchange Rate

(\% difference, $+=$ depreciation)
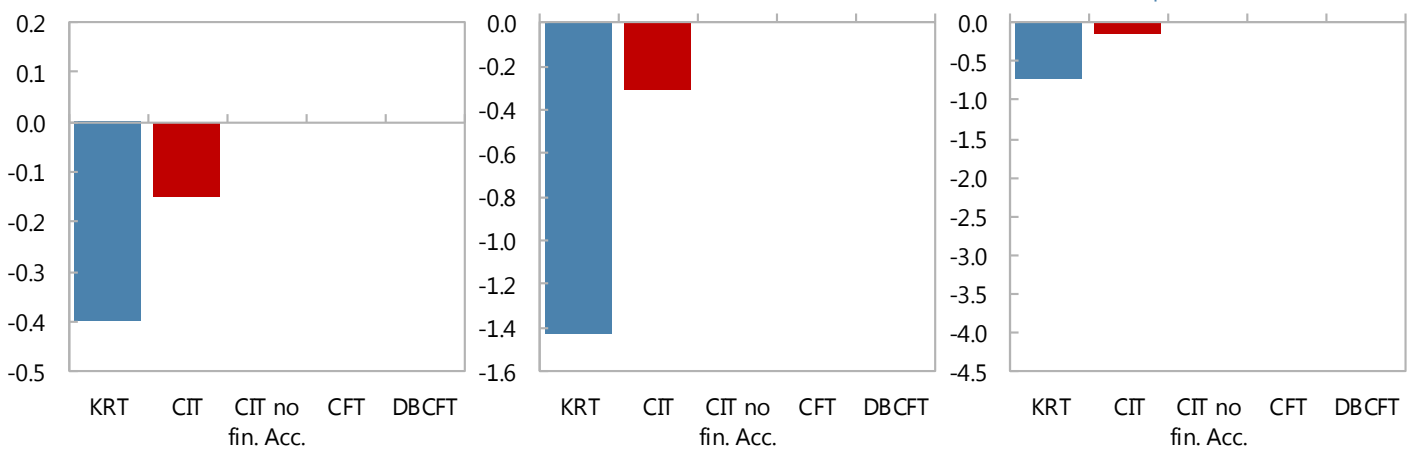

Private Saving/GDP

(\% pt difference)

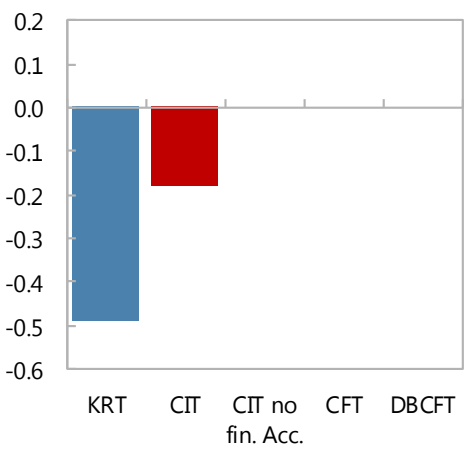

NFA/GDP

(\% pt difference)

Physical Return to Capital

(\% pt difference)
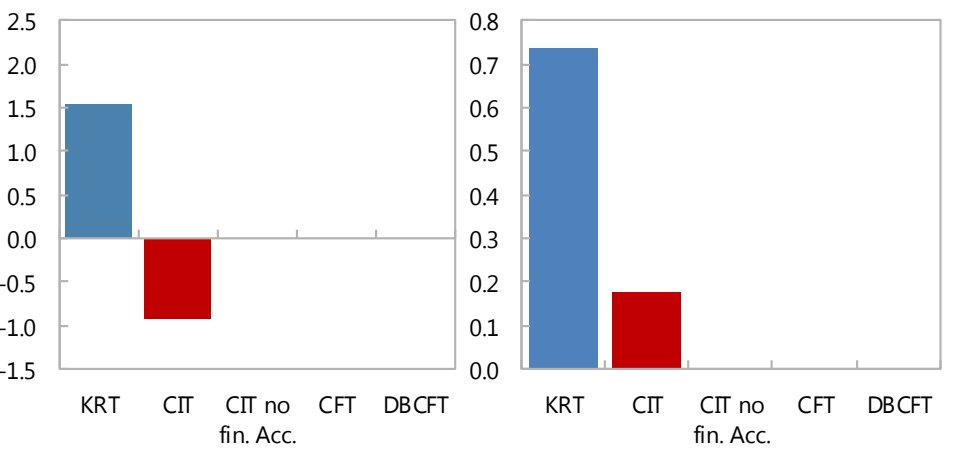

External Finance Premium

(\% pt difference)

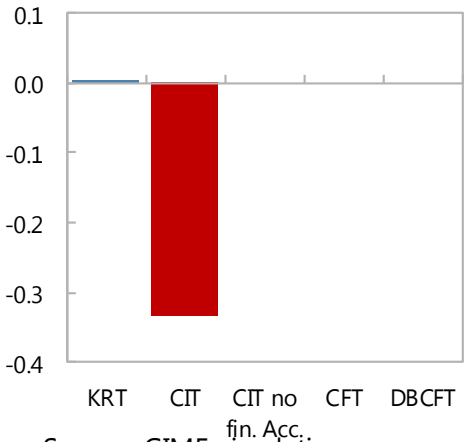

Corporate Debt

(\% difference)

Leverage

(\% pt difference)
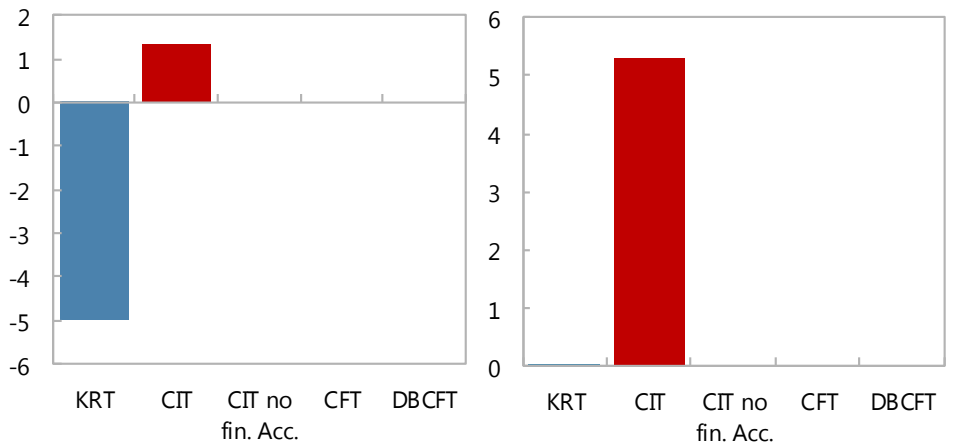

Source: GIMF simulations. 


\section{On the Interaction of the Financial Accelerator and the CIT}

Entrepreneurs and banks are at the heart of the model's financial accelerator. Entrepreneurs own the capital stock and they rent it to firms each period. Part of the increase in the capital stock each period is financed with a loan from the bank. But before repaying the bank loan at the end of each period (using the after-tax returns from renting their capital), entrepreneurs are subject to an idiosyncratic shock that can increase or reduce their returns. Sufficiently negative shocks may prevent entrepreneurs from being able to repay their loan and the result is bankruptcy. When that happens, the bank takes over the entrepreneurs' wealth but in doing so incurs a (monitoring) cost.

The entrepreneurs must choose between internal funding (paying an internal finance premium, or equity premium) and external funding (a loan from a bank) to finance capital accumulation. The cost of capital is a weighted average of the two funding costs. As the external funding cost is lower than the internal one, the entrepreneur would like to leverage as much as possible. The optimal debt contract between the entrepreneur and the bank internalizes the cost of bankruptcy: banks charge a premium (external finance premium) over the risk-free rate to cover the bankruptcy cost. This premium increases with the entrepreneur's leverage ratio preventing the financing of the entire capital stock with credit. Figure 3 provides some intuition about the key ingredients of the debt contract. The figure presents key variables such as the leverage ratio, bankruptcy rates, the return to capital and the external finance premium as a function of the idiosyncratic shock, monitoring costs and the internal finance premium.

The leverage ratio (first row of Figure 3) is a decreasing function in the uncertainty associated with the idiosyncratic shock to the entrepreneur's return and the monitoring cost. With less uncertainty (i.e. lower variance in the idiosyncratic shock), the probability of bankruptcy declines (second row), and with lower monitoring costs, the amount of wealth that the bank receives after bankruptcy increases. In both cases, banks are prone to extend more credit (thereby increasing leverage) and reducing the cost of capital. A higher leverage ratio, in turn, typically results in a higher bankruptcy rate. The bankruptcy rate is an inverted U-shape function of the uncertainty in entrepreneur returns. From a low level of uncertainty (which induces high leverage), a marginal increase in uncertainty puts more entrepreneurs into bankruptcy. But sufficiently high levels of uncertainty result in ever lower levels of leverage thereby reducing bankruptcy rates. 
Figure 3: Debt Contracts and CIT
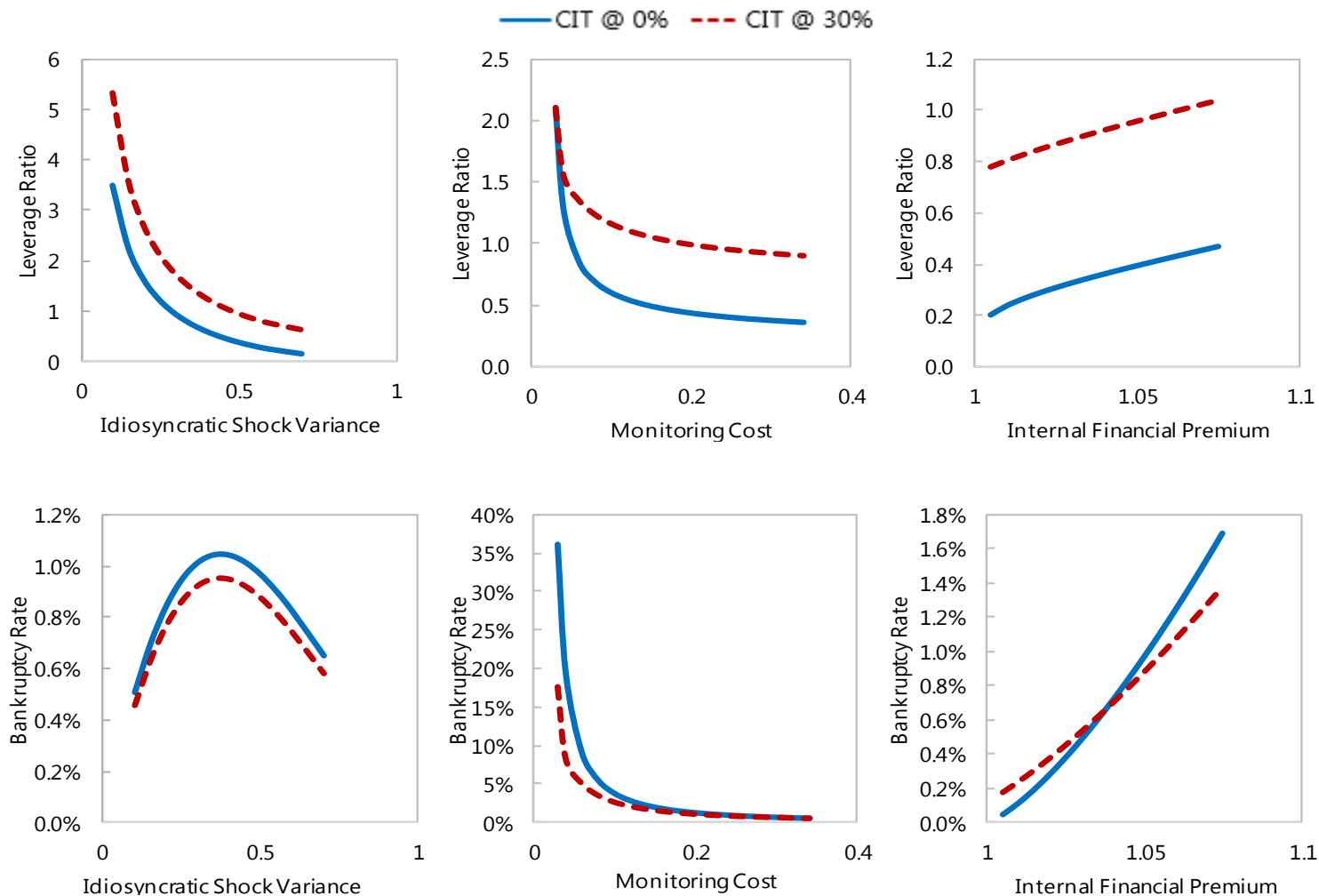

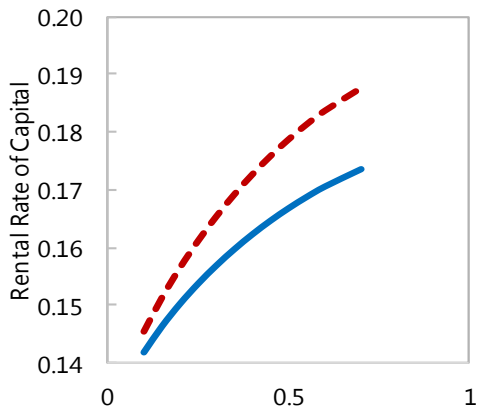

Idiosyncratic Shock Variance

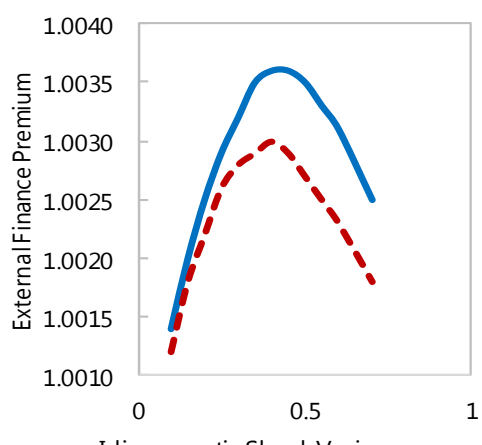

Idiosyncratic Shock Variance

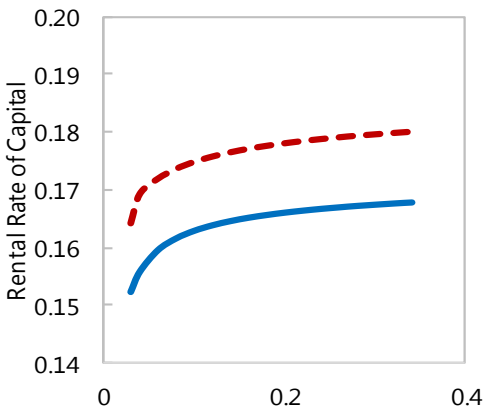

Monitorina Cost

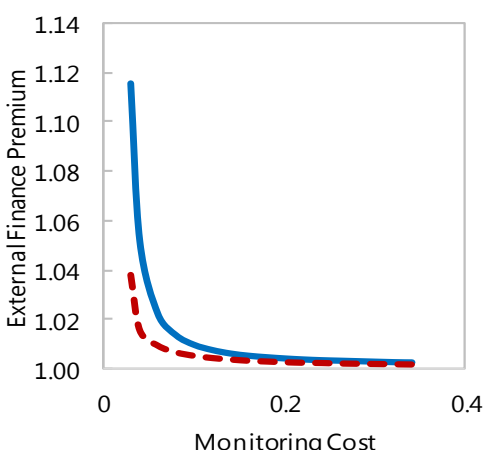

Monitoring Cost
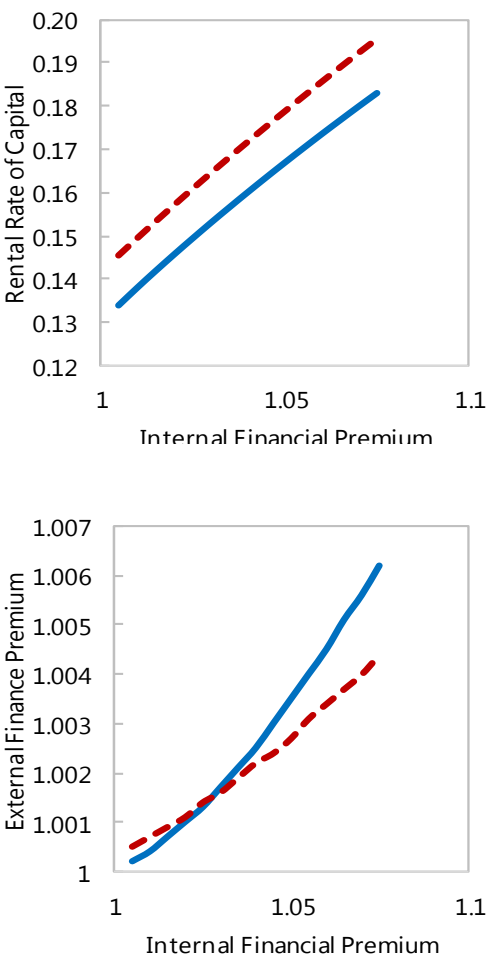

Source: Authors computations 
Taxes on firms can affect the terms of the loan. Taxes are levied on the returns made by entrepreneurs. All else equal, taxes on firms lower the ability to repay the bank. Under the KRT, the pre-tax return on capital rises sufficiently to leave the after-tax return unchanged and thus there is no change in the ability to repay the bank, the external risk premium, or leverage. But in the case of a CIT, entrepreneurs can deduct interest expenses ${ }^{18}$ associated with their loans and hence pay lower taxes. Such a deduction represents an implicit debt subsidy that can increase the after-tax returns of entrepreneurs. This leads to a reduction of the external finance premium. This reduction is not available under the KRT and is what modifies the optimal loan contract. This results in an increase in the optimal leverage ratio everything else equal. ${ }^{19}$ Figure 3 illustrates the upward shift of the leverage ratio where the blue line represents the optimal debt contact with the CIT rate at zero and the red line represents the optimal debt contract with the CIT rate at 30 percent.

Figure 4 compares the long-run impact associated with the permanent tax increase in the CIT in a version with and without the financial accelerator (pink bars). The presence of the financial accelerator reduces the negative impact of the CIT on real activity by more than half, primarily through the impact of tax deductibility on corporate leverage and thus investment and the capital stock. A smaller reduction in the capital stock leads to less decline in the marginal production of labor, real wages and hence consumption and imports.

\footnotetext{
${ }^{18}$ In many business income tax systems, profits are taxed and losses are deductible from future profits: losses do not entail an immediate rebate from tax authorities. As it is difficult to reproduce such a complex scheme in our model, it is assumed that profits and losses are included in the business income tax base each period.

${ }^{19}$ One way to see this, is that just below the threshold where an entrepreneur declares bankruptcy (i.e. at the limit of bankruptcy) in absence of the CIT, the entrepreneur would have to default and the bank would suffer a capital loss as well as incurring the monitoring cost. With a CIT, the entrepreneur receives a tax rebate from the government and escapes the bankruptcy risk.
} 
Figure 4: Long-Run Impact of a Permanent Increase in the CIT w/o Fin. Accel.

- Tax on Return to Capital (KRT)

- Corporate Income Tax (CIT)

w Corporate Income Tax w/o Fin. Accelerator

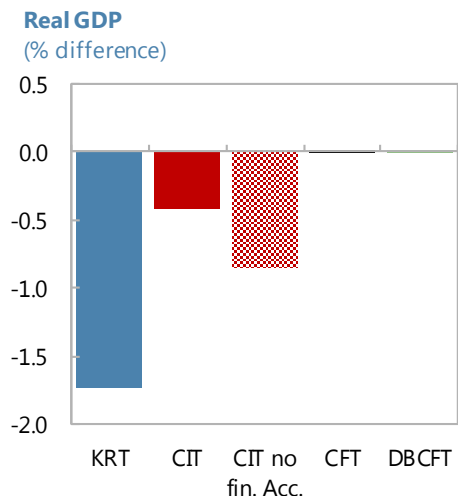

Real Investment

(\% difference)

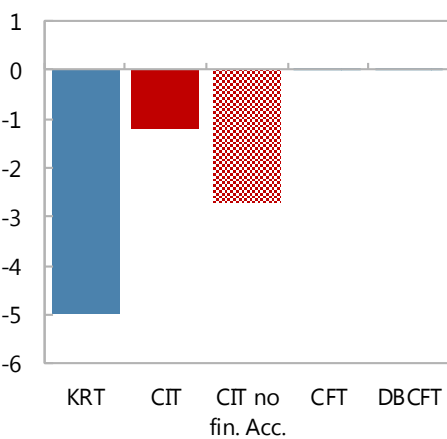

Real Consumption

(\% difference)

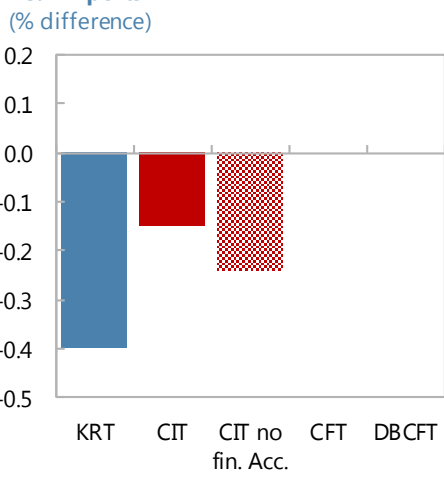

Real Exports

(\% difference)
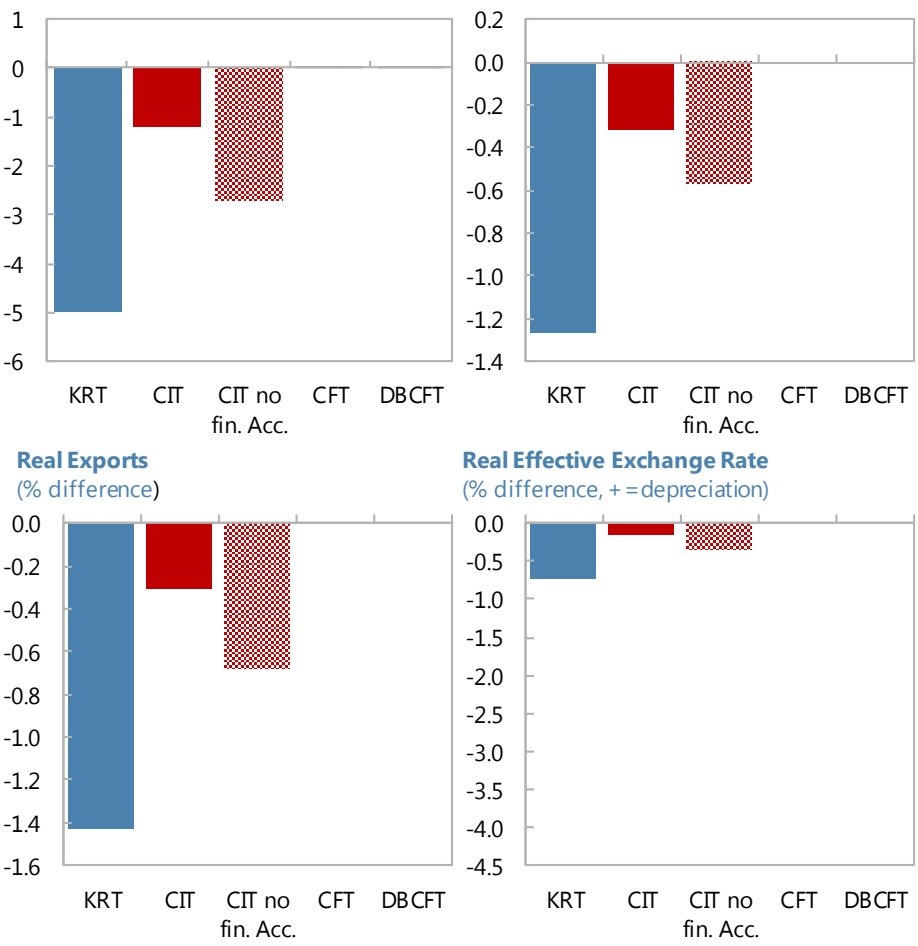

Real Effective Exchange Rate

(\% difference, $+=$ depreciation)

Private Saving/GDP

(\% pt difference)

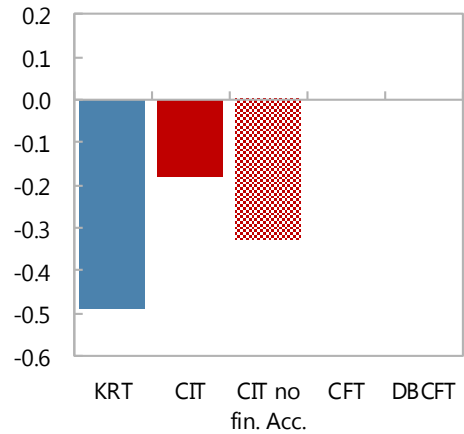

NFA/GDP

(\% pt difference)

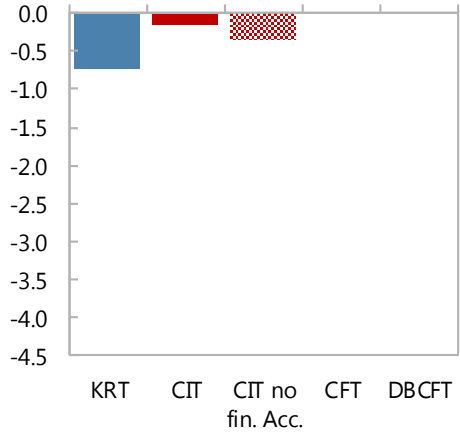

Physical Return to Capital (\% pt difference)
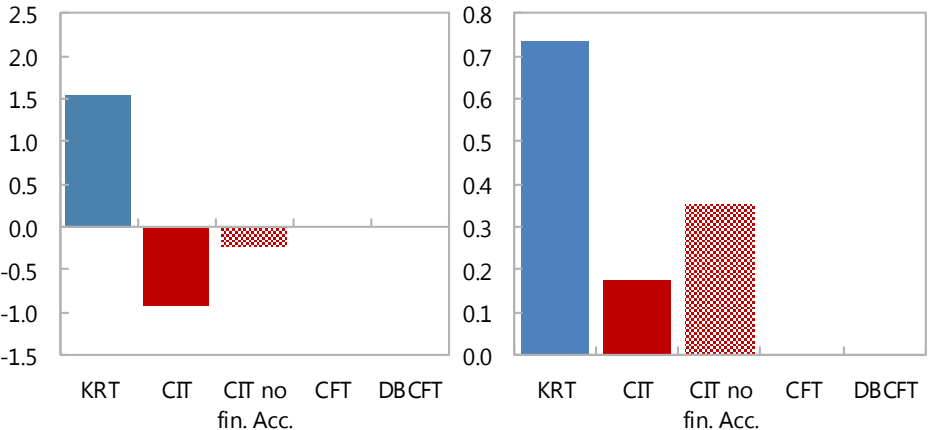

External Finance Premium

(\% pt difference)

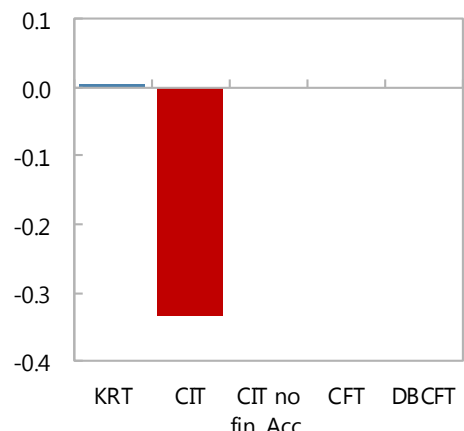

Corporate Debt (\% difference)

Leverage (\% pt difference)
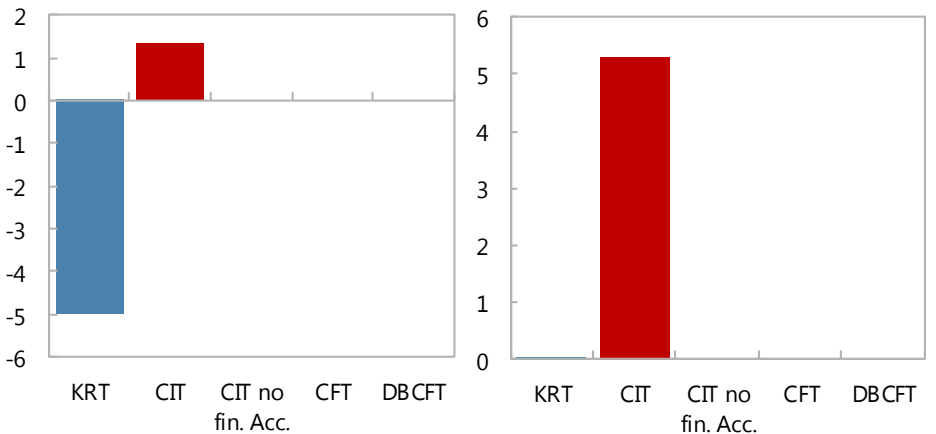

Source: GIMF simulations. 


\section{The Cash Flow Tax (CFT)}

In Figure 5 the macro impact of imposing a CFT (black bars) is compared to the impact of the CIT and the KRT. The most important point to note is that in the long run, there is no negative impact on firms' desired level for the capital stock or investment and thus there is no negative impact on the level of output. This arises because the full deduction of investment expenditure from the firm's tax base implies that the required return to capital is not taxed and the tax falls only on rents. When the firm can fully deduct investment expenditures its tax liability is lowered by the tax rate times the amount invested and this is exactly equal to the net present value of future taxes the firm will pay on the component of their revenue stream that includes the required return to capital. ${ }^{20}$

Although there is no change in the level of the capital stock and thus the return to capital, there is a change in the value of firms and the level of corporate debt. Because the dividend stream produced by firms is lowered by the tax, the value of the firm, captured by Q, the shadow price of capital, falls. With a smaller balance sheet to finance, firms need to borrow less and corporate borrowing declines. However, corporate leverage remains unchanged. The price of investment goods also remains unchanged and the presence of a cashflow tax drives a wedge between the shadow price of capital and the price of investment goods.

The change in the value of the firm and the associated decline in corporate debt outstanding has an impact on household saving behavior. The additional tax revenue stemming from the CFT is rebated back to OLG households, compensating for the loss of after tax dividends: the flow of income for OLG households is therefore unchanged. However, given the lower cost of capital, domestic firms issue less corporate debt to finance a cheaper but constant stock of capital. The lower supply of domestic financial assets bids up its price and hence lowers the real interest rate. ${ }^{21}$ Given the shortage of domestic private debt, OLG households demand more foreign assets to maintain their total stock of wealth. As households accumulate sufficient foreign assets, this results in a trade deficit and a small exchange rate appreciation.

\footnotetext{
${ }^{20}$ An example helps. Assume that the real interest rate, $r$, is equal to 3 percent, the depreciation rate, $\delta$, is equal to 10 percent, inflation, $\pi$, is 2 percent, the discount rate, $\rho$, is equal to $r+\pi$, and the tax rate, $\tau$, is 30 percent. The present value of the tax on the investment's normal return and the return to pay for depreciation amounts to $\tau \cdot(r+\delta) /(\rho+\delta-\pi)=30 \% \cdot(3 \%+10 \%) /(5 \%+10 \%-2 \%)=30 \%$ which exactly equals the corporate tax rate.

${ }^{21}$ In fact, there is an overall decline in global assets, which lowers the world interest rate.
} 
Figure 5: Long-Run Impact of a Permanent Increase in the CFT

- Tax on Return to Capital (KRT)

- Corporate Income Tax (CIT)

. Corporate Income Tax w/o Fin. Accelerator

- Cash Flow (CFT)

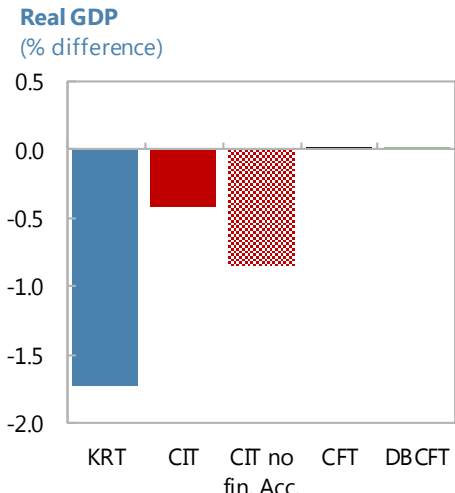

Real Investment

(\% difference)

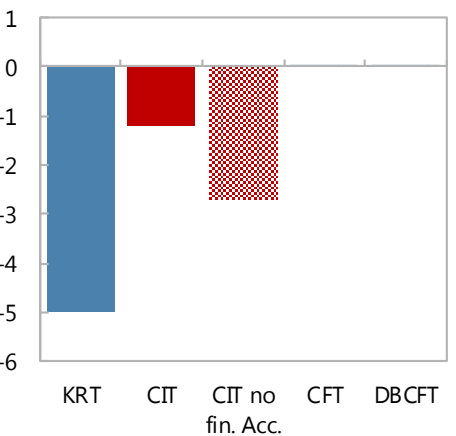

Real Imports

Real Exports

(\% difference)
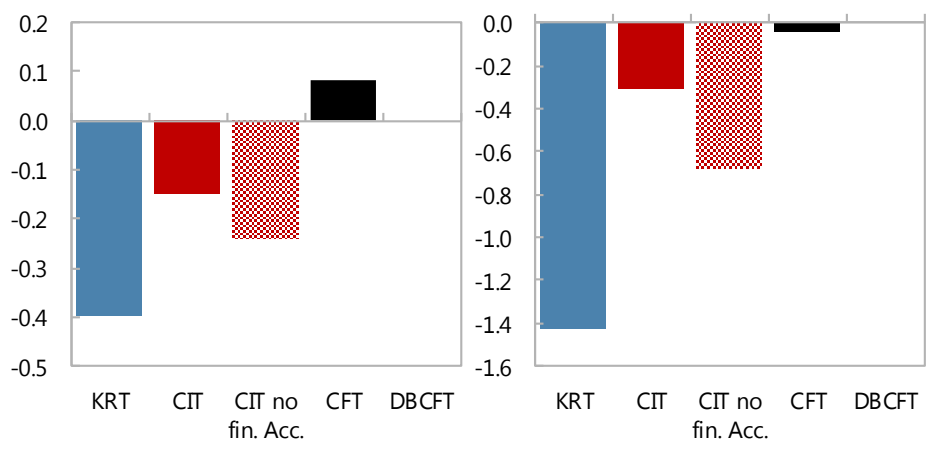

Real Consumption

\% difference)

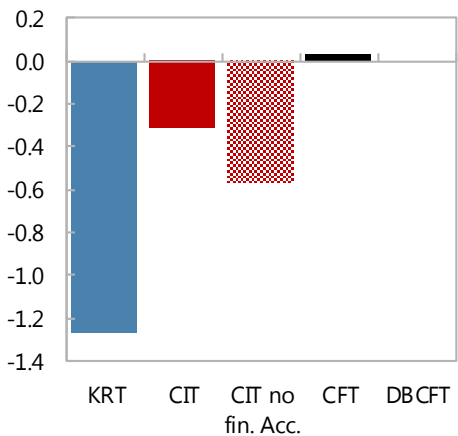

Real Effective Exchange Rate

\% difference, $+=$ depreciation)
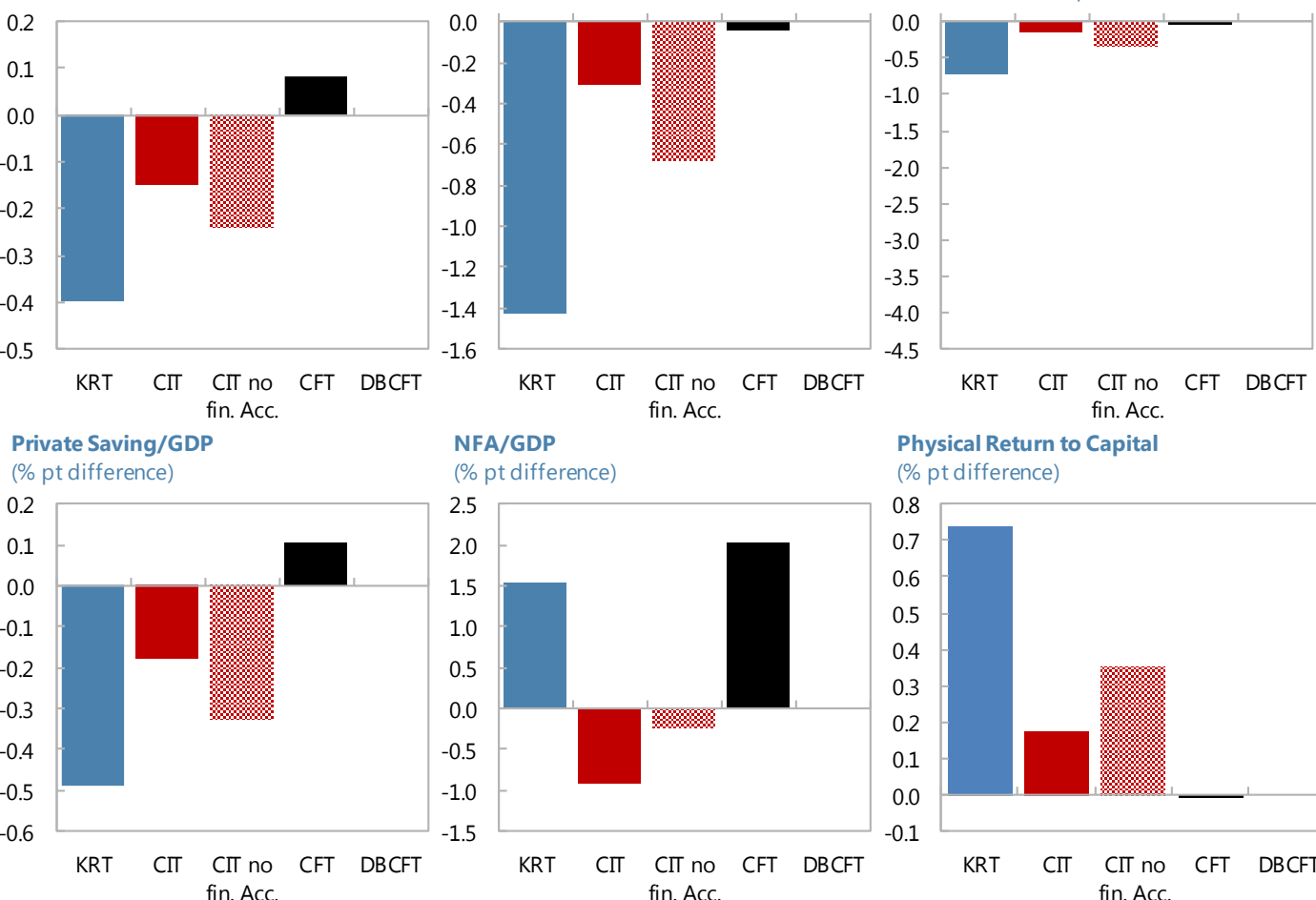

NFA/GDP

(\% pt difference)

Physical Return to Capital

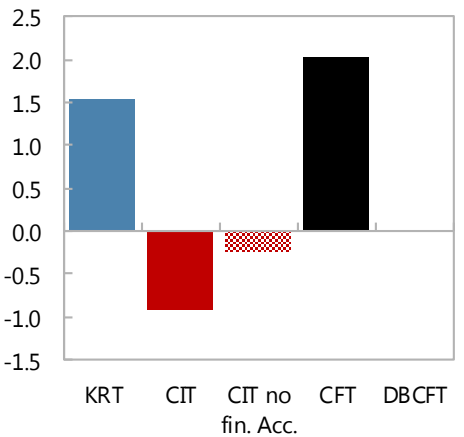

(\% pt difference)

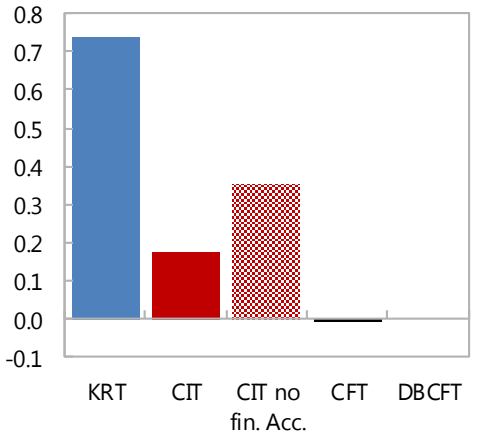

External Finance Premium

(\% pt difference)

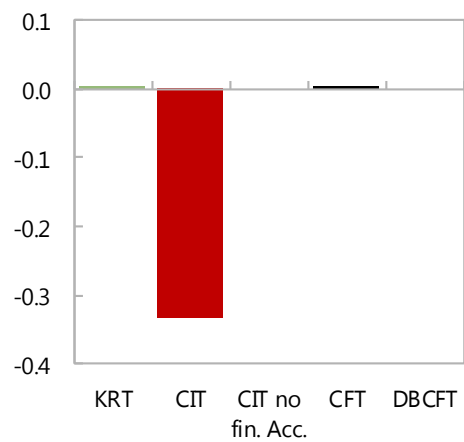

Corporate Debt

(\% difference)

Leverage

(\% pt difference)
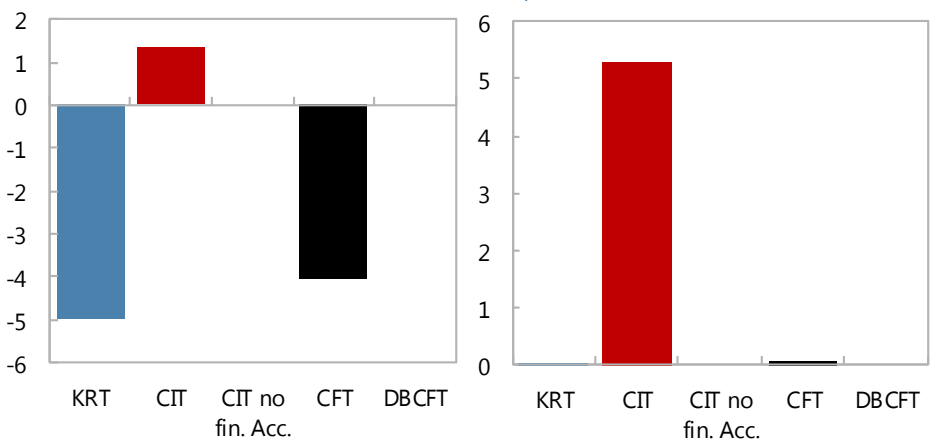

Source: GIMF simulations. 


\section{The Cash Flow Tax vs a Destination-Based Cash Flow Tax (DBCFT)}

In Figure 6 the impact of the DBCFT (green bars) is compared to the impact of the CFT, the CIT and the KRT. The addition of the destination-based component to the cash flow tax only has implications for the real exchange rate, all other macro impacts remain unchanged relative to the CFT..$^{22}$ International trade is conducted through specialized firms. Exporting firms buy domestic intermediate and final goods and sell them in foreign markets. They set prices in the market that they export to. Importing firms buy a basket of foreign goods to produce imported intermediate and final goods bundles. A destination-based business tax affects the pricing behavior of exporting and importing firms in addition to affecting their dividends.

Under a source-based system, both domestic sales and exports are taxed by the cash-flow tax, whereas only domestic sales are taxed under a destination-based version. Sales of exporting firms in foreign markets are not taxed at all under a destination-based system. However, intermediate goods and other domestic input costs give the right to a tax deduction. Therefore, exporting firms receive a tax benefit from their foreign sales under a destinationbased system. Under monopolistic competition, this benefit is eventually passed-through into a lower export price in the long-run.

For the importing firm, however, the cost of imported intermediate inputs is no longer deductible form their tax base. Hence, the price of a good entering the country that is imposing the destination based-tax is increased by the tax as it enters the country. Thus, the destination-based component of the tax reproduces the price implications of a depreciation of the exchange rate. Maintaining balance in the current account and thus the desired holdings of net foreign assets requires a compensatory real appreciation of the currency.

\footnotetext{
${ }^{22}$ Within the framework of Barbiero and others (2017), who examine whether border adjustments are neutral on real variables, the long-run DBCFT simulations relative to the CFT simulations satisfy all the conditions for neutrality. In the next subsection, it will be shown that the border adjustment neutrality is not satisfied in the short-run during the transitional dynamics towards the long-run equilibrium.
} 


\section{Figure 6: Long-Run Impact of a Permanent Increase in the DBCFT}
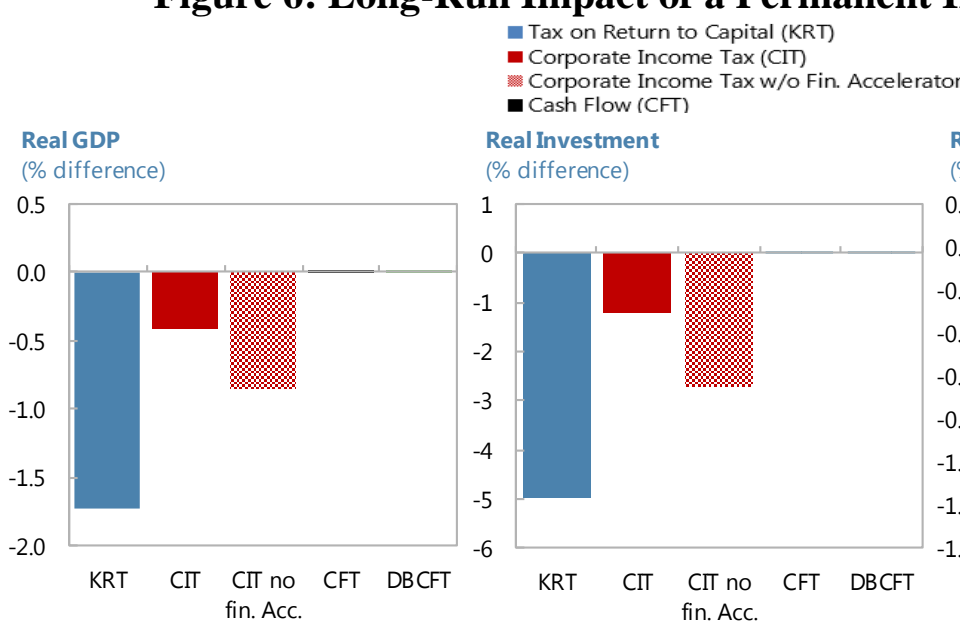

Real Investment

(\% difference)

Real Consumption

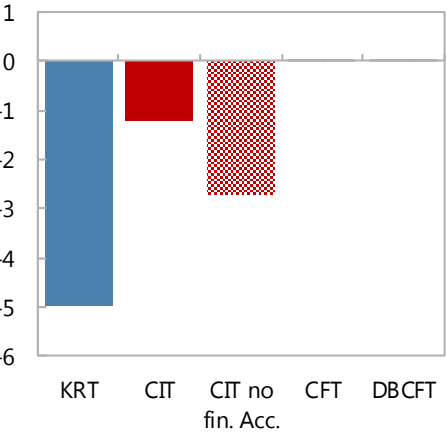
(\% difference)

Real Imports (\% difference)

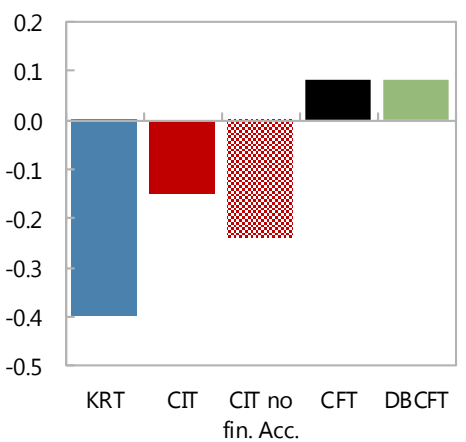

Real Exports

(\% difference)
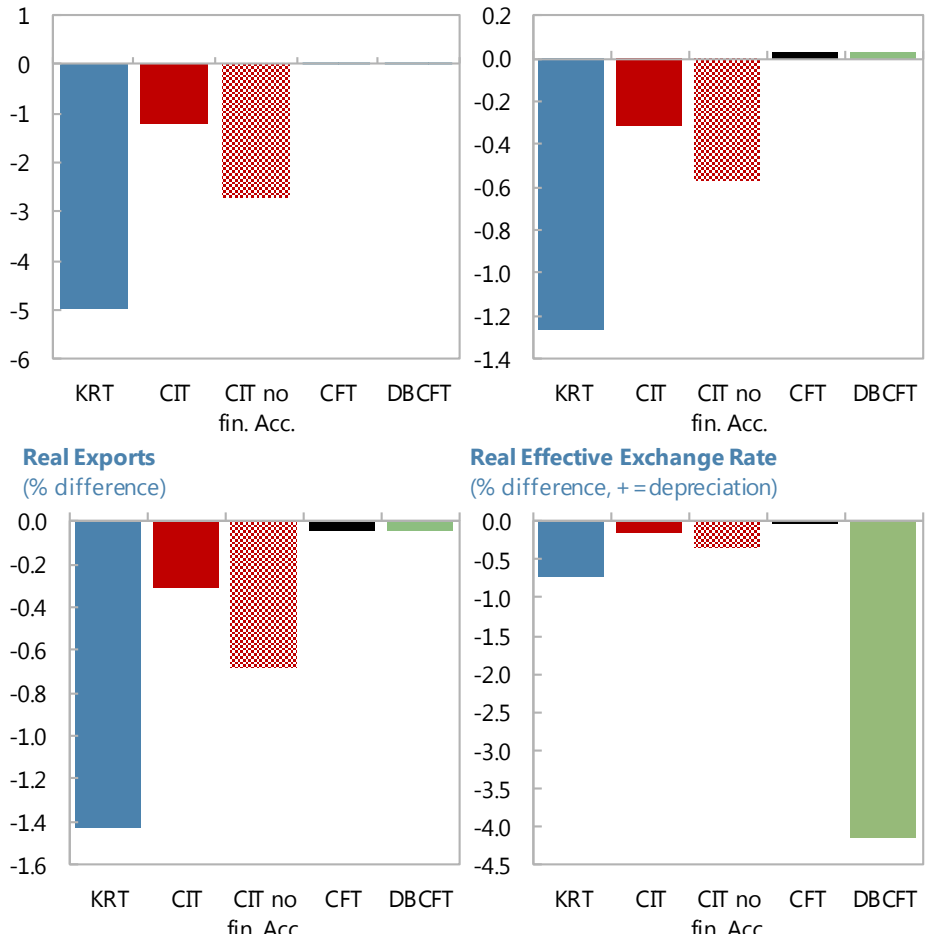

Real Effective Exchange Rate (\% difference, $+=$ depreciation)

Private Saving/GDP

NFA/GDP

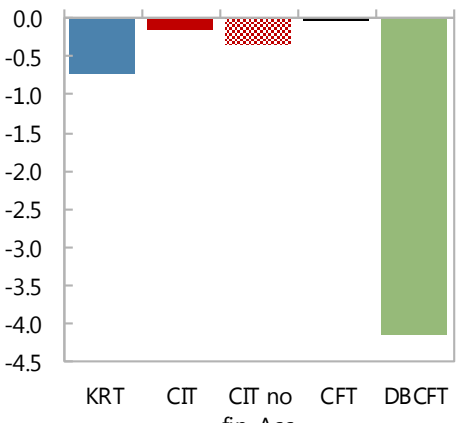

(\% pt difference)

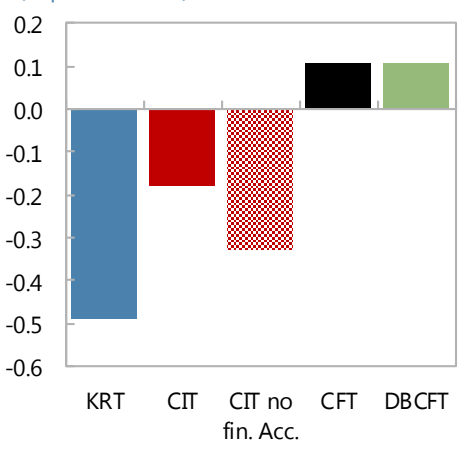

\% pt difference)

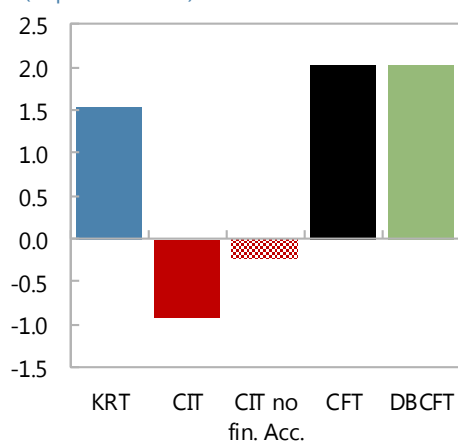

Physical Return to Capital (\% pt difference)

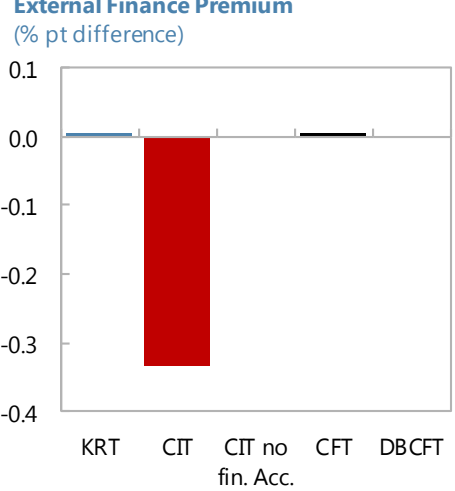

Corporate Debt

(\% difference)

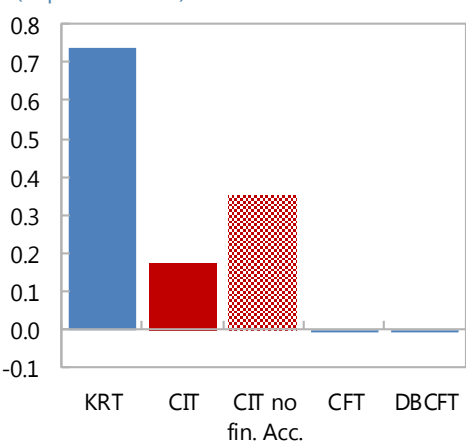

2

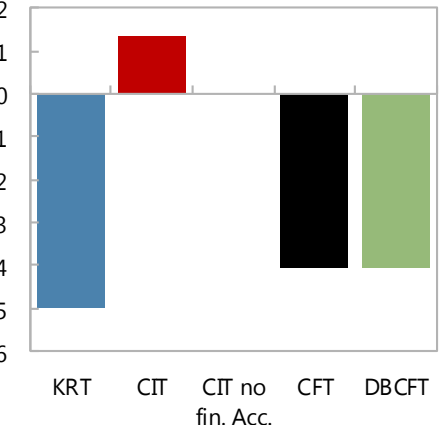

Leverage

(\% pt difference)

Source: GIMF simulations. 


\section{B. Transitional dynamics from the (permanent) introduction of each tax}

Figure 7 presents the transitional dynamics towards the long-run equilibrium just discussed. First the transitional dynamics of both the KRT (blue) and the CIT (red) taxes are discussed. In response to the permanent increase in both taxes which lowers the after-tax return to capital, firms cut investment. However, as there are costs associated with changing investment, firms cut investment only gradually. As noted earlier, the decline in investment and the capital stock is significantly lower in the case of a CIT relative to a KRT. Not only is the CIT less distortionary, but the CIT also allows for deductible interest expensing which interacts with the financial accelerator mechanism. ${ }^{23}$

In response to the lower demand brought about by the decline in investment, monetary policy is eased on impact to produce a decline in the real rate which helps to support consumption in the near-term in the case of a CIT and mitigate its drop in the case of the KRT. Eventually, consumption falls in response to the decline in the capital stock which lowers the marginal product of capital, real wages and hence human wealth. The decline in investment and consumption reduces imports. The response of exports on the other hand is different in the near term, reflecting the different responses of the exchange rate. Under a KRT, the exchange rate depreciates in the short-run due to the large decline in the real interest rate, whereas under a CIT, the exchange rate appreciates slightly. The exchange rate eventually appreciates under both taxes as fewer exports are required to pay for the lower desired import bundle.

While permanent increases in the CFT (black) and the DBCFT (green) have no material impact on GDP in the long-run, the same cannot be said about the short run dynamics, as there is an output contraction owing to the declines in both investment and consumption. These declines arise due to the interaction of nominal and real rigidities plus the financial accelerator. A permanent increase in the CFT and the DBCFT, reduces the value of firms in response to lower after-tax dividend streams, captured by the fall in $\mathrm{Q}$ (the shadow price of capital). The presence of investment adjustment costs, which prevents immediate adjustment, leads to $\mathrm{Q}$ overshooting in the near term. ${ }^{24}$ The decline in the shadow price of capital, reduces the value of entrepreneurs' assets causing leverage to spike up, and thus the external finance premium increases in the near term. Consequently, investment falls sharply in the short run. However, a lower shadow price of capital implies a smaller balance sheet for firms to help fund with borrowing. As firms reduce their borrowing, leverage returns to baseline, the external finance premium declines, and investment recovers.

\footnotetext{
${ }^{23}$ This interaction, all else equal, acts to support investment as a permanent CIT increase results in additional interest expensing. In a version of the model without nominal or real rigidities, investment increases in response to the permanent increase in the CIT on impact, supported by additional corporate debt and leverage. In subsequent periods, investment falls in response to the tax's impact on capital returns.

${ }^{24}$ The initial overshoot is also caused by the tax increase with lowers the after-tax return (rental rate) of capital.
} 
Consumption also falls in the short term. The initial drop in investment lowers labor demand and results in lower real wages, which reduces the consumption of hand-to-mouth consumers. Consumption for OLG consumers also falls on impact. Despite receiving transfer payments from the additional tax revenue stemming from the tax increase, less labor income (which reduces human wealth) and lower after-tax dividend income (which reduces financial wealth) reduce total wealth on impact.

Monetary policy is eased in response to weaker domestic demand in the short-run. The drop in real rates leads to a depreciation in the real exchange rate (under a pure cash flow tax) which supports exports. Net trade improves in response to higher exports and lower imports brought about by lower domestic demand and the depreciated exchange rate. The external surplus eventually returns the exchange rate back close to its initial position (there is a slight appreciation due to additional saving by OLG households).

The propagation of the DBCFT is similar to the CFT on domestic demand (resulting in initial drops in investment and consumption). The addition of the destination-based component to the cash flow tax not only has implications for the real exchange rate as noted earlier, but also on the external sector in the short-run. The real exchange rate appreciates immediately in response to the destination based component to help maintain external stability. In the shortrun however, the presence of sticky prices implies that the exchange rate appreciation is not immediately passed-through into export and import prices. Thus, imports initially fall by more under a DBCFT relative to the case of a simple CFT and net exports provide some additional demand support in the near term moderating the short-run fall in output. ${ }^{25,26}$

\footnotetext{
${ }^{25}$ Despite the temporary improvement in export competitiveness brought about by the tax, exports do not increase as much relative to the pure cash flow tax. This is partly driven by the fact that there is a relative substitution away from imported goods relative to domestic goods in production. Such substitution implies less down-side pressure on domestic prices, which fall by less under a DBCFT relative to a CFT.

26 The differences between the DBCFT and CFT imply, in the language of Barbiero and others (2017) that the destination based component of the cash flow tax is not neutral. The reason this happens in this version of GIMF is because the export and import price changes to movements in the exchange rate are not symmetrical since import prices are set excluding the border adjustment. This is equivalent to the case labelled "border adjustment post-border" (presented in Figure 7, Appendix A.2 by Barbiero and others, 2017).
} 
Figure 7: Transitional Dynamics to the Long-Run after tax increases

Tax on Return to Capital (KRT)

- - Corporate Income Tax (CIT)

Cash Flow (CFT)

Destination Based Cash Flow (DBCFT)
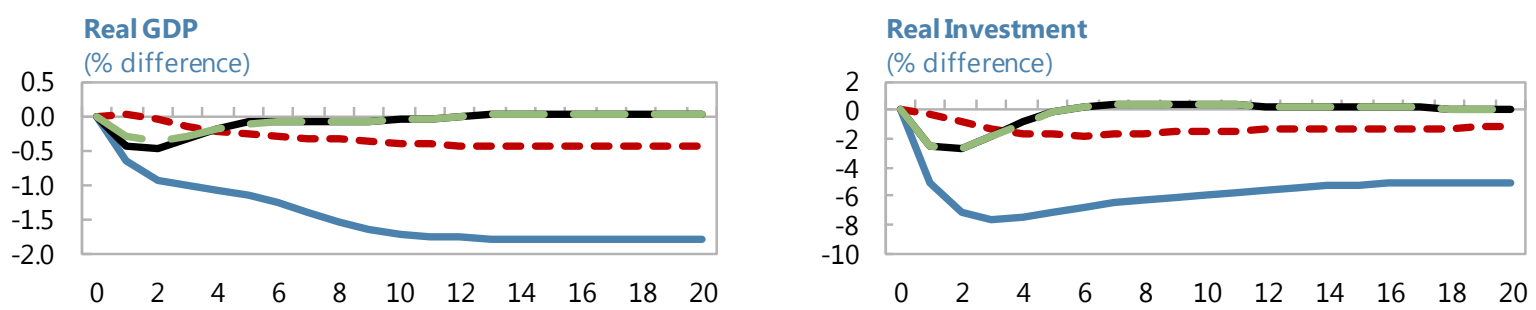

Real Consumption

0.5 (\% difference)

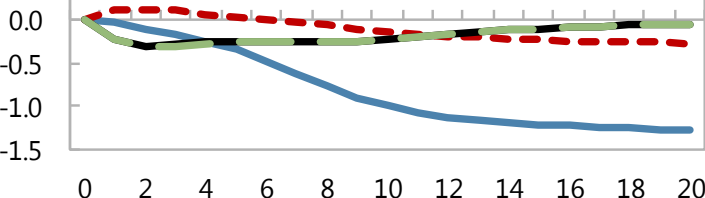

Real Exports

(\% difference)

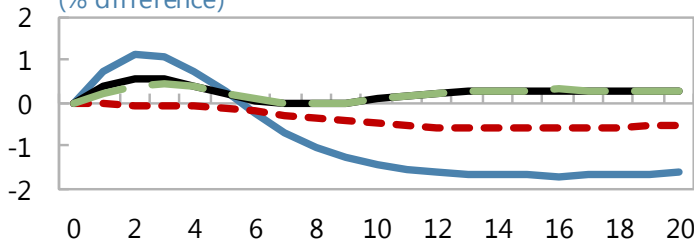

Real Effective Exchange Rate

(\% difference, $+=$ depreciation)

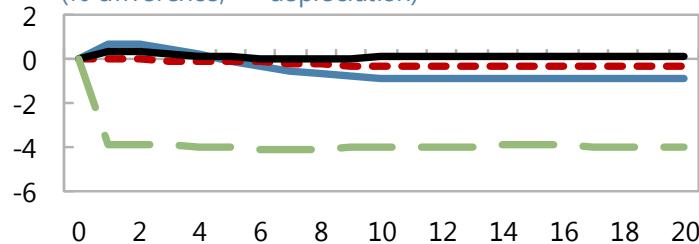

Current Account Balance/GDP

(\% pt difference)

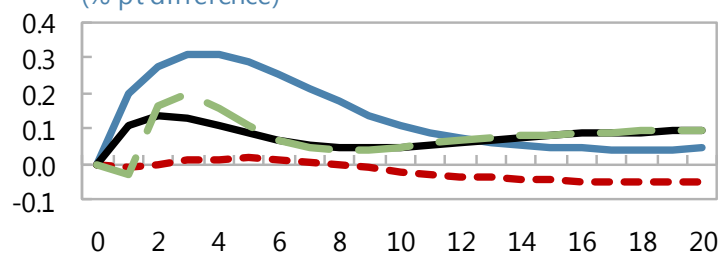

Corporate Debt

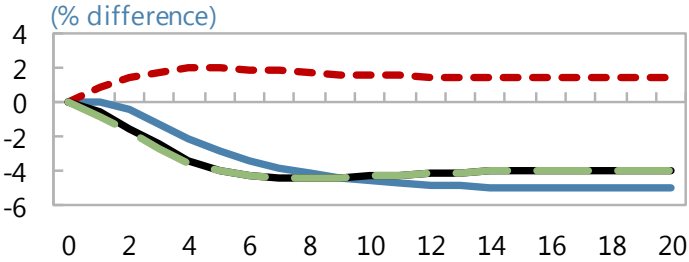

Private Saving/GDP

$$
0.4
$$

(\% pt difference)

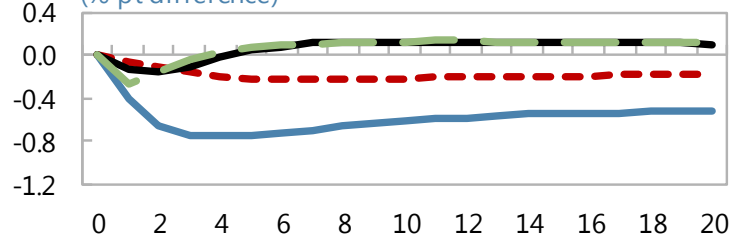

Real Imports

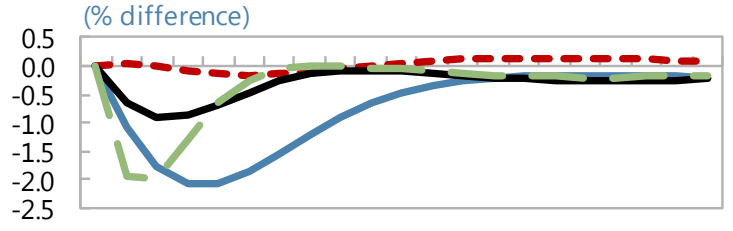

$\begin{array}{lllllllllll}0 & 2 & 4 & 6 & 8 & 10 & 12 & 14 & 16 & 18 & 20\end{array}$

NFA/GDP

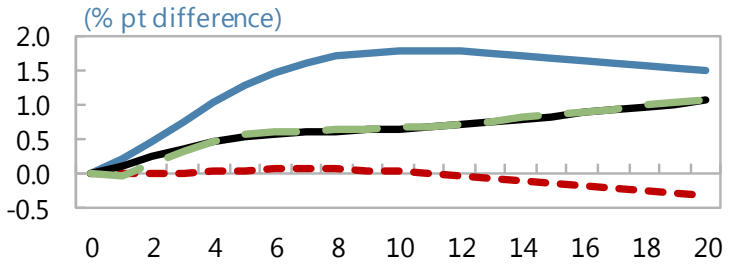

Physical Return to Capital

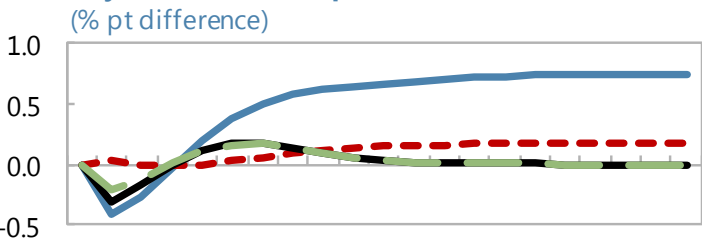

$\begin{array}{lllllllllll}0 & 2 & 4 & 6 & 8 & 10 & 12 & 14 & 16 & 18 & 20\end{array}$

Leverage

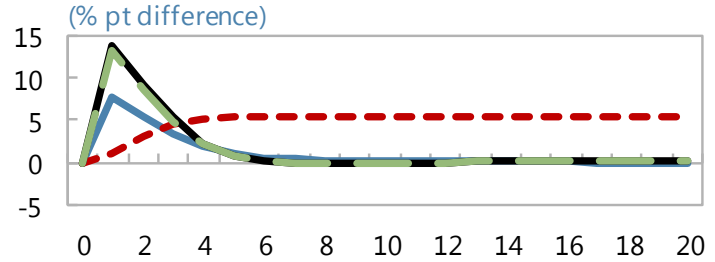

Source: GIMF simulations. X-axis denotes years. 


\section{On the interaction between the financial accelerator, rigidities and taxes}

The presence of the financial accelerator plus nominal and real rigidities all have important consequences for the short-run transmission of each of the different taxes in the economy.

Figure 8: Transitional Dynamics to the Long-Run w/o Fin. Accelerator or Rigidities
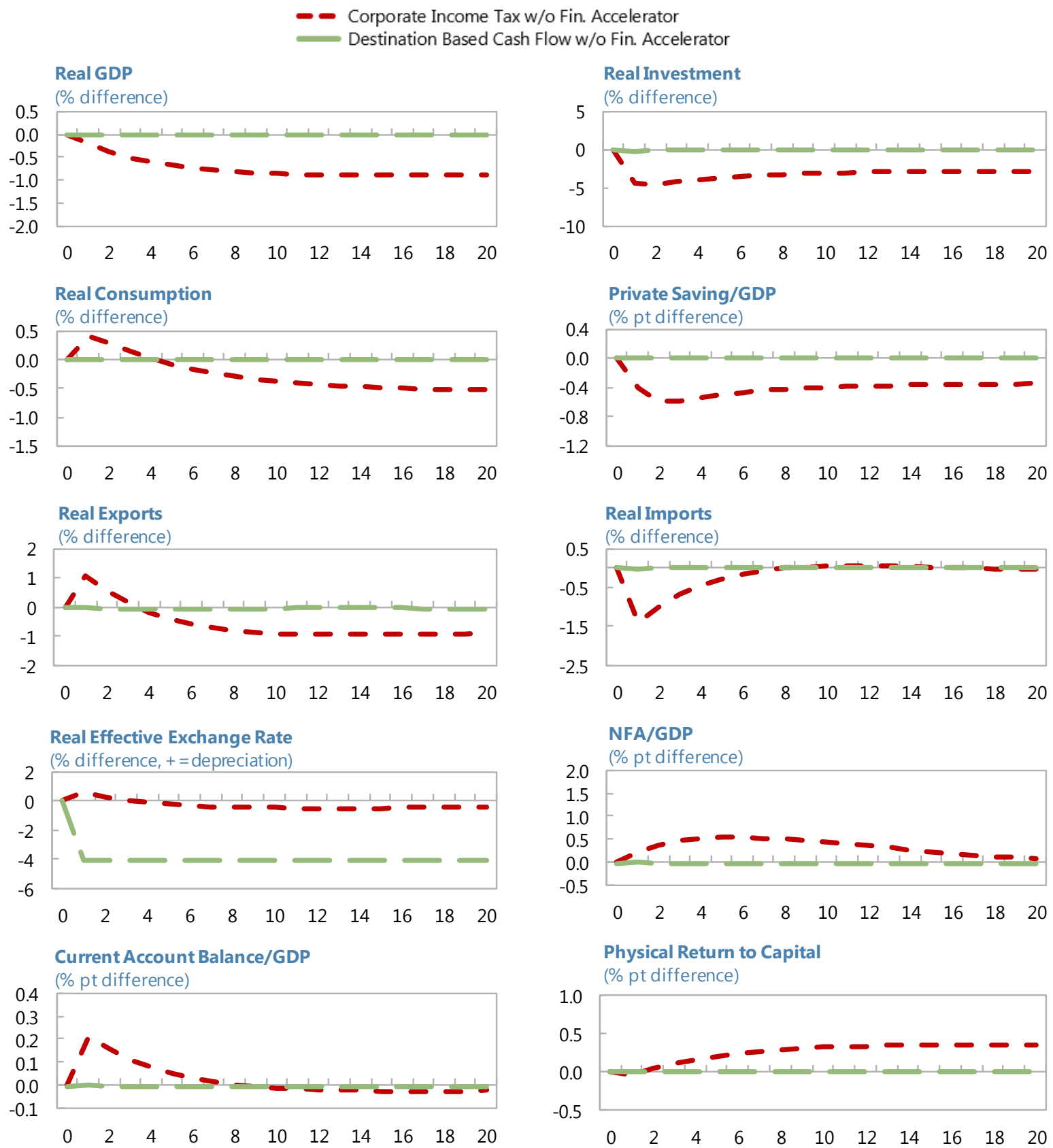

Source: GIMF simulations. X-axis denotes years.

Figure 8 presents the transitional dynamics for each of the taxes assuming no financial accelerator nor nominal or real rigidities. It keeps the same scale as figure 7 for ease of exposition. Several observations arise. First, as noted earlier, the CIT interacts with the 
financial accelerator, thereby mitigating the long-run impact of the tax increase. Hence, the distortionary effect of the CIT is larger without financial frictions. Second, without rigidities, all prices and quantities adjust more rapidly, notably investment. And third, there are no short-run negative impacts on activity from either the CFT or the DBCFT. In the case of the DBCFT, the real exchange rate appreciation is passed through immediately into higher export and lower import prices, thereby fully offsetting the short-run competitiveness gains stemming from the destination based component of the tax.

\section{TRANSIENT CHANGES TO ALL TAXES IN GIMF: PROPERTIES}

The effects of a two-year temporary cut in the KRT, the CIT, the CFT and the DBCFT are presented in Figure 9. All the reported results are in terms of deviation from the steady-state baseline. Two important assumptions are made in the simulation. First, it is assumed that to maintain a debt-to-GDP target in the long run, the government adjusts general lump sum transfers which fall on both OLG and LIQ households. Second, all corporate tax revenues are raised via the tax that is being reduced temporarily with all other corporate taxes set to zero. This means that when looking at the CIT, it is assumed that the KRT, the CFT and the DBCFT rates are set to zero. Likewise, when looking at the CFT and the DBCFT, it is assumed that KRT and the CIT rates are also set to zero. The KRT, the CIT, the CFT and the DBCFT all work via the corporate sector.

A reduction in the KRT (blue line) leads to an increase in the return on capital that stimulates investment, employment, and real wages. The increase in employment and wages raises labor income, stimulating consumption. The pressures from the increase in domestic demand raises the price for domestically produced goods. This leads the monetary authority to tighten policy. The resulting higher real interest rate increases the cost of capital, dampening private investment, and offsetting the impact of higher household incomes on consumption expenditure. The increase in the real interest rate leads to an appreciation of the real effective exchange rate, lowering import prices but raising the cost of exports. Lower import prices increase demand for imports, while higher export prices decrease exports and the reduction in net exports contributes to the dampening of demand pressures. 
Figure 9: Two-Year 1\% of GDP Reduction in all Corporate-Related Taxes

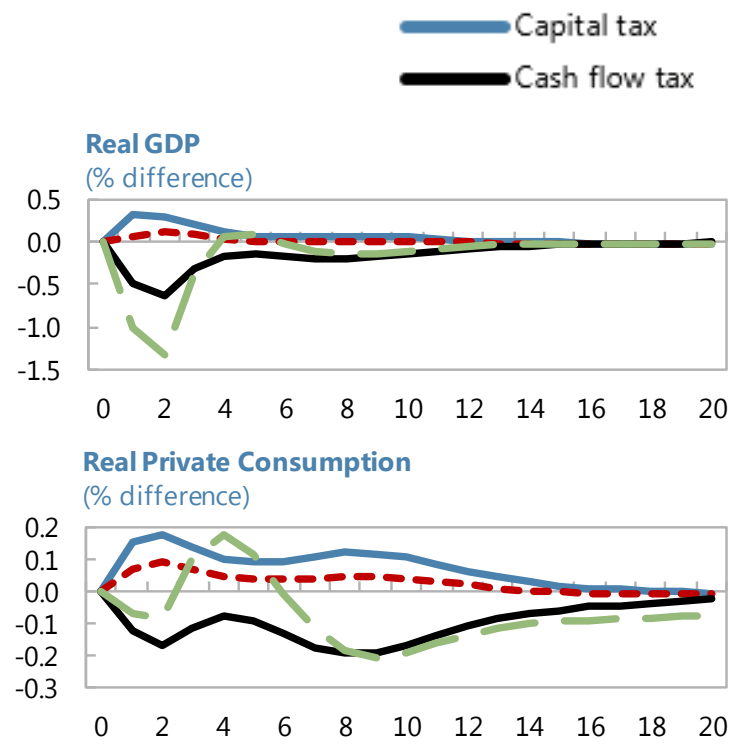

- Corporate income tax
Destination based tax

Government Surplus/GDP

(\% pt difference)

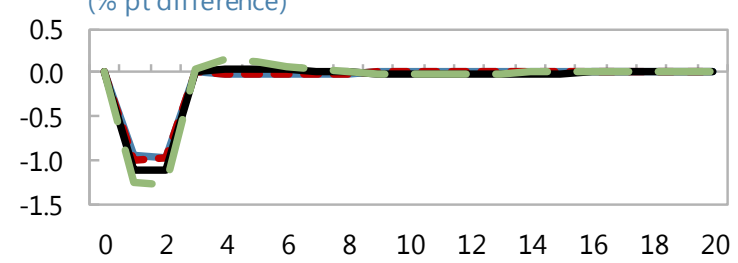

Real Private Investment

(\% pt difference)

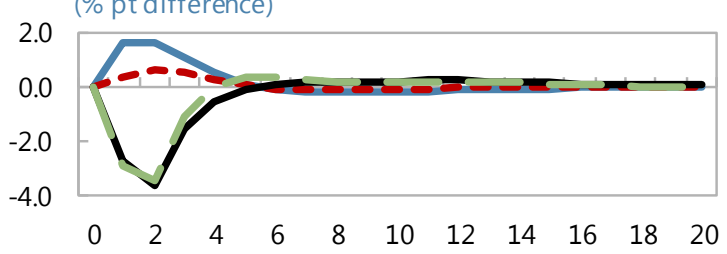

Real Imports

(\% pt difference)

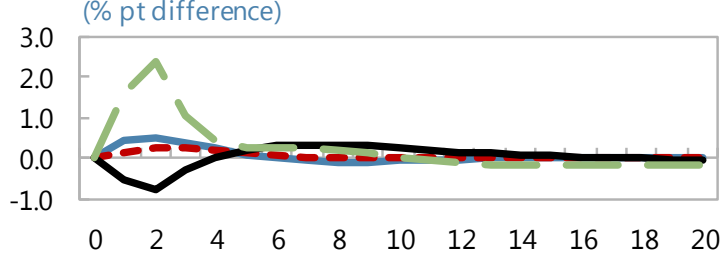

Government Debt/GDP

(\% pt difference)

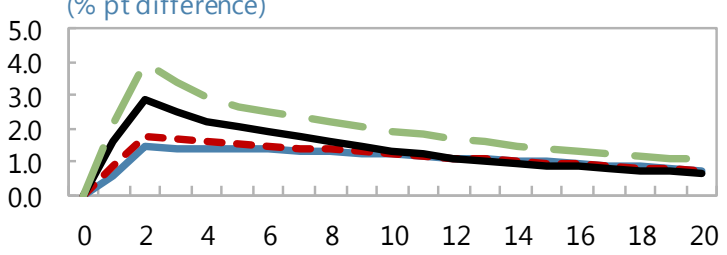

Real Interest Rate

(\% pt difference)

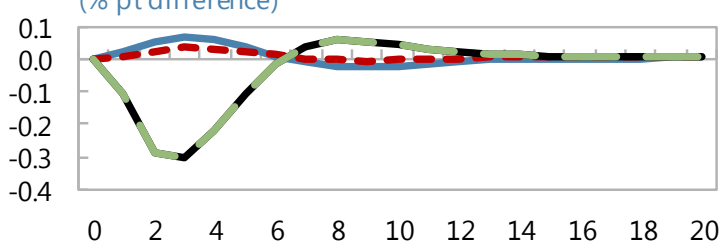

Current Account/GDP

(\% pt difference)

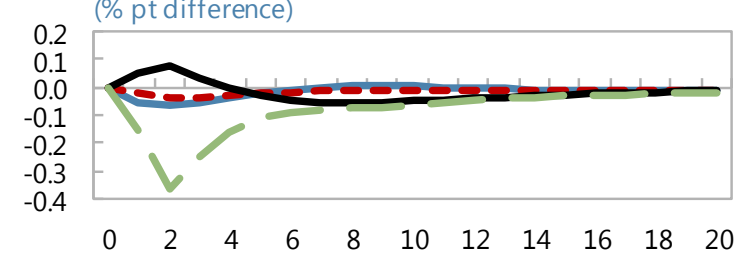

Source:GIMF simulations.X-axis denotes years. 
The impact of a reduction in the CIT (red line in Figure 9) is similar to the impact from a reduction in the KRT. It also acts to increase the returns from capital, thereby supporting investment and OLG consumption (since after-tax dividends increase). However, the reduction in the CIT, unlike the KRT, also acts to reduce the rebate that loss-making entrepreneurs receive, thereby dampening some of the reduction to the financial risk premium that stems from stronger economic activity. This in turn dampens the positive impact from the tax policy on investment. The overall increase in activity leads firms to demand more labor, thereby bidding up real wages. Domestic prices increase and in response the monetary authority slightly raises the policy rate, which flows into higher real rates. In response, there is an appreciation of the real effective exchange that deteriorates the net export position dampening demand pressures. ${ }^{27}$

As noted in Section III a permanent change in the DBCFT does not distort the accumulation of capital since investment expenditures are immediately tax deductible, though adjustment costs and the financial accelerator can result in a fall in investment in the short-run. Temporary changes to the CFT/DBCFT however, can create important distortions. A temporary reduction to the CFT/DBCFT creates an incentive for firms to postpone investment since each unit of investment (temporarily) receives a smaller tax rebate. However, the lower tax rate still results in higher after-tax profits and the value of the firm improves, reducing leverage and the external finance premium. The improvement in financing costs for firms helps dampen the contraction in investment.

The decline in investment demand also results in less demand for labor and therefore lower real wages. The reduction in labor income plus the decline in government transfers in response to the drop in the tax revenue, act to reduce liquidity constrained agents' consumption, further exacerbating the drop in domestic demand. Domestic firms' marginal costs therefore fall. This leads to lower domestic prices and in response the monetary authority reduces the policy rate. The policy response leads to a depreciation in the real exchange rate.

The GDP contraction is larger in the case of a DBCFT relative to a simple CFT. When the DBCFT declines, the destination based part of the tax results in a lower tax rebate for exporters and lower implicit taxes on imports. Despite a temporary depreciation of the real effective exchange rate (which is only partially passed through given sticky export and import prices), exports fall while imports increase, resulting in a deterioration of the trade balance and a sharp negative impact on GDP. Under the CFT, the current account improves as imports fall in response to the fall in domestic demand.

\footnotetext{
27 The temporary reduction in the KRT and CIT reduces the distortions associated with both taxes only temporarily. Hence using both instruments to temporarily reduce distortions during periods of deficient demand will not be optimal. Other instruments for countercyclical policy should be deployed instead.
} 


\section{Conclusions}

This paper has documented the incorporation of corporate income, cash-flow and destination based cash-flow taxes into GIMF. The analysis presented considers the transmission mechanism of these taxes in response to both permanent and temporary changes and details how financial frictions interact with each of the taxes.

The analysis shows that taxes on the return to capital (KRT), typically the only business tax in DSGE models, are by far the most distortionary taxes on investment and hence output. Corporate income taxes (CIT) are also highly distortionary, though their interaction with financial frictions and interest expense deductibility, mitigates some of their distortionary impact. Cash flow types taxes (CFT), including those that permit a destination based component (DBCFT), on the other hand are not distortionary in the long-run given that they fall exclusively on rents and thus do not alter the economy's desired level of capital. 


\section{REFERENCES}

Anderson, D., Hunt, B., Kortelainen, M., Kumhof, M., Laxton, D., Muir, D., Mursula, S. and S. Snudden (2013), "Getting to Know GIMF: The Simulation Properties of the Global Integrated Monetary and Fiscal Model", IMF Working Paper Series WP/13/55. Available at https://www.imf.org/external/pubs/ft/wp/2013/wp1355.pdf

Auerbach, A. J., Devereux, M. P., Keen, M. and J. Vella (2017), "Destination-Based Cash Flow Taxation", Oxford University Centre for Business Taxation WP 17/01, available at https://www.sbs.ox.ac.uk/sites/default/files/Business_Taxation/Docs/Publications/ Working_Papers/Series_17/WP1701c.pdf

Barbiero, O., Farhi, E., Gopinath G. and O. Itskhoki (2017), "The Economics of Border Adjustment Tax", mimeo, available at https://www.princeton.edu/ itskhoki/papers/BAT.pdf

Baron, D. P. (1970), "Price Uncertainty, Utility, and Industry Equilibrium in Pure Competition", International Economic Review Vol. 11, pp. 463-480.

Batra, R. N. (1975), "A General Equilibrium Model of the Incidence of Corporation Income Tax Under Uncertainty", Journal of Public Economics, Vol. 4(4), pp.343-360.

Bhattarai, K., Haughton, J., Head, M. and D.G. Tuerck (2017), "Simulating Corporate Income Tax Reform Proposals with a Dynamic CGE Model", International Journal of Economics and Finance, Vol. 9(5), p.20.

Bernanke, B.S., M. Gertler, and S. Gilchrist (1999), "The Financial Accelerator in a Quantitative Business Cycle Framework," in: John B. Taylor and Michael Woodford, eds., Handbook of Macroeconomics, Volume 1C. Amsterdam: Elsevier.

Blanchard, O. (1985), "Debt, Deficits, and Finite Horizons", Journal of Political Economy, Vol. 93, pp. 223-247.

Carlstrom, C., and T. Fuerst (1997), “Agency Costs, Net Worth, and Business Fluctuations: A Computable General Equilibrium Analysis", American Economic Review, Vol. 87(5), pp. 893-910.

Carroll, R., Diamond, J., Johnson, C. and J. Mackie III, (2006), "A Summary of the Dynamic Analysis of the Tax Reform Options", Office of Tax Analysis, U.S. Department of the Treasury, available at https://www.treasury.gov/resource-center/taxpolicy/Documents/Report-Summary-Dynamic-Analysis-2006.pdf.

Coenen, G., C. Erceg, C. Freedman, D. Furceri, M. Kumhof, R. Lalonde, D. Laxton, J. Lindé, A. Mourougane, D. Muir, S. Mursula, J. Roberts, W. Roeger, C. de Resende, S. Snudden, M. Trabandt, J. in't Veld (2010), "Effects of Fiscal Stimulus in Structural Models," American Economic Journal: Macroeconomics, Vol. 4(1), pp. 22-68.

de Mooij, R. A. and M.P. Devereux, (2011), "An applied analysis of ACE and CBIT reforms in the EU", International Tax Public Finance, Vo. 18, pp. 93-120.

Diamond, J. W. and G. R. Zodrow (2006), "Economic Effects of a Personal Capital Income Tax Add-On to a Consumption Tax", International Studies Program, Working Paper 06-29, Andrew Young School of Policy Studies, Georgia State University, Available at http://icepp.gsu.edu/files/2015/03/ispwp0629.pdf 
Diamond, J. W., Zodrow, G. R., Neubig, T. and R. Carroll (2014), "The Dynamic Economic Effects of a US Corporate Income Tax Rate Reduction", Oxford University Centre for Business Taxation Working Paper No 1405, available at http://EconPapers.repec.org/RePEc:btx:wpaper:1405.

Fehr, H., Jokisch, S., Kambhampati, A. and L.J. Kotlikoff (2013),"Simulating the Elimination of the US corporate income tax", National Bureau of Economic Research, Working Paper No. 19757.

Gale, D. and M. Hellwig (1985), "Incentive-Compatible Debt Contracts: The One-Period Problem”, Review of Economic Studies, Vol. 52, pp. 647-63.

Gertler, M. and P. Karadi (2011), "A Model of Unconventional Monetary Policy”, Journal of Monetary Economics, Vol. 58(1), pp. 17-34.

Harberger, A. C. (1962), "The Incidence of the Corporation Income Tax", The Journal of Political Economy, Vol. 70 (3), pp. 215-240.

Keuschnigg, C. and M.D., Dietz (2007), "A Growth Oriented Dual Income Tax", International Tax and Public Finance, Vol 14(2), pp.191-221.

Kiyotaki, N. and J. Moore (1997). "Credit Cycles", Journal of Political Economy, Vol. 105(2), pp. 211-248

Kumhof, M. and D. Laxton (2007), "A Party Without a Hangover? On the Effects of U.S. Fiscal Deficits" IMF Working Paper Series, WP/07/202, available at http://www.imf.org/external/pubs/ft/wp/2007/wp07202.pdf

Kumhof, M. and D. Laxton(2009a), "Simple, Implementable Fiscal Policy Rules," IMF Working Paper Series, WP/09/76 (April 2009), available at http://www.imf.org/external/pubs/ft/wp/2009/wp0976.pdf

Kumhof, M. and D. Laxton(2009b), "Fiscal Deficits and Current Account Deficits," IMF Working Paper Series, WP/09/237, available at http://www.imf.org/external/pubs/ft/wp/2009/wp09237.pdf

Kumhof, M., D. Laxton, D. Muir and S. Mursula (2010), "The Global Integrated Monetary Fiscal Model (GIMF) - Theoretical Structure", IMF Working Paper Series, WP/10/34, available at http://www.imf.org/external/pubs/cat/longres.cfm?sk=23615.0

Marco, M., and M. T. Monteduro (2011), "From IRAP to CBIT: Tax Distortions and Redistributive Effects", Department of Communication, University of Teramo, Working Paper No.0084, available at http://wp.comunite.it/data/wp_no_84_2011.pdf

Radulescu, D. and M. Stimmelmayr (2010), "The Impact of the 2008 German Corporate Tax Reform: A dynamic CGE analysis", Economic Modelling, Vol. 27(1), pp. 454-467.

Robinson, S. and K. Thierfelder (2017), "Taxes, Prices and the Exchange Rate in the Destination-Based Cash-Flow Tax (DBCFT) System", mimeo, Peterson Institute for International Economics, available at https://www.gtap.agecon.purdue.edu/resources/download/8483.pdf.

Sandmo, A. (1971), "On the Theory of the Competitive Firm Under Price Uncertainty", American Economic Review, Vol. 61, pp. 65-73. 
Sandmo, A. (1979), "A note on the Neutrality of the Cash Flow Corporation Tax", Economics Letters, Vol. 4 (2), 173-176.

Townsend, R. (1979), "Optimal Contracts and Competitive Markets with Costly State Verification", Journal of Economic Theory 21(2), 265-293.

Yaari, M. (1965). "Uncertain Lifetime, Life Insurance, and the Theory of the Consumer." Review of Economic Studies. Vol 32, pp. 137-50.

Zodrow, G. R., and J. W. Diamond (2011), "Dynamic Overlapping Generations Computable General Equilibrium Models and the Analysis of Tax Policy: The Diamond-Zodrow Model." Handbook of computable general equilibrium modeling 1 (2013): 743-813. 


\section{APPENDIX I: CALIBRATION OF THE FINANCIAL ACCELERATOR BLOCK}

In this Appendix, how the financial accelerator block of the model was recalibrated in response to the introduction of the CIT is discussed. The calibration strategy follows Kumhof and others (2011) by choosing the parameters for firm riskiness, monitoring costs and the share of net worth distributed as dividends to fix three key financial-related variables: firm leverage, the firm bankruptcy rate, and the external finance premium. The same values that Kumhof and others (2011) used for these variables are also used here. The leverage ratio (the ratio of corporate debt to corporate equity) is set to 100 percent in all sectors and regions; the share of firms that go bankrupt in any given year is set to 8 percent; and the steady-state external finance premium, excluding any tax effects, is equal to 2.5 percent.

Table A shows the parameter values for firm riskiness, bankruptcy monitoring costs and the share of net worth distributed as dividends in the new version of the model with the CIT and compares them to the previous version of the model which only incorporated the KRT. ${ }^{28}$ The introduction of the CIT increases the parameter values associated with the financial accelerator. This acts to strengthen the amplification effects of the financial accelerator mechanism in the model as it makes investment more sensitive to financial frictions. As noted in section III, the intuition for the increase in the financial accelerator parameters is that, all else equal, the introduction of the CIT (relative to the KRT or the DBCFT) encourages entrepreneurs to increase leverage (see Figure 3 in section III). To match the same values for the financial variables as before - notably the leverage ratio - the financial frictions parameters must increase to prevent entrepreneurs from accumulating additional debt.

Table A:

Financial Accelerator Parameters

\begin{tabular}{|l|c|c|}
\hline & $\begin{array}{c}\text { Extended version of GIMF } \\
\text { with CIT }\left(\tau^{\mathrm{BI}}\right) \text { only }\end{array}$ & $\begin{array}{c}\text { Standard version of GIMF } \\
\text { with KRT }\left(\tau^{\mathrm{K}}\right) \text { only }\end{array}$ \\
\hline Borrower riskiness & 0.52 & 0.45 \\
\hline Cost of bankruptcy & 0.38 & 0.36 \\
\hline Dividend resdistribution & 0.14 & 0.13 \\
\hline
\end{tabular}

\section{APPENDIX II: AN UPDATE ON GIMF FISCAL MULTIPLIERS}

In this Appendix, the effects of temporary fiscal stimulus through each of the nine available fiscal instruments are presented. As the qualitative propagation mechanism associated with the seven fiscal instruments in the previous version of GIMF remains largely unchanged, a brief description of the transmission mechanism (without figures) associated with each fiscal instrument is presented as well as each multiplier. To aid comparison with Anderson and

\footnotetext{
${ }^{28}$ Parameters for tradeables and non tradeables are the same, so only one set of numbers is reported
} 
others (2013), a three-region version of GIMF comprising the United States, the European Union and the Rest of the World is used. All fiscal experiments are undertaken on the US block of the model.

\section{Two Year Government Expenditure Expansions}

Under all expenditure expansions, aggregate demand increases either directly (government consumption and investment) or indirectly through households' income (both types of transfers). Since both private sector and government goods are assumed to have a domestic and imported component, there are notable effects in both the domestic and external sectors. The increase in demand for final domestic goods increases the demand for domestic labor which raises wages, increasing marginal costs and thereby driving up the prices of domestically produced goods. In response, the U.S. monetary authority raises the nominal policy interest rate, which flows through to real interest rates. Higher real interest rates increase the cost of capital, dampening private investment demand. Further, for households, higher real interest rates partially offset the impact of higher incomes on consumption expenditure. In addition, the automatic fiscal stabilizers operate such that transfers adjust to dampen private demand.

The increase in real interest rates appreciates the U.S. real effective exchange rate, lowering import prices for U.S. residents and raising the cost of U.S. exports abroad. Lower import prices increase U.S. demand for imports from abroad, while higher export prices decrease foreign demand for U.S. goods. The net impact is a temporary deterioration in the current account.

As in the previous version of GIMF, the largest expenditure multiplier pertains to government investment. This stems from the additional stimulative effect of the government capital stock on private sector productivity. ${ }^{29}$ The multipliers are smallest for transfers, notably general transfers since the stimulus operates only indirectly via households' income. Transfers to LIQ agents have a higher multiplier than general transfers since LIQ agents have a higher propensity to consume out their current income.

Table B shows that the fiscal multipliers associated with temporary government expenditure expansions are relatively similar in both versions of GIMF. The largest multiplier pertains to government investment, followed by government consumption and then transfers. The multipliers are ever slightly higher for the version of GIMF with capital taxes. The reason for this difference pertains to how the tax base is effected in the two versions of the model. Under the capital income tax (KRT), the fiscal expansion increases the tax base as both the capital stock (through higher investment) and the return on capital increase. The tax base is higher for several periods given that the capital stock is slow moving. Under a corporate income tax (CIT) the tax base increases by less and for a shorter time period in response to

\footnotetext{
${ }^{29}$ Without this channel, an increase in government investment spending would be virtually indistinguishable from an increase in government consumption spending.
} 
the increase in activity associated with the temporary fiscal expansion. Thus, the amount that is rebated to households in terms of government transfers is lower in the version of GIMF with the CIT, which in turn results in lower consumption. As noted earlier, the impact on investment is higher in the new version of GIMF, given that financial frictions are stronger. This means that the domestic demand expansion, all else equal, propagates more strongly in the new version of the model.

Table B:

Government Expenditure Multipliers, Average GDP Impact After First Two Years

\begin{tabular}{|l|l|l|l|l|}
\hline & $\begin{array}{l}\text { Gov't } \\
\text { Consumption }\end{array}$ & $\begin{array}{l}\text { Gov't } \\
\text { Investment }\end{array}$ & $\begin{array}{l}\text { General } \\
\text { Transfers }\end{array}$ & $\begin{array}{l}\text { Transfers to } \\
\text { LIQ households }\end{array}$ \\
\hline \multicolumn{5}{|c|}{ Extended version of GIMF (CIT only) } \\
\hline GDP & 0.83 & 1.17 & 0.12 & 0.48 \\
\hline Consumption & 0.09 & 0.45 & 0.29 & 0.99 \\
\hline Private Invest. & 0.05 & 0.68 & 0.06 & 0.04 \\
\hline \multicolumn{5}{|c|}{ Standard version of GIMF (KRT only) } \\
\hline GDP & 0.84 & 1.18 & 0.12 & 0.48 \\
\hline Consumption & 0.13 & 0.49 & 0.29 & 1.01 \\
\hline Private Invest. & 0.03 & 0.62 & -0.03 & 0.02 \\
\hline
\end{tabular}

\section{Two Year Decrease in Taxation}

Temporary cuts to consumption taxes, labor income taxes or corporate income taxes produce a modest boost to GDP, with multipliers that are well below unity. The propagation of each of the taxes differs with consumption and labor income taxes primarily affecting households (consumption) and capital income tax affecting firms (investment).

The cuts to consumption and labor income taxes act to boost disposable real income. In the case of consumption taxes, the price households pay for consumption goods falls, whereas in the case of lower labor income taxes, after-tax labor income increases. Both act to boost consumption, notably of LIQ households as OLG households smooth their consumption. The increase in consumption raises the demand for labor driving up wages and the marginal cost of production. Despite higher domestic demand, CPI inflation is broadly unchanged. This is because, under the consumption tax reduction, consumption prices including taxes fall and under the labor income tax reduction, labor supply increases which puts downside pressure on real wages and hence marginal costs.

When the government lowers the capital income tax rate, the return on capital rises. Higher returns induce firms to invest more and private consumption expenditure also accelerates as households receive additional dividends from corporates. Stronger private demand prompts firms to demand more labor, which increases the marginal cost of production, and thus the price for domestically produced goods. Both factors lead to the U.S. monetary authority slightly raising the nominal policy rate. The resulting higher real interest rate increases the 
cost of capital, dampening private investment, and offsets the impact of higher household incomes on consumption expenditure.

The increase in the real interest rate leads to an appreciation of the U.S. real effective exchange rate, lowering import prices for U.S. residents and raising the cost of U.S. exports abroad. Lower import prices increase U.S. demand for imports from abroad, while higher export prices decrease foreign demand for U.S. goods. In addition, the automatic fiscal stabilizers also operate, with transfers declining to dampen private demand.

The multipliers under the old and the new model are very similar, albeit they are slightly larger for the case where capital return taxes (KRT) are operational instead of corporate income taxes (CIT). The reasons for the difference relate to the tax base, as noted earlier when explaining the government expenditure multipliers.

Comparing the different taxes on firms, the largest multiplier pertains to the capital return tax, followed by the corporate income tax with the multiplier for the destination-based cash flow tax being negative. The key differences between these multipliers stem from the investment response. While corporate income and capital return taxes are very similar, two factors related to tax rebates dampen the investment response under a corporate income tax. First, under a corporate income tax, it is assumed that firms can deduct investment adjustment costs. As the tax decrease provides an incentive to increase investment, the rebates associated with the additional investment will be lower because the tax rate is lower and this act to dampen investment. This channel is not present under the capital return tax. Second, the temporary decline in the corporate income tax affects the rebates that entrepreneurs obtain in case of bankruptcy. Thus, corporate insolvencies are higher under a corporate income tax reduction relative to the capital return tax reduction.

Table C:

Tax Cut Multipliers, Average GDP Impact After First Two Years

\begin{tabular}{|l|c|c|c|c|c|}
\hline & $\begin{array}{c}\text { Consumption } \\
\text { tax }\end{array}$ & $\begin{array}{c}\text { Labor } \\
\text { income tax }\end{array}$ & $\begin{array}{c}\text { Capital } \\
\text { return tax }\end{array}$ & $\begin{array}{c}\text { Corporate } \\
\text { income tax }\end{array}$ & $\begin{array}{c}\text { Dest. based } \\
\text { cash flow } \\
\text { tax }\end{array}$ \\
\hline \multicolumn{6}{|c|}{ Extended version of GIMF (CIT only) } \\
\hline GDP & 0.25 & 0.26 & NA & 0.12 & -1.33 \\
\hline Consumption & 0.51 & 0.41 & NA & 0.09 & -0.08 \\
\hline $\begin{array}{l}\text { Private } \\
\text { Invest. }\end{array}$ & 0.07 & 0.20 & NA & 0.62 & -3.50 \\
\hline \multicolumn{7}{|c|}{ Standard version of GIMF (KRT only) } \\
\hline GDP & 0.26 & 0.26 & 0.30 & NA & NA \\
\hline Consumption & 0.52 & 0.40 & 0.17 & NA & NA \\
\hline $\begin{array}{l}\text { Private } \\
\text { Invest. }\end{array}$ & 0.06 & 0.18 & 1.58 & NA & NA \\
\hline
\end{tabular}




\section{APPEndix III. Modifications to the GIMF MODEL TO INTRODUCE NEW BUSINESS TAXES}

This Appendix presents the details of the algebraic derivation associated with the CIT, the CFT and the DBCFT in the case there is no financial accelerator. Appendix IV adds the financial accelerator algebra. Familiarity with GIMF (Kumhof and others (2010)) is assumed and the only algebra that is presented pertains to the blocks of the model that are directly affected by the taxes. The module for raw materials is switched off such that labor and capital are the only inputs of production, there is therefore no oil consumption and no raw materials international trade.

It is assumed that the structure of GIMF is unchanged relative to Kumhoff and others (2010) except for the introduction of the new business taxes. As will be shown below, the introduction of the CIT and CFT/DBCFT affects the after-tax profits of all firms (manufacturers, capital capital producers, exporters and importers, investment and consumption goods retailers), entrepreneurs and financial intermediaries (as the optimal debt contract is modified, shown in Appendix IV) and generates additional revenue for the government.

Due to the structure of GIMF, several propagation channels associated with these taxes, often mentioned by critics of the DBCFT (eg Summers' (2017)) are omitted. First, as firms operate in only one location (ie there are no multinational firms), it is not possible for firms in GIMF to modify transfer prices, relocate patents, change their financial structure, or relocate production towards the country with the less distortionary tax system. Second, owing to simplifying assumptions related to the currency denomination of foreign liabilities, the model cannot capture the balance sheet effects of any exchange rate movement. Third, as GIMF is an OLG model without heterogenous agents, it is not possible to examine distributional effects in detail, other than to consider the impact on the two types of households in the model: OLG and LIQ households. Fourth, the model assumes rational expectations and perfect foresight, so that flexible prices, including the real exchange rate, immediately adjust to any change in the tax rate.

In introducing the new taxes in GIMF, the tax incidence of each of the firms in the model needs to be considered. The following generic assumptions are made. First, in the case of a CIT, the economic profits (income) made by corporates are taxed with the revenues from both domestic and foreign sales being subject to the tax. All costs can be deducted from revenues to calculate the profits that form the tax base. These costs include labor, rent, capital depreciation, interest expenses, and intermediate inputs, including those that are imported.

Second, in the case of the CFT, the cash flows of corporates from total sales after deducting the cost of labor, investment, and intermediate inputs are subject to the tax. In the case of a DBCFT, only domestic sales are subject to the tax and only the domestic component of intermediate inputs can be deducted. Consequently, revenues from exports are not subject to tax, while the cost of imports cannot be deducted. 
In what follows, the problems faced by the agents directly affected by the tax and the associated first order conditions are presented. Only the equations that are changed by the CIT and the CFT/DBCFT are presented. ${ }^{1}$ The associated tax bases and revenues are also presented.

\section{III.1. Manufacturers}

Introducing the CIT and the CFT modifies the after-tax dividend (or profit) for manufacturers in sector $J(J=\mathrm{T}$ for the tradable sector or $J=\mathrm{N}$ for the non-tradable sector, for price and inflation, $\tilde{J}=\mathrm{TH}$ for domestic tradable sector or $\tilde{J}=\mathrm{N}$ for the non-tradable sector). Equation (45), p.17, in the original GIMF model is replaced by the following expression:

$$
D_{t}^{J}(i)=\left(1-\tau_{t}^{\mathrm{CI}}-\tau_{t}^{\mathrm{CF}}\right)\left(P_{t}^{\tilde{J}}(i) Z_{t}^{J}(i)-\left[V_{t} U_{t}^{J}(i)+R_{k, t}^{J} K_{t}^{J}(i)\right]-P_{t}^{\tilde{J}} T_{t}^{J} \omega^{J}-P_{t}^{\tilde{J}} G_{P, t}^{J}(i)\right)
$$

where $\tau_{t}^{\mathrm{CI}}$ and $\tau_{t}^{\mathrm{CF}}$ denote the CIT and the CFT tax rates respectively. Note that the incidence of both taxes is the same for manufacturers since their profits are the same as their cash flow. Rescaled aggregate dividends (equation (57) p.18) is replaced by

$$
\check{d}_{t}^{J}=\left(1-\tau_{t}^{\mathrm{CI}}-\tau_{t}^{\mathrm{CF}}\right)\left(p_{t}^{\tilde{J}} \check{Z}_{t}^{J}-\left[\check{v}_{t} \check{U}_{t}^{J}+r_{k, t}^{J} \check{K}_{t}^{J}\right]-p_{t}^{\tilde{J}} \omega^{J}-p_{t}^{\tilde{J}} \check{G}_{P, t}^{J}(i)\right)
$$

The introduction of these taxes creates a wedge in optimal price setting decisions both under sticky prices and sticky inflation.

\section{III.1.1. Price setting under sticky inflation}

Equation (47) p.17 is replaced by: ${ }^{2}$

$$
\begin{aligned}
\frac{1}{\phi_{P}^{J}\left(\mu_{t}^{J}-1\right)} & \left(\mu_{t}^{J} \frac{\lambda_{t}^{J}}{p_{t}^{\tilde{J}}}-1\right)=\left(\frac{\pi_{t}^{\tilde{J}}}{\pi_{t-1}^{\tilde{J}}}\right)\left(\frac{\pi_{t}^{\tilde{J}}}{\pi_{t-1}^{\tilde{J}}}-1\right) \ldots \\
& -\frac{\theta g n}{r_{t}} \mathbb{E}_{t}\left\{\frac{1-\tau_{t+1}^{\mathrm{Cl}}-\tau_{t+1}^{\mathrm{CF}}}{1-\tau_{t}^{\mathrm{CI}}-\tau_{t}^{\mathrm{CF}}} \frac{p_{t+1}^{\tilde{J}}}{p_{t}^{\tilde{J}}} \frac{\check{Z}_{t+1}^{J}}{\check{Z}_{t}^{J}}\left(\frac{\pi_{t+1}^{\tilde{J}}}{\pi_{t}^{\tilde{J}}}\right)\left(\frac{\pi_{t+1}^{\tilde{J}}}{\pi_{t}^{\tilde{J}}}-1\right)\right\} .
\end{aligned}
$$

\footnotetext{
${ }^{1}$ The problem for capacity utilization / capital services is also presented to facilitate the exposition of the capital producers.

${ }^{2}$ The original paper denotes $\check{r}$ the real interest rate. However, as the variable is already stationary, there is no need for a rescaling factor.
} 


\section{III.1.2. Price setting under sticky prices}

Equation (48) p.17 is replaced by:

$$
\begin{aligned}
\frac{1}{\phi_{P}^{J}\left(\mu_{t}^{J}-1\right)} & \left(\mu_{t}^{J} \frac{\lambda_{t}^{J}}{p_{t}^{\tilde{J}}}-1\right)=\pi_{t}^{\tilde{J}}\left(\pi_{t}^{\tilde{J}}-\bar{\pi}\right) \ldots \\
& -\frac{\theta g n}{r_{t}} \mathbb{E}_{t}\left\{\frac{1-\tau_{t+1}^{\mathrm{CI}}-\tau_{t+1}^{\mathrm{CF}}}{1-\tau_{t}^{\mathrm{CI}}-\tau_{t}^{\mathrm{CF}}} \frac{p_{t+1}^{\tilde{J}}}{p_{t}^{\tilde{J}}} \frac{\check{Z}_{t+1}^{J}}{\check{Z}_{t}^{J}} \pi_{t+1}^{\tilde{J}}\left(\pi_{t+1}^{\tilde{J}}-\bar{\pi}\right)\right\} .
\end{aligned}
$$

Setting $\tau^{\mathrm{CI}}=0$ and $\tau^{\mathrm{CF}}=0$ returns the original dividend and price setting equations reported in the previous version of GIMF. The impact of the CIT and CFT only have second order effects on price setting (the tax terms would disappear under a first-order log-linearization of the price setting equations). Likewise, note that under flexible prices, $\phi_{P}^{J}=0$, the introduction of both the CIT and the CFT do not matter. in both the sticky inflation and the sticky price cases.

Note that the taxes do not distort the optimal conditions for labor demand (equation (49), p.17) or capital demand (equation (53), p.18). The market clearing conditions (equations (60) and (61) p.18) are also unaffected.

\section{III.2. Utilization rate of capital}

Whilst the optimality condition for $u_{t}^{J}$ (Equation (79) p.20) is not modified by the introduction of the various business taxes, dedicating a section to it helps to simplify the presentation of the capital good producers' and entrepreneur's (see next section) problems and permits the introduction of notations that are not present in the original working paper.

In each sector $(J=\mathrm{T}$ or $\mathrm{N})$, the capital services are rented to firms by either capital goods producers (without financial frictions) or entrepreneurs (with financial frictions, as presented in Appendix IV). In each case, the utilization rate of capital, $u_{t}^{J}$, is chosen to maximize the capital return per unit of capital:

$$
\bar{R}_{k, t}^{J} \equiv\left(R_{k, t}^{J} u_{t}^{J}-P_{t} a\left(u_{t}^{J}\right)\right)
$$

where $R_{k, t}^{J}$ denotes the rental rate of capital and $a\left(u_{t}^{J}\right)$ is a convex real adjustment cost on capital utilization. the real capital return is defined by

$$
\bar{r}_{k, t}^{J}=\frac{\bar{R}_{k, t}^{J}}{P_{t}} .
$$

As in equation (80) p.21, total real adjustment costs associated with capital accumulation are given by $r \check{c} u_{t} \equiv a\left(u_{t}^{J}\right) \bar{K}_{t}^{J} / p_{t}^{J}$. 


\section{III.3. Capital goods producers}

The CIT and the CFT not only affect the after-tax dividends of capital producers, but also a number of first order conditions. The problems faced by capital producers vary slightly depending on whether the model allows for a financial accelerator mechanism. In both cases, the accumulation of capital (equation (71) p.20) is unchanged.

\section{III.3.1. Capital goods producers without financial accelerator}

Capital producers produce the capital stock and rent it directly to manufacturers. They are competitive price takers and must choose how much investment to undertake each period and how many capital services to rent. With the three types of business tax, after tax dividends of capital goods producers need to be modified (vs. Equation (76) pg. 20):

$$
\begin{aligned}
D_{J, t}^{K}= & \left(1-\tau_{t}^{\mathrm{KR}}-\tau_{t}^{\mathrm{CI}}-\tau_{t}^{\mathrm{CF}}\right) \bar{R}_{k, t}^{J} \bar{K}_{t}^{J} \\
& +\left(\tau_{t}^{\mathrm{KR}}+\tau_{t}^{\mathrm{CI}}\right) \delta_{t}^{J} Q_{t}^{J} \bar{K}_{t}^{J} \\
& -\tau_{t}^{\mathrm{CI}}\left(Q_{t}^{J}-Q_{t-1}^{J}\right) \bar{K}_{t}^{J} \\
& -\left(1-\tau_{t}^{\mathrm{CF}}\right) P_{t}^{\mathrm{I}} I_{t}^{J} \\
& -\left(1-\tau_{t}^{\mathrm{CI}}-\tau_{t}^{\mathrm{CF}}\right) P_{t}^{\mathrm{I}} G_{I, t}^{J}
\end{aligned}
$$

net of taxes return to capital

depreciation of capital tax rebate

tax on capital gains/losses

investment expensing full tax rebate

adjustment costs of investment tax rebate

where $Q_{t}^{J}$ is the shadow price of capital (i.e. the end of period market value of the marginal unit of capital, assuming optimal investment and capital utilization plans starting at $t+1$ ) and $\tau^{\mathrm{KR}}$ is the capital returns tax (that was already present in GIMF). Note that the incidence of each tax is different. Both the CIT and KRT permit expensing of capital (second line), the CIT taxes capital gains (third line), whereas the CFT allows full expensing of investment (fourth line). Adjustment costs associated with changing the capital stock are assumed to be deductible under both the CIT and CFT (fifth line).

The real value of dividends (equation (81) p.21) now writes:

$$
\begin{aligned}
\check{d}_{J, t}^{K}= & \left(1-\tau_{t}^{\mathrm{KR}}-\tau_{t}^{\mathrm{CI}}-\tau_{t}^{\mathrm{CF}}\right) \bar{r}_{k, t}^{J} \check{\check{K}}_{t}^{J}+\left(\tau_{t}^{\mathrm{KR}}+\tau_{t}^{\mathrm{CI}}\right) \delta_{t}^{J} q_{t}^{J} \check{\bar{K}}_{t}^{J} \\
& -\tau_{t}^{\mathrm{CI}}\left(q_{t}^{J}-\frac{q_{t-1}^{J}}{\pi_{t}}\right) \check{\check{K}}_{t}^{J}-\left(1-\tau_{t}^{\mathrm{CF}}\right) p_{t}^{\mathrm{I}} \check{I}_{t}^{J}-\left(1-\tau_{t}^{\mathrm{CI}}-\tau_{t}^{\mathrm{CF}}\right) p_{t}^{\mathrm{I}} \check{G}_{I, t}^{J} .
\end{aligned}
$$


Capital producers maximize the present value of the stream of future dividends, leading to the following optimal investment equation (which replaces Equation (77) p.20):

$$
\begin{aligned}
\frac{S_{t}^{\mathrm{inv}} q_{t}^{J}-\left(1-\tau_{t}^{\mathrm{CF}}\right) p_{t}^{\mathrm{I}}}{\phi_{I}} & =\left(1-\tau_{t}^{\mathrm{CI}}-\tau_{t}^{\mathrm{CF}}\right) p_{t}^{\mathrm{I}}\left(\frac{\check{I}_{t}^{J}}{\check{I}_{t-1}^{J}}\right)\left(\frac{\check{I}_{t}^{J}}{\check{I}_{t-1}^{J}}-1\right) \\
& -\frac{\theta g n}{r_{t}} \mathbb{E}_{t}\left\{\left(1-\tau_{t+1}^{\mathrm{CI}}-\tau_{t+1}^{\mathrm{CF}}\right) p_{t+1}^{\mathrm{I}}\left(\frac{\check{I}_{t+1}^{J}}{\check{I}_{t}^{J}}\right)\left(\frac{\check{I}_{t+1}^{J}}{\check{I}_{t}^{J}}-1\right)\right\} .
\end{aligned}
$$

The (real) price of capital, $q_{t}^{J}$, is equal to the dividend reduction that is required to add a marginal unit of capital $\left(1-\tau_{t}^{\mathrm{CF}}\right) p_{t}^{\mathrm{I}}$. With adjustment costs on capital accumulation, $\phi_{I}>0$, this equality is broken in the short term. Note that the expression $\left(1-\tau_{t}^{\mathrm{CI}}-\tau_{t}^{\mathrm{CF}}\right)$ arises due to the tax deductability associated with adjusting investment.

The first order condition for capital equates the shadow price of capital to the net of tax expected return next period. Let $\bar{r}_{k, t}^{J} \equiv \bar{R}_{k, t}^{J} / P_{t}$ denote the real effective rental rate of capital. The optimal capital decision, equation (78) p.20, becomes:

$$
q_{t}^{J}=\frac{\theta g n}{r_{t}} \mathbb{E}_{t}\left\{\begin{array}{l}
\left.\left[1-\tau_{t+1}^{\mathrm{KR}}-\tau_{t+1}^{\mathrm{CI}}-\tau_{t+1}^{\mathrm{CF}}\right] \bar{r}_{k, t}^{J}\right) \\
+\left[1-\left(1-\tau_{t+1}^{\mathrm{KR}}-\tau_{t+1}^{\mathrm{CI}}\right) \delta_{t+1}^{J}\right] q_{t+1}^{J} \\
-\tau_{t+1}^{\mathrm{CI}}\left[q_{t+1}^{J}-q_{t}^{J} / \pi_{t+1}\right]
\end{array}\right\}
$$

The different taxes have three different impacts on the optimal capital decision, seen on the right hand side of the equation above. First, the KRT, CIT and CFT are levied on the excess returns/profits of an additional unit of capital services, $r_{k, t+1}^{J} u_{t+1}^{J}-p_{t+1}^{J} a\left(u_{t+1}^{J}\right)$, (the first line). Second, both the KRT and CIT allow for depreciation expensing of capital (second line). Finally, the CIT is levied on any capital gains (the third line).

\section{III.3.2. Capital Goods Producers with Financial Accelerator}

With the presence of the financial accelerator, the problem faced by capital producers changes somewhat. In this case, capital producers purchase existing capital from entrepreneurs and investment goods from investment goods producers to produce new capital which they then sell back to entrepreneurs. In this case, the dividends of capital goods producers are modified to take into account the CIT and the CFT as follows (replacing equation (65) p.19):

$$
D_{J, t}^{K}=Q_{t}^{J} S_{t}^{\mathrm{inv}} I_{t}^{J}-P_{t}^{\mathrm{I}}\left[\left(1-\tau_{t}^{\mathrm{CF}}\right) I_{t}^{J}+\left(1-\tau_{t}^{\mathrm{CI}}-\tau_{t}^{\mathrm{CF}}\right) G_{I, t}^{J}\right]
$$

The first term inside the square brackets reflects the immediate expensing of investment under a CFT, whereas the second term reflects the expensing associated with adjustment costs for investment. The real value of dividends (equation (70) p.19) now writes:

$$
\check{d}_{J, t}^{K}=q_{t}^{J} S_{t}^{\mathrm{inv}} \check{I}_{t}^{J}-p_{t}^{\mathrm{I}}\left[\left(1-\tau_{t}^{\mathrm{CF}}\right) \check{I}_{t}^{J}+\left(1-\tau_{t}^{\mathrm{CI}}-\tau_{t}^{\mathrm{CF}}\right) \check{G}_{I, t}^{J}\right]
$$


The introduction of these taxes affects the first order condition for investment which now reads (replacing Equation (66)):

$$
\begin{aligned}
\frac{S_{t}^{\mathrm{inv}} q_{t}^{J}-\left(1-\tau_{t}^{\mathrm{CF}}\right) p_{t}^{\mathrm{I}}}{\phi_{I}} & =\left(1-\tau_{t}^{\mathrm{CI}}-\tau_{t}^{\mathrm{CF}}\right) p_{t}^{\mathrm{I}}\left(\frac{\check{I}_{t}^{J}}{\check{I}_{t-1}^{J}}\right)\left(\frac{\check{I}_{t}^{J}}{\check{I}_{t-1}^{J}}-1\right) \\
& -\frac{\theta g n}{r_{t}} \mathbb{E}_{t}\left\{\left(1-\tau_{t+1}^{\mathrm{CI}}-\tau_{t+1}^{\mathrm{CF}}\right) p_{t+1}^{\mathrm{I}}\left(\frac{\check{I}_{t+1}^{J}}{\check{I}_{t}^{J}}\right)\left(\frac{\check{I}_{t+1}^{J}}{\check{I}_{t}^{J}}-1\right)\right\} .
\end{aligned}
$$

This equation is the same as equation (8) representing the optimal investment equation derived in the case of no financial accelerator. The expressions for optimal capital decisions as well as the optimal loan contract will be covered in Appendix IV when the problems faced by entrepreneurs and banks is derived.

\section{III.4. Exporting firms (previously referred to as import agents) and their price setting}

In GIMF, two kinds of firms carry out international transactions of goods and services: exporting firms in the origin country (denoted by $j$ ) and importing firms in the destination country (denoted by $i$ ). In Kumhof and others (2010), exporting firms were labeled "import agents" whereas importing firms were part of the "distribution sector". While such labelling distinction is not crucial under the CIT or the CFT, it is important in the case of destination-based tax systems: under the DBCFT, a distinction between "exporting firms" (that belong to the origin country where it pays taxes according to the source-based or destination-based system) and "importing firms" (that belong to the destination country) is crucial.

The corporate cash-flow tax interacts with the pricing decisions of exporting and importing firms if the destination-based option is activated. To keep the algebra general, a switch denoted by $\Omega^{\mathrm{sB}}$ is introduced. It is activated (that is, equal to one) if the corporate cash-flow tax is source-based and deactivated (equal to zero) if it is destination-based. In order to simplify the presentation, it is assumed that there are neither export subsidies nor import tariffs..$^{3}$

Exporting firms, purchase domestic (origin) goods (both intermediate and final) to sell at the destination country. The representative exporting firm $k$, that belongs to sector $J(J=\mathrm{T}$ for intermediate goods and $J=\mathrm{D}$ for final goods) of the origin country $j$, sets a price $P_{o, t}^{\mathrm{M}}(k)$ in terms of destination country $i$ currency, where $o$ is the triplet $(j, i, J)$. This price times their export quantity determine their (nominal) revenues, whereas their costs relate to the purchase of the domestic good plus any adjustment costs, $G_{P, o, t}^{\mathrm{M}}(k)$, that depend on the inflation rate in destination currency. Their dividend in terms of destination country $i$ currency is given by

\footnotetext{
${ }^{3}$ Additional material including the interaction between export subsidies, import tariffs and business taxation is available on request.
} 
(which replaces Equation (150), p. 31):

$$
D_{o, t}^{\mathrm{M}}(k)=\left(1-\tau_{j, t}^{\mathrm{CI}}-\Omega_{j}^{\mathrm{sB}} \tau_{j, t}^{\mathrm{CF}}\right) \underbrace{P_{o, t}^{\mathrm{M}}(k) Y_{o, t}^{\mathrm{M}}(k)}_{\text {sales abroad }}-\left(1-\tau_{j, t}^{\mathrm{CI}}-\tau_{j, t}^{\mathrm{CF}}\right) \underbrace{\left(P_{o, t}^{\mathrm{M}} G_{P, o, t}^{\mathrm{M}}(k)+P_{o, t}^{\mathrm{M}, \mathrm{cif}} Y_{o, t}^{\mathrm{M}}(k)\right)}_{\text {domestic intermediate consumption }},
$$

where $P_{o, t}^{\mathrm{M}, \mathrm{cif}}$ denotes the nominal costs of inputs, i.e. the price in $i$ currency of the good produced in sector $J$ and country $j$. As with manufacturers, the introduction of the different taxes only affects the pricing decisions of firms. The inflation dynamics in destination currency now includes terms related to the level of income and cash-flow taxes.

\section{III.4.1. Price setting under sticky inflation}

This replaces Equation (151) p.31:

$$
\begin{aligned}
\frac{1}{\phi_{P}^{\mathrm{M}}\left(\mu^{\mathrm{M}}-1\right)} & \left(\mu^{\mathrm{M}} \frac{1-\tau_{j, t}^{\mathrm{CI}}-\tau_{j, t}^{\mathrm{CF}}}{1-\tau_{j, t}^{\mathrm{CI}}-\Omega_{j}^{\mathrm{SB}} \tau_{j, t}^{\mathrm{CF}}} \frac{p_{o, t}^{\mathrm{M}, \mathrm{cif}}}{p_{o, t}^{\mathrm{M}}}-1\right)=\left(\frac{\pi_{o, t}^{\mathrm{M}}}{\pi_{o, t-1}^{\mathrm{M}}}\right)\left(\frac{\pi_{o, t}^{\mathrm{M}}}{\pi_{o, t-1}^{\mathrm{M}}}-1\right) \ldots \\
& -\frac{\theta g n}{r_{t}} \mathbb{E}_{t}\left\{\frac{1-\tau_{j, t+1}^{\mathrm{CI}}-\tau_{j, t+1}^{\mathrm{CF}}}{1-\tau_{j, t}^{\mathrm{CI}}-\tau_{j, t}^{\mathrm{CF}}} \frac{p_{o, t+1}^{\mathrm{M}}}{p_{o, t}^{\mathrm{M}}} \frac{\check{Y}_{o, t+1}^{\mathrm{M}}}{\check{Y}_{o, t}^{\mathrm{M}}}\left(\frac{\pi_{o, t+1}^{\mathrm{M}}}{\pi_{o, t}^{\mathrm{M}}}\right)\left(\frac{\pi_{o, t+1}^{\mathrm{M}}}{\pi_{o, t}^{\mathrm{M}}}-1\right)\right\} .
\end{aligned}
$$

\section{III.4.2. Under sticky prices}

This equation does not appear in the original paper, but it is presented for completeness

$$
\begin{aligned}
\frac{1}{\phi_{P}^{\mathrm{M}}\left(\mu^{\mathrm{M}}-1\right)} & \left(\mu^{\mathrm{M}} \frac{1-\tau_{j, t}^{\mathrm{CI}}-\tau_{j, t}^{\mathrm{CF}}}{1-\tau_{j, t}^{\mathrm{CI}}-\Omega_{j}^{\mathrm{SB}} \tau_{j, t}^{\mathrm{CF}}} \frac{p_{o, t}^{\mathrm{M}, \mathrm{cif}}}{p_{o, t}^{\mathrm{M}}}-1\right)=\pi_{o, t}^{\mathrm{M}}\left(\pi_{o, t}^{\mathrm{M}}-\bar{\pi}_{i}\right) \ldots \\
& -\frac{\theta g n}{r_{t}} \mathbb{E}_{t}\left\{\frac{1-\tau_{j, t+1}^{\mathrm{CI}}-\tau_{j, t+1}^{\mathrm{CF}}}{1-\tau_{j, t}^{\mathrm{CI}}-\tau_{j, t}^{\mathrm{CF}}} \frac{p_{o, t+1}^{\mathrm{M}}}{p_{o, t}^{\mathrm{M}}} \frac{\check{Y}_{o, t+1}^{\mathrm{M}}}{\check{Y}_{o, t}^{\mathrm{M}}} \pi_{o, t+1}^{\mathrm{M}}\left(\pi_{o, t+1}^{\mathrm{M}}-\bar{\pi}_{i}\right)\right\} .
\end{aligned}
$$

Noticeably, at the steady-state or under flexible prices, the destination-based cash flow tax affects relative prices in the same way as an export subsidy. Assuming a pure destination-based cash-flow tax where $\Omega_{j}^{\mathrm{sB}}=0$ :

$$
P_{o}^{\mathrm{M}}=\left(1-\tau_{j}^{\mathrm{CF}}\right) \mu^{\mathrm{M}} P_{o}^{\mathrm{M}, \mathrm{cif}}
$$

Finally, rescaled real dividends writes:

$$
\check{d}_{o, t}^{\mathrm{M}}=\left(1-\tau_{j, t}^{\mathrm{CI}}-\Omega_{j}^{\mathrm{SB}} \tau_{j, t}^{\mathrm{CF}}\right) p_{o, t}^{\mathrm{M}} \check{Y}_{o, t}^{\mathrm{M}}-\left(1-\tau_{j, t}^{\mathrm{CI}}-\tau_{j, t}^{\mathrm{CF}}\right)\left(p_{o, t}^{\mathrm{M}} \check{G}_{P, o, t}^{\mathrm{M}}+p_{o, t}^{\mathrm{M}, \mathrm{cif}} \check{Y}_{o, t}^{\mathrm{M}}\right)
$$




\section{III.5. Importing firms (previously foreign input composite distributors)}

In country $i$, the importing firms in sector $J(J=\mathrm{T}$ for intermediate goods and $J=\mathrm{D}$ for final goods) import goods from other countries $j \neq i$ and aggregate them into a foreign good. Each country-specific good is considered as imported (i.e. purchased by a domestic firm from a foreign firm) but the foreign good is considered as domestic for the destination-based cash-flow tax. Let $o$ refers to the triplet $(i, j, J)$, so that dividends of the importing firm in sector $J$ and country $i$ are given by

$$
D_{i, J, t}^{\mathrm{F}}(k)=\left(1-\tau_{i, t}^{\mathrm{CI}}-\tau_{i, t}^{\mathrm{CF}}\right) P_{i, J, t}^{\mathrm{F}} Y_{i, J, t}^{\mathrm{F}}-\left(1-\tau_{i, t}^{\mathrm{CI}}-\Omega_{i}^{\mathrm{SB}} \tau_{i, t}^{\mathrm{CF}}\right) \sum_{j \neq i} P_{o, t}^{\mathrm{M}} Y_{o, t}^{\mathrm{F}},
$$

where domestic sales are taxed by the cash-flow tax whereas imported intermediate consumption benefits from a tax rebate only if the cash-flow tax is source-based. This equation does not appear in the original GIMF working paper as dividends of importing firms are zero except in the case where some destination-based cash-flow tax is in place. The real rescaled version of dividends writes:

$$
\check{d}_{i, J, t}^{\mathrm{F}}(k)=\left(1-\tau_{i, t}^{\mathrm{CI}}-\tau_{i, t}^{\mathrm{CF}}\right) p_{i, J, t}^{\mathrm{F}} \check{Y}_{i, J, t}^{\mathrm{F}}-\left(1-\tau_{i, t}^{\mathrm{CI}}-\Omega_{i}^{\mathrm{SB}} \tau_{i, t}^{\mathrm{CF}}\right) \sum_{j \neq i} p_{o, t}^{\mathrm{M}} \check{Y}_{o, t}^{\mathrm{F}}
$$

The price level for the aggregated imported good, equation (160) p.33, is modified by the destination-based cash-flow tax:

$$
P_{i, J, t}^{\mathrm{F}}=\frac{1-\tau_{i, t}^{\mathrm{CI}}-\Omega_{i}^{\mathrm{SB}} \tau_{i, t}^{\mathrm{CF}}}{1-\tau_{i, t}^{\mathrm{CI}}-\tau_{i, t}^{\mathrm{CF}}}\left(\sum_{j \neq i} \zeta_{o} P_{o, t}^{\mathrm{M} 1-\xi_{\mathrm{MI}}}\right)^{\frac{1}{1-\xi_{\mathrm{MI}}}} .
$$

Noticeably, the destination-based cash-flow tax modifies relative prices like an import tariff does. Perfect competition and constant returns to scale drives dividends of importing firms to zero. However, with a destination-based cash-flow tax, import agents pay taxes to the government.

\section{III.6. Investment and consumption goods producers}

Firms producing consumption and investment goods buy domestic final output from domestic distributors and foreign final output from importing firms. Dividends appearing in the profit maximization problem, Equations (199) and (220) of the original GIMF working paper, now 
include corporate income and corporate cash-flow taxes: ${ }^{4}$

$$
\begin{aligned}
D_{t}^{\mathrm{I}}(i) & =\left(1-\tau_{t}^{\mathrm{CI}}-\tau_{t}^{\mathrm{CF}}\right)\left(\left(P_{t}^{\mathrm{I}}(i)-P_{t}^{\mathrm{II}}(i)\right) Z_{t}^{\mathrm{I}}(i)-P_{t}^{\mathrm{I}} G_{P, t}^{\mathrm{I}}(i)-P_{t}^{\mathrm{I}} T_{t} \omega^{\mathrm{I}}\right), \text { and } \\
D_{t}^{\mathrm{C}}(i) & =\left(1-\tau_{t}^{\mathrm{CI}}-\tau_{t}^{\mathrm{CF}}\right)\left(\left(P_{t}(i)-P_{t}^{\mathrm{CC}}(i)\right) Z_{t}^{\mathrm{C}}(i)-P_{t} G_{P, t}^{\mathrm{C}}(i)-P_{t} T_{t} \omega^{\mathrm{C}}\right) .
\end{aligned}
$$

\section{III.6.1. Investment goods price setting under sticky inflation}

The price setting decision, Equation (200), is therefore modified to include the impact of corporate taxes:

$$
\begin{aligned}
\frac{1}{\phi_{P^{\mathrm{I}}}\left(\mu_{t}^{\mathrm{I}}-1\right)}\left(\mu_{t}^{\mathrm{I}} \frac{p_{t}^{\mathrm{II}}}{p_{t}^{\mathrm{I}}}-1\right) & =\left(\frac{\pi_{t}^{\mathrm{ZI}}}{\pi_{t-1}^{\mathrm{ZI}}}\right)\left(\frac{\pi_{t}^{\mathrm{ZI}}}{\pi_{t-1}^{\mathrm{ZI}}}-1\right) \\
& -\frac{\theta g n}{r_{t}} \mathbb{E}_{t}\left\{\frac{1-\tau_{t+1}^{\mathrm{CI}}-\tau_{t+1}^{\mathrm{CF}}}{1-\tau_{t}^{\mathrm{CI}}-\tau_{t}^{\mathrm{CF}}} \frac{p_{t+1}^{\mathrm{I}}}{p_{t}^{\mathrm{I}}} \frac{\check{Z}_{t+1}^{\mathrm{I}}}{\check{Z}_{t}^{\mathrm{I}}}\left(\frac{\pi_{t+1}^{\mathrm{ZI}}}{\pi_{t}^{\mathrm{ZI}}}\right)\left(\frac{\pi_{t+1}^{\mathrm{ZI}}}{\pi_{t}^{\mathrm{ZI}}}-1\right)\right\} .
\end{aligned}
$$

\section{III.6.2. Investment goods price setting under sticky prices}

This equation does not appear in the original working paper but can be switched on in GIMF:

$$
\begin{aligned}
\frac{1}{\phi_{P^{\mathrm{I}}}\left(\mu_{t}^{\mathrm{I}}-1\right)}\left(\mu_{t}^{\mathrm{I}} \frac{p_{t}^{\mathrm{II}}}{p_{t}^{\mathrm{I}}}-1\right) & =\pi_{t}^{\mathrm{ZI}}\left(\pi_{t}^{\mathrm{ZI}}-\bar{\pi}\right) \\
& -\frac{\theta g n}{r_{t}} \mathbb{E}_{t}\left\{\frac{1-\tau_{t+1}^{\mathrm{CI}}-\tau_{t+1}^{\mathrm{CF}}}{1-\tau_{t}^{\mathrm{CI}}-\tau_{t}^{\mathrm{CF}}} \frac{p_{t+1}^{\mathrm{I}}}{p_{t}^{\mathrm{I}}} \frac{\check{Z}_{t+1}^{\mathrm{I}}}{\check{Z}_{t}^{\mathrm{I}}} \pi_{t+1}^{\mathrm{ZI}}\left(\pi_{t+1}^{\mathrm{ZI}}-\bar{\pi}\right)\right\} .
\end{aligned}
$$

\section{III.6.3. Consumption goods price setting under sticky inflation}

The price setting decision, Equation (221), is also modified to include the impact of corporate taxes, keeping in mind that the price of consumption goods is the numeraire:

$$
\begin{aligned}
\frac{1}{\phi_{P^{\mathrm{C}}}\left(\mu_{t}^{\mathrm{C}}-1\right)}\left(\mu_{t}^{\mathrm{I}} p_{t}^{\mathrm{CC}}-1\right) & =\left(\frac{\pi_{t}}{\pi_{t-1}}\right)\left(\frac{\pi_{t}}{\pi_{t-1}}-1\right) \\
& -\frac{\theta g n}{r_{t}} \mathbb{E}_{t}\left\{\frac{1-\tau_{t+1}^{\mathrm{CI}}-\tau_{t+1}^{\mathrm{CF}}}{1-\tau_{t}^{\mathrm{CI}}-\tau_{t}^{\mathrm{CF}}} \frac{\check{Z}_{t+1}^{\mathrm{C}}}{\check{Z}_{t}^{\mathrm{C}}}\left(\frac{\pi_{t+1}}{\pi_{t}}\right)\left(\frac{\pi_{t+1}}{\pi_{t}}-1\right)\right\} .
\end{aligned}
$$

\footnotetext{
${ }^{4}$ The working paper uses $D$ for demand instead of $Z$ for sales but, for consistency with other sectors, $Z$ is kept. The two concepts are equals in equilibrium.
} 


\section{III.6.4. Consumption goods price setting under sticky prices}

This equation does not appear in the original working paper but can be switched on in GIMF:

$$
\frac{1}{\phi_{P^{\mathrm{C}}}\left(\mu_{t}^{\mathrm{C}}-1\right)}\left(\mu_{t}^{\mathrm{I}} p_{t}^{\mathrm{CC}}-1\right)=\pi_{t}\left(\pi_{t}-\bar{\pi}\right)-\frac{\theta g n}{r_{t}} \mathbb{E}_{t}\left\{\frac{1-\tau_{t+1}^{\mathrm{CI}}-\tau_{t+1}^{\mathrm{CF}}}{1-\tau_{t}^{\mathrm{CI}}-\tau_{t}^{\mathrm{CF}}} \frac{\check{Z}_{t+1}^{\mathrm{C}}}{\check{Z}_{t}^{\mathrm{C}}} \pi_{t+1}\left(\pi_{t+1}-\bar{\pi}\right)\right\} .
$$

\section{III.7. Tax revenues associated with all taxes, no financial accelerator}

All that remains is to describe the tax revenues received by the fiscal authorities. In this section the tax revenues arising from the version of GIMF without the financial accelerator are presented. The next section will document the case where the financial accelerator is in operation. In both cases, it is assumed that there is no change to fiscal policies relative to the original version of GIMF, other than the fact that there are additional sources of tax revenue. Total tax revenue arising from all taxes is given by (this replaces equation (244), p. 44):

$$
\check{\tau}_{t}=\tau_{t}^{L} \check{w}_{t} \check{L}_{t}+\tau_{t}^{C} p_{t}^{c} \check{C}_{t}+\check{\tau}_{l s, t}+\sum_{J=K R, C I, C F} \check{T R}_{t}^{J}
$$

where $\breve{T R}_{t}^{\mathrm{J}}$ for $J=K R, C I, C F$ are the tax revenues stemming from the KRT, CIT and CFT taxes. These are now defined, starting with the tax revenue for KRT:

$$
\check{T R}_{t}^{\mathrm{KR}}=\tau_{t}^{\mathrm{KR}} \sum_{J=T, N}\left[\bar{r}_{k, t}^{J}-\delta_{t}^{J} q_{t}^{J}\right] \bar{K}_{t}^{J} .
$$

The tax base only includes net of depreciation capital services. For the CIT, the tax revenue is:

$$
\begin{aligned}
\check{T R}_{t}^{\mathrm{CI}} & =\tau_{t}^{\mathrm{CI}} \sum_{J=T, N}\left[p_{t}^{\tilde{J}}\left(\check{Z}_{t}^{J}-\omega^{J}-\check{G}_{P, t}^{J}-r \check{c} u_{t}\right)-\check{v}_{t} \check{U}_{t}^{J}+\left(\left(1-\delta_{t}^{J}\right) q_{t}^{J}-\frac{q_{t-1}^{J}}{\pi_{t}}\right) \bar{K}_{t}^{J}-p_{t}^{\mathrm{I}} \check{G}_{I, t}^{J}\right] \\
& +\tau_{t}^{\mathrm{CI}}\left[\left(p_{t}^{\mathrm{I}}-p_{t}^{\mathrm{II}}\right) \check{Z}_{t}^{\mathrm{I}}-p_{t}^{\mathrm{I}} \check{G}_{P, t}^{\mathrm{I}}-p_{t}^{\mathrm{I}} \omega^{\mathrm{I}}\right]+\tau_{t}^{\mathrm{CI}}\left[\left(p_{t}-p_{t}^{\mathrm{cC}}\right) \check{Z}_{t}^{\mathrm{C}}-p_{t} \check{G}_{P, t}^{\mathrm{C}}-p_{t} \omega^{\mathrm{C}}\right] \\
& +\tau_{t}^{\mathrm{CI}} \sum_{i \in \mathscr{I}} \sum_{J=T, N} \frac{E_{i, t}}{E_{j, t}}\left[p_{i, J, t}^{\mathrm{M}} \check{Y}_{i, J, t}^{\mathrm{M}}-p_{i, J, t}^{\mathrm{M}, c i f} \check{Y}_{i, J, t}^{\mathrm{M}}-p_{i, J, t}^{\mathrm{M}} \check{G}_{P, i, J, t}^{\mathrm{M}}\right] \\
& +\tau_{t}^{\mathrm{CI}} \sum_{J=T, D}\left[p_{J, t}^{\mathrm{F}} \check{Y}_{J, t}^{\mathrm{F}}-\sum_{i \in \mathscr{I}} p_{i, J, t}^{\mathrm{M}} \check{Y}_{i, J, t}^{\mathrm{F}}\right]
\end{aligned}
$$

where $\mathscr{I}$ denotes, in summations, the set of all other countries and $E_{i, t}$ the real exchange rate. Note that the tax base for the corporate income tax includes (first line) sales of domestically produced goods, plus revaluation effects on the stock of capital, minus depreciation allowance, labor costs and all adjustment costs; (second line) profits made by monopolistic distributors of consumption and investment goods; (third line) taxes on profits made by ex- 
porters; and (fourth line) profits made by importers. ${ }^{5}$ The only tax revenue affected by the financial accelerator is the first line of the CIT as it needs to include interest deductability on debt (see Appendix IV).

The tax revenue for the CFT is given by:

$$
\begin{aligned}
\check{T R}_{t}^{\mathrm{CF}} & =\tau_{t}^{\mathrm{CF}} \sum_{J=T, N}\left[p_{t}^{\tilde{J}}\left(\check{Z}_{t}^{J}-\omega^{J}-\check{G}_{P, t}^{J}-r \check{c} u_{t}\right)-\check{v}_{t} \check{U}_{t}^{J}-p_{t}^{\mathrm{I}}\left(\check{I}_{t}^{J}+\check{G}_{t}^{\mathrm{I}}\right)\right] \\
& +\tau_{t}^{\mathrm{CF}}\left[\left(p_{t}^{\mathrm{I}}-p_{t}^{\mathrm{II}}\right) \check{Z}_{t}^{\mathrm{I}}-p_{t}^{\mathrm{I}} \check{G}_{P, t}^{\mathrm{I}}-p_{t}^{\mathrm{I}} \omega^{\mathrm{I}}\right]+\tau_{t}^{\mathrm{CF}}\left[\left(p_{t}-p_{t}^{\mathrm{CC}}\right) \check{Z}_{t}^{\mathrm{C}}-p_{t} \check{G}_{P, t}^{\mathrm{C}}-p_{t} \omega^{\mathrm{C}}\right] \\
& +\tau_{t}^{\mathrm{CF}} \sum_{i \in \mathscr{I}} \sum_{J=T, N} \frac{E_{i, t}}{E_{j, t}}\left[\Omega^{\mathrm{SB}} p_{i, J, t}^{\mathrm{M}} \check{Y}_{i, J, t}^{\mathrm{M}}-p_{i, J, t}^{\mathrm{M}, c i f} \check{Y}_{i, J, t}^{\mathrm{M}}-p_{i, J, t}^{\mathrm{M}} \check{G}_{P, i, J, t}^{\mathrm{M}}\right] \\
& +\tau_{t}^{\mathrm{CF}} \sum_{J=T, D}\left[p_{J, t}^{\mathrm{F}} \check{Y}_{J, t}^{\mathrm{F}}-\Omega^{\mathrm{sB}} \sum_{i \in \mathscr{I}} p_{i, J, t}^{\mathrm{M}} \check{Y}_{i, J, t}^{\mathrm{F}}\right] .
\end{aligned}
$$

The tax base for the corporate cash-flow tax includes (first line) sales of domestically produced goods, minus investment expenses, labor costs and all adjustment costs; (second line) profits made by monopolistically competitive distributors of consumption and investment goods; (third line) taxes on profits made by exporters under a source-based system or a rebate on exported domestic goods and associated adjustment costs; and (fourth line) profits made by importers in the source-based system but total imports in destination-based system. ${ }^{6}$

\footnotetext{
${ }^{5}$ The last term is equal to zero unless there is a destination-based cash-flow tax in operation. Therefore, in most cases, this fourth line vanishes.

${ }^{6}$ The last term is equal to zero in a source-based system.
} 


\section{APPENDIX IV. IMPLICATIONS OF THE INTRODUCTION OF CORPORATE TAXES FOR

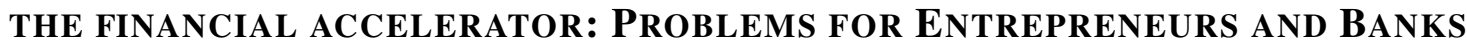

In this appendix the problems faced by the entrepreneurs and banks, and the resulting optimal loan contract are derived. A full description of the problems faced by each agent is provided, rather than simply presenting the equations that are affected by the introduction of the new taxes. This is done in order to best explain the implications of the introduction of the taxes on the optimal loan contract.

\section{IV.1. The entrepreneurs problem}

The entrepreneur $j$ in sector $J$ ( $\mathrm{N}$ or $\mathrm{T}$ ) purchases, at the end of period $t$, a capital stock from capital goods producers. In the next period, $t+1$, the entrepreneur is subject to an idiosyncratic shock, $\omega_{t+1}^{J}(j)$, that can either increase or reduce the capital stock, $\omega_{t+1}^{J}(j) \bar{K}_{t+1}^{J}$. These idiosyncratic shocks are assumed to be independently and identically distributed (i.i.d.) and to follow a $\log$ normal distribution with cumulative distribution $\operatorname{Pr}\left(\omega_{t+1}^{J}(j) \leq w\right)=F_{t+1}^{J}(w)$.

To finance the capital stock, entrepreneurs use both internal and external funds:

$$
q_{t}^{J} \bar{K}_{t}^{J}(j)=N W_{t}^{J}(j)+B_{t}^{J}(j)
$$

where $N W_{t}^{J}(j)$ is the net worth of the entrepreneur (internal funds) and $B_{t}^{J}(j)$ the loan from the bank (external funds), both in real terms.

The relationship between the entrepreneur and the lender assumes asymmetric information between both parties and is modeled as a costly state verification problem as in Townsend (1979) and Gale and Hellwig (1985). As the idiosyncratic shock is not observed by the bank, a debt contract (the amount to be reimbursed by the entrepreneur) is not contingent on its realization, unless the bank pays the cost to observe it. This state verification cost is a timevarying fraction, $\mu_{t+1}^{J}$, of the remaining worth of the monitored entrepreneur. For a given level of leverage, both the ability to service debt and the state-verification cost are increasing functions of the idiosyncratic shock. As a result, in the optimal debt contract, either the entrepreneur is able to service its debt and the bank does not pay the monitoring cost, or it has to default and the bank pays for this cost to recover any remaining assets. More specifically, there exists a threshold level, $\bar{\omega}_{t+1}^{J}$, such that the entrepreneur is able to service its debt if its idiosyncratic shock is above the threshold, and defaults otherwise.

A debt contract between an entrepreneur and a bank specifies (i) a leverage ratio $\mathfrak{l}_{t}^{J}$, (ii) a statutory real interest factor $r_{B, t+1}^{J}$, that only depends on macroeconomic shocks at $t+1$, (iii) a monitoring policy (monitoring occurs if the entrepreneur fails to reimburse at the statutory interest factor), and (iv) a state-dependent interest factor $r_{B, t+1}^{J}(\omega)$ if the entrepreneur is monitored. The interest factor $r_{B, t+1}^{J}(\omega)$ is non-decreasing with the idiosyncratic shock and constant once the shock is above the threshold $r_{B, t+1}^{J}$ (in this case, the bank does not observe the idiosyncratic shock). 
The introduction of the different taxes affects the loan contract between the bank and the entrepreneur. First, all business taxes (KRT, CIT, CFT) are levied on the entrepreneur's return to capital which in turn is used to pay back the loan to the bank (by assumption, tax liabilities are senior to bank liability). Hence the introduction of all taxes, all else equal, reduces the ability of the entrepreneur to pay back the loan and increases $\bar{\omega}_{t+1}^{J}$, the threshold level where the entrepreneur defaults. Second, in the case of a CIT, because it permits interest expensing on debt (loans), the threshold level is reduced, partly mitigating the first effect. Third, as the corporate income tax rebate increases with leverage, the CIT also interferes directly with the debt contact. In what follows, the different constraints defining the set of possible debt contracts offered to entrepreneurs are defined and the resulting optimal contract chosen by entrepreneurs is derived.

It is assumed that net worth of entrepreneurs at $t$ is equal to $q_{t}^{J}$, the value of one unit of capital. ${ }^{7}$ Let $\mathfrak{l}_{t}^{J}(j) \equiv \frac{B_{t}^{J}(j)}{N W_{t}^{J}(j)}$ denote the leverage decision at $t$. With both internal (net worth) and external (leverage) funds, the entrepreneur is able to purchase $1+\mathfrak{l}_{t}^{J}(j)$ units of capital.

The after tax return associated with $1+\mathfrak{l}_{t}^{J}(j)$ units of capital is split between the entrepreneur and the bank. The split depends on whether the entrepreneurs bankrupts (the bank takes it all) or not (the bank receives a fixed amount determined below and the rest is for the entrepreneur). Three cases need to be described: the case where the entrepreneur does not default (the idiosyncratic shock is larger than the threshold level), the threshold level, and the case where the entrepreneur defaults (when the shock falls below the threshold).

\section{IV.1.1. No bankruptcy case}

Assuming the entrepreneurs draws an idiosyncratic shock above the threshold (that will be determined below), the entrepreneur first pays the different taxes and then repays the loan. The net income (after tax, after loan repayment) of the entrepreneur in $t+1$ is defined as income (capital return [I1]) net of expenditures (capital return tax [E1], corporate cash-flow tax [E2], corporate income tax [E3] and loan repayment [E4]). Box 1 describes the different flows. Net income then writes:

$$
N I_{t+1}^{J}(j) \equiv\left[r e t_{k, t+1}^{J} \omega_{t+1}^{J}(j)\left(1+\mathfrak{l}_{t}^{J}\right)-\left(1-\tau_{t+1}^{\mathrm{CI}}\right) r_{B, t+1}^{J} \mathfrak{l}_{t}^{J}+\frac{\tau_{t+1}^{\mathrm{CI}}}{\pi_{t+1}}\right] q_{t}^{J},
$$

where

$$
r e t_{k, t+1}^{J} \equiv \frac{\left.\left(1-\tau_{t+1}^{\mathrm{KR}}-\tau_{t+1}^{\mathrm{CI}}-\tau_{t+1}^{\mathrm{CF}}\right)\right)_{k, t+1}^{J}+\left[\left(1-\tau_{t+1}^{\mathrm{CI}}\right)-\left(1-\tau_{t+1}^{\mathrm{KR}}-\tau_{t+1}^{\mathrm{CI}}\right) \delta_{t+1}^{J}\right] q_{t+1}^{J}}{q_{t}^{J}}
$$

According to equations (29) and (30), all business taxes reduce the net income from renting the capital stock to firms. The CFT has the largest impact (but the overall effect is lowered

\footnotetext{
${ }^{7}$ Optimal decisions of entrepreneurs are linear in net worth.
} 
Box 1 Entrepreneurs' Income and Expenditures Decomposition Without Bankruptcy INCOME

\section{[I1] Entrepreneur's capital return}

The capital return includes the rental income from capital, $\bar{r}_{k, t+1}^{J}$ (defined in Appendix III), plus the revenue from selling back the remaining capital stock to the capital firms, $\left(1-\delta_{t+1}^{J}\right) q_{t+1}^{J}$ :

$$
\left(\bar{r}_{k, t+1}^{J}+\left(1-\delta_{t+1}^{J}\right) q_{t+1}^{J}\right) \omega_{t+1}^{J}(j)\left(1+\mathfrak{l}_{t}^{J}\right)
$$

\section{EXPENDITURES}

\section{[E1] Entrepreneur's capital return tax}

The KRT rate, $\tau^{\mathrm{KR}}$, applies on the rental income of capital minus the capital depreciation evaluated at market price (tax allowance):

$$
\tau_{t+1}^{\mathrm{KR}}\left(\bar{r}_{k, t+1}^{J}-\delta_{t+1}^{J} q_{t+1}^{J}\right) \omega_{t+1}^{J}(j)\left(1+\mathfrak{l}_{t}^{J}\right) .
$$

\section{[E2] Entrepreneur's corporate cash-flow tax}

The CFT rate, $\tau^{\mathrm{CF}}$, only applies to the rental income from capital (capital gains/losses and capital depreciation do not enter in the calculation of the tax base)

$$
\tau_{t+1}^{\mathrm{CF}} \bar{r}_{k, t+1}^{J} \omega_{t+1}^{J}(j)\left(1+\mathfrak{l}_{t}^{J}\right)
$$

Since entrepreneurs do not undertake the investment decision (capital goods producers do), the investment expenditures tax rebate does not appear here (capital good producers receive the tax allowance).

\section{[E3] Entrepreneur's corporate income tax}

The CIT rate $\tau_{t+1}^{\text {cl }}$ applies to the net of depreciation rental income from capital, plus capital gains/losses, minus the interest payments (to capture the deductibility of interest expensing). If the tax base is negative, the entrepreneur receives a subsidy from the fiscal authorities:

$$
\tau_{t+1}^{\mathrm{Cl}}\left[\left(\bar{r}_{k, t+1}^{J}-\delta_{t+1}^{J} q_{t+1}^{J}\right) \omega_{t+1}^{J}(j)\left(1+\mathfrak{l}_{t}^{J}\right)+\left(\omega_{t+1}^{J}(j) q_{t+1}^{J}-\frac{q_{t}^{J}}{\pi_{t+1}}\right)\left(1+\mathfrak{l}_{t}^{J}\right)-\left(r_{B, t+1}^{J}-\frac{1}{\pi_{t+1}}\right) \mathfrak{l}_{t}^{J} q_{t}^{J}\right] .
$$

\section{[E4] Entrepreneur's loan repayment}

In the case of no bankruptcy, the entrepreneur repays the bank the loan with an interest factor specified in the loan contract, $r_{B, t+1}^{J}$ :

$$
r_{B, t+1}^{J} \mathfrak{l}_{t}^{J} q_{t}^{J}
$$

\section{NET INCOME}

\section{[NI] Entrepreneur's net income}

The entrepreneur's net (after-tax, after loan repayment) income is equal to total income [I1] minus all expenditures [E1 to E4] (see equation (29) in the main text).

by the investment expenditure rebate), the KRT has the second largest effect (thanks to the capital depreciation rebate), and the CIT the smallest effect (thanks to the interest expenditure rebate). 


\section{IV.1.2. Threshold level}

When the net income of the entrepreneur (defined by Equation (29)) is negative, the entrepreneur defaults. This happens if its idiosyncratic productivity shock $\omega_{t+1}^{J}(j)$ falls below the threshold level, $\bar{\omega}_{t+1}^{J}$, defined by:

$$
\bar{\omega}_{t+1}^{J} \equiv \frac{\left(1-\tau_{t+1}^{\mathrm{CI}}\right) r_{B, t+1}^{J} \mathfrak{l}_{t}^{J}-\frac{\tau_{t+1}^{\mathrm{CI}}}{\pi_{t+1}}}{r e t_{k, t+1}^{J}\left(1+\mathfrak{l}_{t}^{J}\right)}
$$

As noted earlier, the threshold level is dependent on all taxes. KRT, CFT and CIT all reduce the net income of the entrepreneur and increase the threshold level. Moreover, in the case of the CIT, interest expensing of debt acts to lower the threshold. At this stage, note that the threshold level depends on $r_{B, t+1}^{J}$, the interest factor associated with the debt contract. This interest rate is determined by the bank's participation constraint, described below.

\section{IV.1.3. Bankruptcy case}

In case of default, first the different corporate taxes are payed and then the bank seizes the remaining real income (partial loan repayment). As a result, the net income of the entrepreneur at the end of period $t+1$ is zero (i.e. $N I_{t+1}^{J}(j)=0$ if $\omega_{t+1}^{J}(j)<\bar{\omega}_{t+1}^{J}$ ). The entrepreneur's capital return, the capital return tax and cash flow tax are the same as in the case where there is no bankruptcy. Although the corporate income tax varies since the corporate income tax paid depends on the interest payment to the bank which itself depends on how much the bank is able to seize after taxes have been paid. Box 2 describes how the corporate income tax [E3] and the loan repayment [E5] are modified. As the entrepreneur bankrupts, its net (after-tax, after loan repayment) income [NIb], by definition equal to total income [I1] minus all expenditures [E1], [E2], [E3b] and [E4b], is also equal to zero.

\section{IV.2. Bank's participation constraint (ex post zero profit condition)}

Banks are risk adverse whereas entrepreneurs are risk neutral. Their participation constraint plus the assumption of perfect competition ensures that profits are exactly zero ex post (i.e. whatever the realization of macroeconomic shocks). Thus, the revenue of the bank at $t+1$, net of monitoring costs, exactly covers the previous period's total loan amount times the interest factor determined on the money market $\left(R_{t}\right.$, the one-period risk-free nominal interest factor). Box 3 describes the different flows faced by the bank. ${ }^{8}$

\footnotetext{
${ }^{8}$ Perfect competition drives the margins of the banking sector to zero such that banks does not pay any tax.
} 
Box 2 Changes to Entrepreneurs' Income and Expenditures Decomposition With Bankruptcy EXPENDITURES

\section{[E3b] Entrepreneur's corporate income tax}

Once the entrepreneur is monitored by the bank, the interest factor needed to calculate the CIT base, $r_{B, t+1}^{J}\left(\omega_{t+1}^{J}(j)\right)$, becomes dependent on the idiosyncratic shock. The amount of corporate taxes is then:

$$
\tau_{t+1}^{\mathrm{Cl}}\left[\begin{array}{c}
\left(\bar{r}_{k, t+1}^{J}-\delta_{t+1}^{J} q_{t+1}^{J}\right) \omega_{t+1}^{J}(j)\left(1+\mathfrak{l}_{t}^{J}\right)+\left(\omega_{t+1}^{J}(j) q_{t+1}^{J}-\frac{q_{t}^{J}}{\pi_{t+1}}\right)\left(1+\mathfrak{l}_{t}^{J}\right) \\
-\left(r_{B, t+1}^{J}\left(\omega_{t+1}^{J}(j)\right)-\frac{1}{\pi_{t+1}}\right) \mathfrak{l}_{t}^{J} q_{t}^{J}
\end{array}\right]
$$

\section{[E4b] Entrepreneur's loan repayment}

Default implies that corporate income tax payment and partial loan repayment exhausts the remaining worth of the entrepreneur.

$$
r_{B, t+1}^{J}\left(\omega_{t+1}^{J}(j)\right) \mathfrak{l}_{t}^{J} q_{t}^{J} \quad \text { with } \quad r_{B, t+1}^{J}\left(\omega_{t+1}^{J}(j)\right)=\frac{\operatorname{ret}_{k, t+1}^{J} \omega_{t+1}^{J}(j)\left(1+\mathfrak{l}_{t}^{J}\right)+\tau_{t+1}^{\mathrm{Cl}} / \pi_{t+1}}{1-\tau_{t+1}^{\mathrm{Cl}}} \frac{1}{\mathfrak{l}_{t}^{J}}
$$

NET INCOME

Net income is zero as the entrepreneur bankrupts.

\section{Box 3 Bank Income and Expenditures}

\section{INCOME}

\section{[BI1] Loan repayment by non-defaulting entrepreneurs}

The total amount collected is equal to the share of non-defaulting entrepreneurs (let $\bar{F}_{t+1}^{J} \equiv F_{t+1}^{J}\left(\bar{\omega}_{t+1}^{J}\right)$ ) times the repayment in absence of bankruptcy:

$$
\left[1-\bar{F}_{t+1}^{J}\right] r_{B, t+1}^{J} \mathfrak{l}_{t}^{J} q_{t}^{J}
$$

\section{[BI2] Partial loan repayment by defaulting entrepreneurs}

The total amount collected is equal to the integral over defaulting entrepreneurs of their partial loan repayment:

$$
\int_{w=0}^{\bar{\omega}_{t+1}^{J}} \frac{r e t_{k, t+1}^{J} w\left(1+\mathfrak{l}_{t}^{J}\right)+\tau_{t+1}^{\mathrm{Cl}} / \pi_{t+1}}{1-\tau_{t+1}^{\mathrm{Cl}}} q_{t}^{J} \mathrm{~d} F_{t+1}^{J}(w)
$$

\section{EXPENDITURES}

\section{[BE1] Monitoring costs on defaulting entrepreneurs}

The monitoring cost is a fraction of partial loan repayment of defaulting entrepreneurs

$$
\mu_{t+1} \int_{w=0}^{\bar{\omega}_{t+1}^{J}} \frac{r e t_{k, t+1}^{J} w\left(1+\mathfrak{l}_{t}^{J}\right)+\tau_{t+1}^{\mathrm{Cl}} / \pi_{t+1}}{1-\tau_{t+1}^{\mathrm{Cl}}} q_{t}^{J} \mathrm{~d} F_{t+1}^{J}(w) .
$$

[BE2] Repayment on the money market

Banks have to pay interest on the funds borrowed from the money market (households):

$$
\frac{R_{t}}{\pi_{t+1}} \mathfrak{l}_{t}^{J} q_{t}^{J}
$$

NET INCOME

Net income is zero as the banking sector is in perfect competition. 
Under perfect competition, the bank's participation constraint drives its net income to zero, i.e. $[\mathrm{BI} 1]+[\mathrm{BI} 2]-[\mathrm{BE} 1]-[\mathrm{BE} 2]=0$. This implies:

$$
\left[1-\bar{F}_{t+1}^{J}\right] r_{B, t+1}^{J} \mathfrak{l}_{t}^{J}+\left(1-\mu_{t+1}\right) \int_{w=0}^{\bar{\omega}_{t+1}^{J}} \frac{r e t_{k, t+1}^{J} w\left(1+\mathfrak{l}_{t}^{J}\right)+\tau_{t+1}^{\mathrm{CI}} / \pi_{t+1}}{1-\tau_{t+1}^{\mathrm{CI}}} \mathrm{d} F_{t+1}^{J}(w)=\frac{R_{t}}{\pi_{t+1}} \mathfrak{l}_{t}^{J}
$$

A higher corporate income tax rate increases the net-of-monitoring-costs partial loan repayment of defaulting entrepreneurs and relaxes the participation constraint of banks. As a result, banks lower the statutory interest factor $r_{B, t+1}^{J}$ and the amount non-defaulting entrepreneurs have to reimburse. Together with the definition of the threshold level, Equation (31), the participation constraint is summarized by:

$$
\left(1+\mathfrak{l}_{t}^{J}\right) r e t_{k, t+1}^{J} \bar{g}_{t+1}^{J}-\mu_{t+1}^{J} \frac{\tau_{t+1}^{\mathrm{CI}}}{\pi_{t+1}} \bar{F}_{t+1}^{J}=\left(1-\tau_{t+1}^{\mathrm{CI}}\right) \mathfrak{l}_{t} \frac{R_{t}}{\pi_{t+1}}-\frac{\tau_{t+1}^{\mathrm{CI}}}{\pi_{t+1}}
$$

where

$$
\bar{g}_{t+1}^{J} \equiv g_{t+1}^{J}\left(\bar{\omega}_{t+1}^{J}\right) \quad \text { with } \quad g_{t+1}^{J}(\omega) \equiv\left(1-\mu_{t+1}^{J}\right) \int_{0}^{\omega} w \mathrm{~d} F_{t+1}^{J}(w)+\omega\left(1-F_{t+1}^{J}(\omega)\right) .
$$

\section{IV.3. Optimal debt contract (leverage)}

Each entrepreneur chooses the debt contract, i.e. a leverage ratio $\mathfrak{l}_{t}^{J}$, a corresponding interest factor on the loan $r_{B, t+1}^{J}$ (according to the bank participation constraint (33)), and a threshold level $\bar{\omega}_{t+1}^{J}$ (satisfying equation (31)) to maximize its expected net income the following period, i.e. $\mathbb{E}_{t}\left\{N I_{t+1}^{J}(j)\right\}$ :

$$
\max _{\mathfrak{l}_{t}^{J}} \mathbb{E}_{t}\left\{\left(1+\mathfrak{l}_{t}^{J}\right) \bar{h}_{t+1}^{J} r e t_{k, t+1}^{J}\right\}
$$

where

$$
\bar{h}_{t+1}^{J} \equiv h_{t+1}^{J}\left(\bar{\omega}_{t+1}^{J}\right) \quad \text { with } \quad h_{t+1}^{J}(\omega) \equiv \int_{\omega}^{\infty}(w-\omega) \mathrm{d} F_{t+1}^{J}(w)
$$

The optimal leverage condition, derived in more detail in Box 4, is given by:

$$
\mathbb{E}_{t}\left\{\bar{h}_{t+1}^{J} \operatorname{ret}_{k, t+1}^{J}\right\}\left(1+\mathfrak{l}_{t}^{J}\right)=-\mathbb{E}_{t}\left\{\frac{\bar{h}_{t+1}^{J}\left(\left[1-\tau_{t+1}^{\mathrm{CI}}\right] R_{t}+\tau_{t+1}^{\mathrm{CI}}\left[1-\mu_{t+1}^{J} \bar{F}_{t+1}^{J}\right]\right)}{\pi_{t+1} \bar{g}_{t+1}^{J}-\frac{\mu_{t+1}^{J} \tau_{t+1}^{\mathrm{CI}} \bar{\varphi}_{t+1}^{J}}{r e t_{k, t+1}^{J}}}\right\} .
$$

The different corporate taxes appear either directly as in the case of the corporate income tax, $\tau_{t+1}^{\mathrm{CI}}$, or indirectly via $\mathrm{ret}_{k, t+1}^{J}$. Note that when all corporate tax rates are set to zero, the opti- 
mal leverage condition becomes

$$
\mathbb{E}_{t}\left\{\frac{\bar{h}_{t+1}^{J} \operatorname{ret}_{k, t+1}^{J} \pi_{t+1}}{R_{t}}\right\}\left(1+\mathfrak{l}_{t}^{J}\right)=-\mathbb{E}_{t}\left\{\frac{\bar{h}_{t+1}^{\prime J}}{\bar{g}_{t+1}^{\prime J}}\right\} .
$$

The equity premium is defined as the ratio of the expected equity nominal return, i.e. expected after tax net income of entrepreneur, $\mathbb{E}_{t}\left\{\left(1+\mathfrak{l}_{t}^{J}\right) \bar{h}_{t+1}^{J} r t_{k, t+1}^{J} \pi_{t+1}\right\}$, to the risk free nominal interest factor $R_{t}$. Equation (35) illustrates that the equity premium is a function of the financial frictions i.e. the ratio of the marginal entrepreneur's share $h^{\prime}$ (i.e. the derivative respect to the threshold value) to the marginal bank's share $g^{\prime}$. In the absence of frictions, the two shares exactly sum to one, such that the equity premium is equal to 1 . With financial frictions, the RHS of equation (35) determines the strength of the financial frictions: the two shares sum to one minus the monitoring costs share. Higher monitoring costs drive the ratio of the two marginal shares up, and so the equity premium upward.

The three business taxes increase the wedge between the equity premium and the capital return: for a given equity premium, the rental rate of capital has to increase (see equation (30)). But both the KRT and the CFT leave the equity premium unchanged. indeed, neither the bank participation constraint, equation (33), nor the entrepreneur's optimal leverage condition, equation (34), are modified. The CIT is more complex to analyze as it interacts with the financial accelerator and modifies both the participation constraint and the optimal leverage condition.

\section{IV.4. Representing the financial accelerator equilibrium in the short run}

The bank is an intermediate between the money market, which is characterized by the riskfree interest rate $R$, and the entrepreneur. The entrepreneur operates in the capital market, which is characterized by the after-tax return on investment $\bar{R}_{K}$, and gets a loan from the bank. ${ }^{9}$ On one side, the bank's participation constraint (BPC) pins down the credit conditions for the entrepreneur, i.e. a set of possible contracts (a leverage ratio and a statutory rates). On the other side, the entrepreneur's optimal leverage (EOL) determines, among this set of possible contracts, the one that maximizes its expected return. Strictly speaking, the two curves depend on both the risk-free interest rate and the expected investment return. Furthermore, the (EOL) curve also depends on the (BPC) curve as the entrepreneur maximizes among the set defined by the latter. However, in order to shape the intuition behind the two curves, and understand how the corporate income tax modifies them and thus the financial accelerator equilibrium, a shift of (BPC) curve is analyzed as a variation of the risk-free rate (i.e. of credit supply conditions) and a shift of the (EOL) as a change in the return to investment (i.e. in demand for credit).

\footnotetext{
${ }^{9}$ Both $R$ and $\bar{R}_{K}$ are considered as exogenous so the presentation below is a partial equilibrium one.
} 
Figure 10. Credit Supply and Demand Shocks in the Financial Accelerator

\section{CREDIT SUPPLY}

$-R=1.05 \quad--R=1.03$

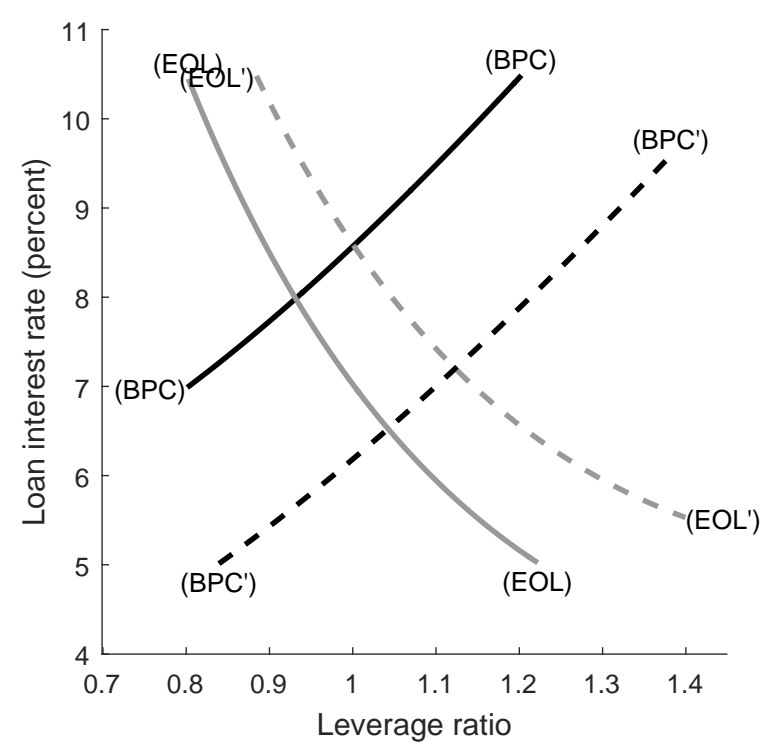

(BPC): Bank's participation constraint
CREDIT DEMAND

$-\bar{r}_{k, t}^{J}=0.26 \quad--\bar{r}_{k, t}^{J}=0.28$

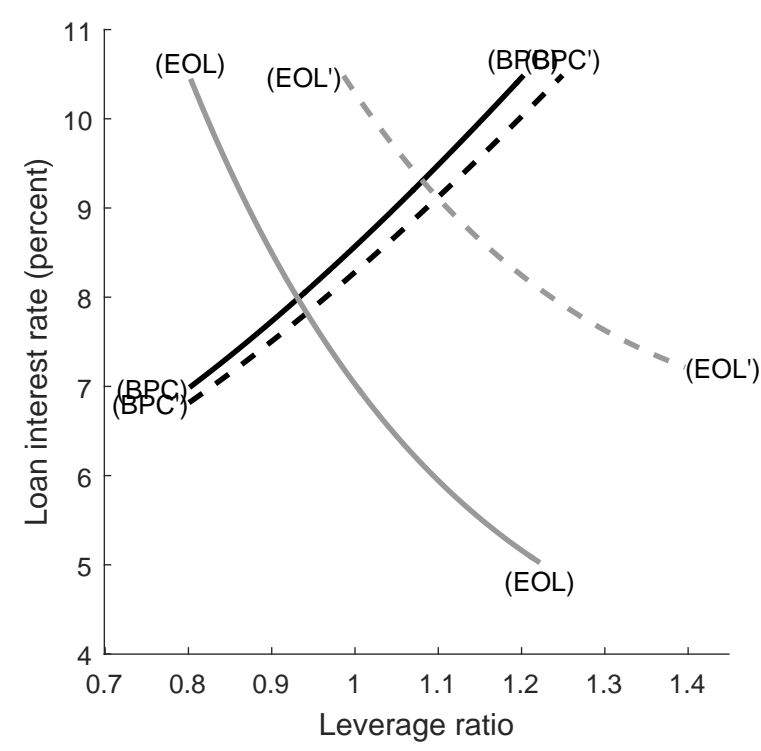

(EOL): Entrepreneurs's optimal leverage

Equilibrium is determined by the intersection of two curves, the supply of credit (BPC) and the demand for credit (EOL), in a plane with a price in the $y$-axis and volume in the $\mathrm{x}$-axis. It is both natural and convenient to use the statutory interest rate, $r_{B}$, and the leverage ratio, $\mathfrak{l}$, to define the two axes.

In the short-run, when all macroeconomic variables, $R_{t}, \bar{r}_{k, t}^{J}$ and $q_{t}^{J}$ are given, the (BPC) curve is upward slopping: a higher leverage ratio means that the bank expects a higher delinquency rate and has to increase the statutory rate to cover the financing cost. The (EOL) curve is downward slopping: as the cost of external funds increases, the entrepreneur finds it optimal to reduce leverage. Figure 10 represents the two curves under a baseline calibration (plain lines) and examines the impact of both a credit supply and a credit demand shock (dotted lines). ${ }^{10}$

A positive credit supply shock, i.e. a reduction of the risk-free interest rate, shifts down the (BPC) curve: for a given leverage ratio, the bank lowers the statutory interest rate. The change in the banks' participation constraint also affects the (EOL) curve because the entrepreneur internalizes the banks' constraint in its optimal decision. In the new equilibrium, the loan interest rate is lower and the leverage increases.

\footnotetext{
${ }^{10}$ The financial accelerator is calibrated with (i) a standard error of the idiosyncratic shock, $\sigma_{\omega}$, equal to 0.5 , (ii) a monitoring cost, $\mu$, representing $25 \%$ of the worth seized. The nominal interest rate, $R$, is $5 \%$ and the inflation rate, $\pi=1.02$, is $2 \%$. The real rental rate of capital, $\bar{r}_{k}$, is assumed to be 0.26 whereas the depreciation rate of capital, $\delta$, is $10 \%$.
} 
Figure 11. How the Business Income Tax Modifies the Financial Accelerator in the Short Run

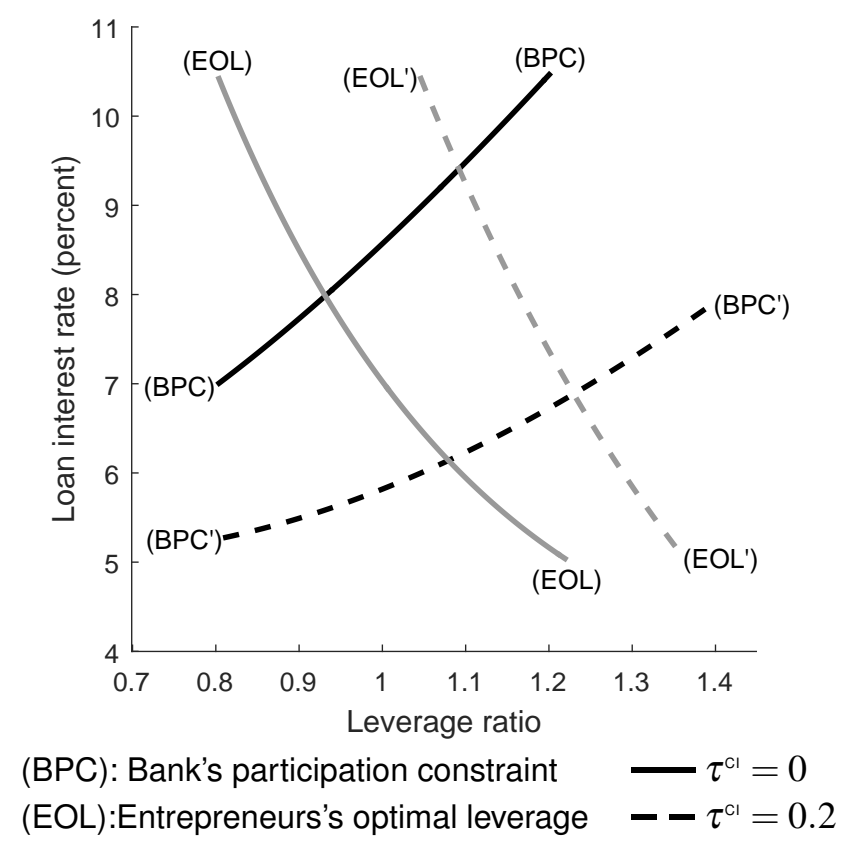

A positive credit demand shock barely modifies the bank's participation constraint (the higher return to investment increases the probability that the entrepreneur will repay the loan), such that the (BPC) curve is almost unaffected. With a higher return to investment, the entrepreneur decides to increase its leverage and the (EOL) curve shifts to the right. As a results, both the loan interest rate and leverage are higher.

To illustrate how the CIT modifies the financial accelerator, Figure 11 plots the bank's participation constraint (BPC, black line) and the entrepreneur's optimal leverage condition (EOL, gray line) in the short-run. Plain lines represent the baseline calibration whereas dotted lines represent the equilibrium for a corporate income tax rate set at $20 \%$.

All else equal, the bank's participation constraint is shifted down as the tax rebate on interest expenditures eases the participation constraint. The impact of the corporate income tax rate on the entrepreneurs curve is less straight forward, given two offsetting effect. First, the tax reduces the after tax return on capital, which lowers the leverage decision. Second, the tax increases the expensing deductibility available to entrepreneurs. As Figure 11 shows, in the short run, where the rental rate of capital is unchanged, the second effect dominates. Overall, this acts to increase leverage and lower the loan interest rate in the short run. This partial equilibrium chart does not take into account how leverage impacts the capital stock and thus the rental rate of capital, which can only be considered as part of the long-run analysis and is shown in Figure 12 below. To present such analysis, the evolution of the entrepreneur's wealth needs to be defined. 


\section{IV.5. The evolution of entrepreneur's net worth}

To prevent the net worth of entrepreneurs from increasing to a point where they do not have to use external funds, dividends, $d i v_{t}^{J}$, are paid to households. The net worth of entrepreneurs evolves as:

$$
\check{n}_{t}^{J}=\left(\frac{\left(1+\mathfrak{l}_{t-1}^{d}\right) h_{t}^{J} \operatorname{ret}_{k, t}^{J}}{g n}\right) \check{n}_{t-1}^{J}-p_{t}^{J}\left(\check{d i d}_{t}^{J}+\check{S}_{t}^{s, n w y s h k}\right) .
$$

Following Kumhof and others (2010), the model deviates from the simple financial accelerator assumption that dividends be proportional to net income (or, as it is more often done in the literature that entrepreneurs leave the market at a constant rate), by assuming the following dividend policy:

$$
\begin{aligned}
d i v_{t}^{J} & =i n c_{t}^{J, m a}+\theta_{n w}^{J}\left(n_{t}^{J}-n_{t}^{J, m a}\right) \\
p_{t}^{J} i n c_{t}^{J} & =S_{t}^{J, n w d} n_{t}^{J}+S_{t}^{s, n w d} p_{t}^{J}\left(d i v_{t}^{J}+S^{J, n w y s h k}\right) \\
\left(1+\kappa^{i n c S}\right) \log \left(i n c_{t}^{J, m a}\right) & =\log \left(i n c_{t}^{J}\right)+\kappa^{i n c S} \log \left(i n c_{t+1}^{J, m a}\right) \\
\left(1+\kappa^{n w S}\right) \log \left(n_{t}^{J, m a}\right) & =\log \left(n_{t}^{J}\right)+\kappa^{n w S} \log \left(n_{t+1}^{J, m a}\right),
\end{aligned}
$$

where $S_{t}^{J, n w y s h k}$ is a shock to new worth that gets re-distributed to households and $S_{t}^{J, n w d}$ is a fraction of smoothed gross returns on net worth (that are set aside as dividends). These policies act to smooth the payment of dividends made by entrepreneurs each period. ${ }^{11}$

In the steady-state, the evolution of net worth implies

$$
1+S^{J, n w d}=\frac{\left(1+\mathfrak{l}^{J}\right) h^{J} r e t_{k}^{J}}{g n} .
$$

As a result, the rental rate of capital is determined by the risk free rate, the various corporate taxes and the financial frictions. Figure 12 shows how different tax rates affect the long run leverage devision and the rental rate of capital assuming that there is one corporate tax in place.

- The rental rate of capital is highly distorted by the KRT because the rental rate of capital has to compensate for the rental income lost from the tax.

- The CFT has no impact when all other corporate taxes are zero. Indeed, ret ${ }_{k}^{J}$ (Equation (30)) now reads

$$
\operatorname{ret}_{k}^{J}=\frac{1-\tau^{\mathrm{CF}}}{q^{J}} \bar{r}_{k}^{J}+1-\delta^{J}
$$

where Equation (11) gives $q^{J}=\left(1-\tau^{\mathrm{CF}}\right) p^{\mathrm{I}}$. The impact of the CFT is canceled out by the change in the price of capital and, as a consequence, the CFT does not modify the accumulation of capital and its rental rate.

\footnotetext{
${ }^{11}$ Setting $\kappa^{i n c S}=\theta_{n w}^{J}=0$ is equivalent to an assumption that a fraction of entrepreneurs leave the market each period.
} 
Figure 12. Corporate Tax Rates, Financial Accelerator and Rental Rate of Capital in the Long Run

Leverage Ratio and Corporate tax Rates

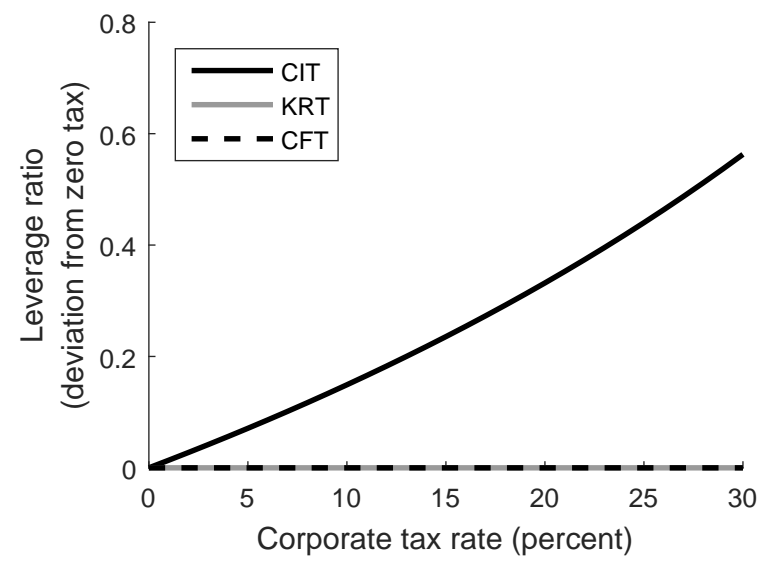

Rental Rate of Capital and Corporate tax Rates

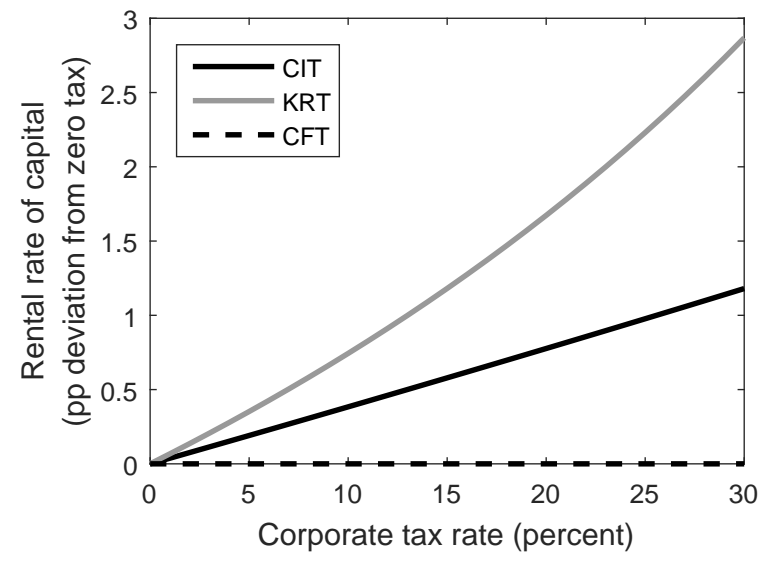

- The CIT stands between the KRT and the CFT: like the KRT it reduces the after tax return on capital, but the effect is mitigated by interest expenditures allowance and the ease of financial constraints. Indeed, the corporate income tax is the only tax that modifies the leverage decision in the long run, both the KRT and CFT have no impact.

\section{IV.6. Tax revenue from entrepreneurs}

The only tax revenue affected by the financial accelerator is the one associated with the CIT which needs to include the interest expenditure rebates. CIT revenue now writes:

$$
\begin{aligned}
\check{T R}_{t}^{\mathrm{CI}} & =\tau_{t}^{\mathrm{CI}} \sum_{J=T, N}\left[p_{t}^{\tilde{J}}\left(\check{Z}_{t}^{J}-\omega^{J}-\check{G}_{P, t}^{J}-r \check{c} u_{t}\right)-\check{v}_{t} \check{U}_{t}^{J}-p_{t}^{\mathrm{I}} \check{G}_{I, t}^{J}\right] \\
& +\tau_{t}^{\mathrm{CI}} \sum_{J=T, N}\left[\left(\left(1-\delta_{t}^{J}\right) q_{t}^{J}-\frac{q_{t-1}^{J}}{\pi_{t}}-\Gamma_{\mathrm{E}, t}^{J}\right) \check{\bar{K}}_{t}^{J}-\frac{R_{t-1}-1}{n g \pi_{t}} \check{B}_{t-1}^{J}\right] \\
& +\tau_{t}^{\mathrm{CI}}\left[\left(p_{t}^{\mathrm{I}}-p_{t}^{\mathrm{II}}\right) \check{Z}_{t}^{\mathrm{I}}-p_{t}^{\mathrm{I}} \check{G}_{P, t}^{\mathrm{I}}-p_{t}^{\mathrm{I}} \omega^{\mathrm{I}}\right]+\tau_{t}^{\mathrm{CI}}\left[\left(p_{t}-p_{t}^{\mathrm{CC}}\right) \check{Z}_{t}^{\mathrm{C}}-p_{t} \check{G}_{P, t}^{\mathrm{C}}-p_{t} \omega^{\mathrm{C}}\right] \\
& +\tau_{t}^{\mathrm{CI}} \sum_{i \in \mathscr{I}} \sum_{J=T, N} \frac{E_{i, t}}{E_{j, t}}\left[p_{i, J, t}^{\mathrm{M}} \check{Y}_{i, J, t}^{\mathrm{M}}-p_{i, J, t}^{\mathrm{M}, c i} \check{Y}_{i, J, t}^{\mathrm{M}}-p_{i, J, t}^{\mathrm{M}} \check{G}_{P, i, J, t}^{\mathrm{M}}\right]+\tau_{t}^{\mathrm{CI}} \sum_{J=T, D}\left[p_{J, t}^{\mathrm{F}} \check{Y}_{J, t}^{\mathrm{F}}-\sum_{i \in \mathscr{I}} p_{i, J, t}^{\mathrm{M}} \check{Y}_{i, J, t}^{\mathrm{F}}\right],
\end{aligned}
$$

where $\Gamma_{\mathrm{E}, t}^{J}$ is the real monitoring cost paid by banks to observe the idiosyncratic shock of defaulting entrepreneurs

$$
\Gamma_{\mathrm{E}, t}^{J} \equiv \frac{q_{t}^{J} \mu_{t+1}}{1+\mathfrak{l}_{t}^{J}} \int_{w=0}^{\bar{\omega}_{t+1}^{J}} \frac{\operatorname{ret}_{k, t+1}^{J} w\left(1+\mathfrak{l}_{t}^{J}\right)+\tau_{t+1}^{\mathrm{CI}} / \pi_{t+1}}{1-\tau_{t+1}^{\mathrm{CI}}} \mathrm{d} F_{t+1}^{J}(w) .
$$


Box 4 Derivation of the first order condition on leverage ratio

The maximization problem is written without the sector specific $J$ superscript.

$$
V\left(\mathfrak{l}_{t}\right)=\left(1+\mathfrak{l}_{t}\right) \mathbb{E}_{t}\left\{\bar{h}_{t+1} \operatorname{ret}_{k, t+1}\right\}
$$

The entrepreneur maximizes $V$ under loan curve constraint (33):

$$
\left(1+\mathfrak{l}_{t}\right)\left[\left(1-\tau_{t+1}^{\mathrm{CI}}\right) R_{t}-\operatorname{ret}_{k, t+1} \pi_{t+1} \bar{g}_{t+1}\right]=\left(1-\tau_{t+1}^{\mathrm{CI}}\right) R_{t}+\tau_{t+1}^{\mathrm{CI}}-\mu \tau_{t+1}^{\mathrm{CI}} \bar{F}_{t+1} .
$$

The total differentiation of the constraint gives

$$
\left(1+\mathfrak{l}_{t}\right)^{2} r e t_{k, t+1} \frac{d \bar{\omega}_{t+1}}{d \mathfrak{l}}=\left(1+\mathfrak{l}_{t}\right) \frac{\left(1-\tau_{t+1}^{\mathrm{CI}}\right) R_{t}+\tau_{t+1}^{\mathrm{CI}}-\mu \tau_{t+1}^{\mathrm{CI}} \bar{F}_{t+1}}{\pi_{t+1} \bar{g}_{t+1}^{\prime}-\frac{\mu \tau_{t+1}^{\mathrm{CI}} \bar{\varphi}_{t+1}}{r e t_{k, t+1}}}
$$

where

$$
\bar{\varphi}_{t+1}=\int_{0}^{\bar{\omega}_{t+1}} w \mathrm{~d} F_{t+1}^{J}(w) .
$$

The maximum is obtained for $V^{\prime}(\mathfrak{l})=0$ where:

$$
\left(1+\mathfrak{l}_{t}\right) V^{\prime}(\mathfrak{l})=\mathbb{E}_{t}\left\{\left(1+\mathfrak{l}_{t}\right) h_{t+1}\left(\bar{\omega}_{t+1}\right) r e t_{k, t+1}+\left(1+\mathfrak{l}_{t}\right)^{2} h_{t+1}^{\prime}\left(\bar{\omega}_{t+1}\right) \frac{d \bar{\omega}_{t+1}}{d \mathfrak{l}} r e t_{k, t+1}\right\} .
$$

Replacing $\frac{d \bar{\omega}_{t+1}}{d \downarrow}$ by its value gives the first order condition on leverage ratio (34). 